\title{
Petroleum geology features and research developments of hydrocarbon accumulation in deep petroliferous basins
}

\author{
Xiong-Qi Pang · Cheng-Zao Jia · Wen-Yang Wang
}

Received: 26 September 2014/Published online: 3 February 2015

(c) The Author(s) 2015. This article is published with open access at Springerlink.com

\begin{abstract}
As petroleum exploration advances and as most of the oil-gas reservoirs in shallow layers have been explored, petroleum exploration starts to move toward deep basins, which has become an inevitable choice. In this paper, the petroleum geology features and research progress on oil-gas reservoirs in deep petroliferous basins across the world are characterized by using the latest results of worldwide deep petroleum exploration. Research has demonstrated that the deep petroleum shows ten major geological features. (1) While oil-gas reservoirs have been discovered in many different types of deep petroliferous basins, most have been discovered in low heat flux deep basins. (2) Many types of petroliferous traps are developed in deep basins, and tight oil-gas reservoirs in deep basin traps are arousing increasing attention. (3) Deep petroleum normally has more natural gas than liquid oil, and the natural gas ratio increases with the burial depth. (4) The residual organic matter in deep source rocks reduces but the hydrocarbon expulsion rate and efficiency increase with
\end{abstract}

X.-Q. Pang $(\bowtie) \cdot$ W.-Y. Wang

State Key Laboratory of Petroleum Resources and Prospecting, Beijing 102249, China

e-mail: pangxq@cup.edu.cn

X.-Q. Pang · W.-Y. Wang

Basin and Reservoir Research Center, China University of Petroleum, Beijing 102249, China

C.-Z. Jia

PetroChina Company Limited, Beijing 100011, China

C.-Z. Jia

Research Institute of Petroleum Exploration and Development, Beijing 100083, China

Edited by Jie Hao the burial depth. (5) There are many types of rocks in deep hydrocarbon reservoirs, and most are clastic rocks and carbonates. (6) The age of deep hydrocarbon reservoirs is widely different, but those recently discovered are predominantly Paleogene and Upper Paleozoic. (7) The porosity and permeability of deep hydrocarbon reservoirs differ widely, but they vary in a regular way with lithology and burial depth. (8) The temperatures of deep oil-gas reservoirs are widely different, but they typically vary with the burial depth and basin geothermal gradient. (9) The pressures of deep oil-gas reservoirs differ significantly, but they typically vary with burial depth, genesis, and evolution period. (10) Deep oil-gas reservoirs may exist with or without a cap, and those without a cap are typically of unconventional genesis. Over the past decade, six major steps have been made in the understanding of deep hydrocarbon reservoir formation. (1) Deep petroleum in petroliferous basins has multiple sources and many different genetic mechanisms. (2) There are high-porosity, high-permeability reservoirs in deep basins, the formation of which is associated with tectonic events and subsurface fluid movement. (3) Capillary pressure differences inside and outside the target reservoir are the principal driving force of hydrocarbon enrichment in deep basins. (4) There are three dynamic boundaries for deep oil-gas reservoirs; a buoyancy-controlled threshold, hydrocarbon accumulation limits, and the upper limit of hydrocarbon generation. (5) The formation and distribution of deep hydrocarbon reservoirs are controlled by free, limited, and bound fluid dynamic fields. And (6) tight conventional, tight deep, tight superimposed, and related reconstructed hydrocarbon reservoirs formed in deep-limited fluid dynamic fields have great resource potential and vast scope for exploration. Compared with middle-shallow strata, the petroleum geology and accumulation in deep basins are more 
complex, which overlap the feature of basin evolution in different stages. We recommend that further study should pay more attention to four aspects: (1) identification of deep petroleum sources and evaluation of their relative contributions; (2) preservation conditions and genetic mechanisms of deep high-quality reservoirs with high permeability and high porosity; (3) facies feature and transformation of deep petroleum and their potential distribution; and (4) economic feasibility evaluation of deep tight petroleum exploration and development.

Keywords Petroliferous basin - Deep petroleum geology features · Hydrocarbon accumulation · Petroleum exploration · Petroleum resources

\section{Introduction}

As the world demands more petroleum and petroleum exploration continues, deep petroleum exploration has become an imperative trend. As it is nearly impractical to expect any major breakthrough in middle or shallow basins (Tuo 2002), petroleum exploration turning toward deep basins has become inevitable. After half a century's exploitation in major oilfields across the world, shallow petroleum discoveries tend to be falling sharply (Simmons 2002). Nor are things optimistic in China, where the rate of increase of mid-and-shallow petroleum reserves is increasingly slowing down (Wang et al. 2012). At the same time, the world's petroleum consumption continues to increase. According to BP Statistical Review of World Energy 2014, from 2002 to 2012, the world's petroleum consumption increase was virtually the same as its petroleum output increase, with annual average oil and natural gas consumption increases of $1.35 \%$ and $3.14 \%$, respectively, compared to the annual average output increases of $1.47 \%$ and $3.23 \%$. In China, however, the petroleum consumption increase is far greater than its output increase. According to National Bureau of Statistic of China statistics in 2013, from 2000 to 2013, China's average annual oil and natural gas consumption increases were $6.1 \%$ and $14.6 \%$, respectively, compared to the annual average output increases of $1.93 \%$ and $11.9 \%$. Deep petroleum, as one of the strategic "three-new" fields for the global oil industry (Zou 2011) as well as one of the most important development areas for China's oil industry, forms the most important strategically realistic area for China's oil industry to lead future petroleum exploration and development (Sun et al. 2013). All indicate that deep hydrocarbon exploration is an inevitable choice toward ensuring energy supply and meeting market demands.

After half a century's effort, gratifying achievements have been made in deep petroleum exploration throughout the world, despite being faced with challenges and problems today. The Former Soviet Union discovered four $6,000 \mathrm{~m}$ or deeper industrial oil-gas reservoirs out of its 24 petroliferous basins (Tuo 2002). The oil discovered in deep basins in Mexico, the USA, and Italy contributes more than $31 \%$ of their present recoverable oil reserves (Kutcherov et al. 2008) and the natural gas discovered there makes up approximately $47 \%$ of their total proved natural gas reserves (Burruss 1993). China, too, has appreciable achievements in deep petroleum exploration. Compared with 2000, the deep reserves discovered in West China in 2013 increased an average of 3.5 times. The ratio of deep petroleum reserves increased from $40 \%$ in 2002 to $80 \%$ in 2013. Of the 156 well intervals in the Tarim Basin that have been tested so far, 58 have gone deeper than $5,000 \mathrm{~m}$. The deep drillhole success rate in the Jizhong Depression is as high as $21.4 \%$. A 5,190-m-deep "Qianmiqiao buried hill hydrocarbon reservoir" was discovered in the Huanghua Depression (Tuo 2002). Despite these achievements, however, a lot of problems have also emerged in deep petroleum exploration. These include (a) the difficulty in understanding the conditions of deep oil-gas reservoirs and evolution due to the multiple tectonic events having taken place in deep basins (Zhang et al. 2000; He et al. 2005), (b) the difficulty in evaluating the resource potential and relative contribution due to the complex sources and evolution processes of deep petroleum (Barker 1990; Mango 1991; Dominé et al. 1998; Zhao et al. 2001; Jin et al. 2002; Zhao et al. 2005; Darouich et al. 2006; Huang et al. 2012; Pang et al. 2014a), (c) the difficulty in predicting and evaluating favorable targets due to the complex genesis and distribution of deep, relatively high-porosity and highpermeability reservoirs (Surdam et al. 1984; Ezat 1997; Dolbier 2001; Rossi et al. 2001; Moretti et al. 2002; Lin et al. 2012), and (d) the difficulty in predicting and evaluating the petroleum possibility in deposition targets due to the complex deposition mechanism and development pattern of deep petroleum (Luo et al. 2003, 2007; Ma and Chu 2008; Ma et al. 2008; Pang et al. 2008). All these problems provide a tremendous challenge to deep petroleum exploration.

With abundant resource bases and low proved rates, deep petroliferous basins are important for further reserve and output increases (Tuo 2002; Zhao et al. 2005; Dai 2006, Pang et al. 2007a; Zhu and Zhang 2009; Sun et al. 2010; Pang et al. 2014a). According to Dai (2006), the proved rate of the exploration concessions of PetroChina is $17.6 \%$ for deep oil and $9.6 \%$ for deep natural gas, far lower than their mid-andshallow counterparts of $39.6 \%$ for oil and $14.6 \%$ for natural gas. Pang et al. (2007a, b) suggest that West China contains around $45 \%$ of the residual petroleum resources of China, and $80 \%$ of these residual resources are buried in deep horizons more than 4,500 $\mathrm{m}$ below the surface, yet the present proved 
rate is less than $20 \%$. As such, implementing deep petroleum resource research, tapping deep petroleum and increasing petroleum backup reserves are urgently needed if we ever want to relieve the nation's petroleum shortage and mitigate energy risks. Many scholars have investigated deep petroleum geologies and exploration (Perry 1997; Dyman et al. 2002; Pang 2010; Ma et al. 2011; He et al. 2011; Wang et al. 2012; Wu et al. 2012; Bai and Cao 2014). Our study in connection with the national "973 Program" (2011CB201100) involves a summary and description of the development and orientation of research by scholars in China and elsewhere with respect to petroleum geology and hydrocarbon accumulation in deep petroliferous basins.

\section{Concept and division criteria of deep basins}

Deep basins are also called deep formations by some scholars. The definition and criteria of deep petroliferous basins differ from country to country, from institution to institution and from scholar to scholar.

\subsection{Concept and division criteria of deep basins proposed by overseas scholars}

So far, there are two sets of definition and criteria for deep petroliferous basins outside China. One is according to the formation depth, i.e., formations within a certain limit of depth are called deep formations. However, the criteria for classifying deep basins also differ from scholar to scholar. Representative criteria include 4,000 m (Rodrenvskaya 2001), 4,500 $\mathrm{m}$ (Barker and Takach 1992), 5,000 m (Samvelov 1997; Melienvski 2001), and 5,500 m (Manhadieph 2001; Bluokeny 2001). Another is according to the formation age, i.e., for a given basin, formations older in age and deeper are called deep formations (Sugisaki 1981). Table 1 summarizes the criteria used by different institutions and scholars for deep basins from which it is easy to see that 4,000 and $4,500 \mathrm{~m}$ are the criteria accepted by more institutions and scholars.

\subsection{Concept and division criteria of deep basins proposed by Chinese scholars}

Chinese scholars use roughly the same criteria for deep petroliferous basins as their overseas counterparts. Most of them use three indicators: (1) formation depth (Wang et al. 1994; Li and Li 1994; Tuo et al. 1994; Zhou et al. 1999; Hao et al. 2002; Shi et al. 2005; Dai et al. 2005); (2) formation age (Kang 2003; Ma et al. 2007; Ma and Chu 2008); and (3) formation characteristics (Tuo et al. 1999a; Wang et al. 2001; Wang 2002; Pang 2010). Table 2 summarizes the criteria used for deep basins. Obviously, the concept of deep basins does not only differ from scholar to scholar, it also varies with the basin position and formation characteristics.

\subsection{Importance of using the same concept and criteria in deep basins}

No uniform concept or criteria have been agreed upon by scholars either in or out of China with respect to deep petroliferous basins, hence preventing further development and mutual promotion on science research. For this reason, we suggest using $4,500 \mathrm{~m}$ as the criterion for deep basins on grounds of the following considerations:

First, this classification represents a succession to previous findings. The U.S. Geological Survey and some former Soviet Union scholars used 4,500 $\mathrm{m}$ as the criteria for deep basins (Barker and Takach 1992). Chinese scholars, represented by Shi, Dai, and Zhao et al., also used 4,500 m to demarcate deep formations (Shi et al. 2005; Dai et al. 2005; Zhao et al. 2005). Chinese administrations like Ministry of Land and Resources even issued public documents that define deep petroliferous basins in West China to $4,500 \mathrm{~m}$. Second, $4,500 \mathrm{~m}$ represents the general depth at which the hydrocarbon entrapment mechanism of a petroliferous basin transits from buoyancy accumulation to non-buoyancy accumulation. Above this depth, the porosities of the sand reservoirs are generally above $12 \%$; the permeabilities are higher than $1 \mathrm{mD}$; and the pore throat radii are larger than $2 \mu \mathrm{m}$. "High-point accumulation, highstand closure, high-porosity enrichment, high-pressure accumulation" (Pang et al. 2014a) normal oil-gas reservoirs generally formed under the action of buoyant forces. Below this depth, to the contrary, "low-depression accumulation, low-stand inversion, low-porosity enrichment, low-pressure stability" unconventional oil-gas reservoirs generally formed. To make things easier, we divide a petroliferous basin into four parts according to the buried depth, using the criteria accepted by previous scholars: shallow $(<2,000 \mathrm{~m})$, middle $(2,000-4,500 \mathrm{~m})$, deep $(4,500-6,000 \mathrm{~m})$, and ultra-deep $(>6,000 \mathrm{~m})$. According to the maximum depths of basins, we divide them into shallow basins $(<2,000 \mathrm{~m})$, middle basins $(2,000-4,500 \mathrm{~m})$, deep basins $(4,500-6,000 \mathrm{~m})$, and ultra-deep basins $(>6,000 \mathrm{~m})$. Third, deep basins should be classified according to the depth rather than incorporating the geological aspects that constrain the depth distribution of hydrocarbon entrapment. For example, the fact that oil-gas reservoirs in East China basins are commonly shallow while those in West China basins are commonly deep is attributable to their respective unique basin evolution geologies such as the geothermal gradient, reservoir rock type, formation age, and evolution history. These should not form the basis for diverging the criteria for basin depths. 
Table 1 Criteria for deep basins proposed by scholars outside China

\begin{tabular}{llll}
\hline Basis for deep basins & Criteria for deep basins & Targeted area & Researcher and year \\
\hline Formation depth & $>4,000 \mathrm{~m}$ & In former Soviet Union & Rodrenvskaya (2001) \\
& $>4,500 \mathrm{~m}$ & Caspian Basin & \\
& $>4,500 \mathrm{~m}$ & In the USA & Barker and Takach (1992) \\
& & Gulf of Mexico, USA & Samvelov (1997) \\
& & & Melienvski (2001) \\
Formation age & $>5,500 \mathrm{~m}$ & West Siberia Basin, East Siberia Basin & Manhadieph (2001) \\
& Stratigraphically old formations & South Caspian Basin & Bluokeny (2001) \\
& with large buried depths & Timan-Pechora Basin & Sugisaki (1981) \\
\hline
\end{tabular}

Table 2 Criteria of deep basins proposed by Chinese scholars

\begin{tabular}{|c|c|c|c|}
\hline $\begin{array}{l}\text { Basis for deep } \\
\text { basins }\end{array}$ & Criteria for deep basins & Targeted area or parameter features & Researcher and year \\
\hline \multirow[t]{11}{*}{ Formation depth } & $>2,500 \mathrm{~m}$ & Bohai Bay Basin & Qiao et al. (2002) \\
\hline & $>2,800 \mathrm{~m}$ & Songliao Basin & Wang et al. (1994) \\
\hline & \multirow[t]{4}{*}{$>3,500 \mathrm{~m}$} & Liaohe Basin & Li et al. (1999) \\
\hline & & Bohai Bay Basin & Tuo (1994) \\
\hline & & Bohai Bay Basin & Zhou et al. (1999) \\
\hline & & Yinggehai Basin & Hao et al. (2002) \\
\hline & $>3,500 \mathrm{~m}$ & East China basins & $\begin{array}{l}\text { Ministry of Land and Resources } \\
\text { (2005) }\end{array}$ \\
\hline & \multirow[t]{3}{*}{$>4,500 \mathrm{~m}$} & Junggar Basin & Shi et al. (2005) \\
\hline & & Tarim, Junggar, Sichuan basins & Dai (2003) \\
\hline & & Sichuan Basin & Zhao et al. (2005) \\
\hline & $>4,500 \mathrm{~m}$ & West China basins & $\begin{array}{l}\text { Ministry of Land and Resources } \\
\text { (2005) }\end{array}$ \\
\hline $\begin{array}{l}\text { Formation age \& } \\
\text { depth }\end{array}$ & $\begin{array}{l}\text { Stratigraphically old with large buried } \\
\text { depths }\end{array}$ & Varies from basin to basin & $\begin{array}{l}\text { Kang (2003), Ma et al. (2007), Ma } \\
\text { and Chu (2008) }\end{array}$ \\
\hline \multirow{3}{*}{$\begin{array}{l}\text { Formation } \\
\text { characteristics }\end{array}$} & Formation thermal evolution level & $R_{\mathrm{o}} \geq 1.35 \%$ & Tuo et al. (1999b), Tuo (2002) \\
\hline & $\begin{array}{l}\text { Formation thermal evolution level or } \\
\text { formation pressure }\end{array}$ & $\begin{array}{l}R_{\mathrm{o}} \geq 1.35 \% \text { or formation depth } \\
\text { overpressure }\end{array}$ & $\begin{array}{l}\text { Wang et al. (2001), Tuo et al. } \\
\text { (1999b), Wang et al. (2002) }\end{array}$ \\
\hline & $\begin{array}{l}\text { Formation thermal evolution level and } \\
\text { tightness level }\end{array}$ & $\begin{array}{c}R_{\mathrm{o}} \geq 1.35 \% \text { or sandstone formation } \\
\Phi \leq 12 \%, K \leq 1 \mathrm{mD}, Y \leq 2 \mu \mathrm{m}\end{array}$ & Pang (2010) \\
\hline
\end{tabular}

\section{Exploration for deep oil-gas reservoirs}

\subsection{Exploration for deep oil-gas reservoirs} across the world

Following the discovery of the first deep hydrocarbon field below 4,500 $\mathrm{m}$ in the USA in 1952, deep petroleum exploration boomed in many countries. Seventy countries tried deep exploration (Wu and Xian 2006). Echoing breakthroughs in deep well drilling and completion techniques, a succession of major breakthroughs have been made in deep hydrocarbon reservoir exploration (Dyman et al. 2002). First, major breakthroughs in drilling operation led to the discovery of a number of oil-gas reservoirs including a gas reservoir in the Cambrian-Ordovician Arbuckle Group dolomites at 8,097 m depth in the Mills Ranch gas field in the Anadarko Basin in 1977 (Jemison 1979). From 1980, deep petroleum exploration started to extend from onshore to offshore. Examples include a gas field discovered in Permian Khuff Formation limestones at 4,500 $\mathrm{m}$ in the Fateh gas reservoir in the Arabian-Iranian Basin in 1980, and an oil reservoir at a depth of $6,400 \mathrm{~m}$ was discovered in the Triassic dolomites of the Villifortuna-Trecate oilfield in Italy in 1984. Recently, major 
breakthroughs in deep oil exploitation have been reported in the deep and ultra-deep waters of the Gulf of Mexico, East Brazil, and West Africa (Bai and Cao 2014). According to IHS data as of 2010, 171 deep basins and 29 ultra-deep basins had been discovered out of the 1,186 petroliferous basins in the world. These deep basins are predominantly situated in the former Soviet Union, Middle East, Africa, Asia-Pacific, North America, and Central and South America (Fig. 1). A total of 1,290 oil-gas reservoirs have been discovered in deep basins and 187 oil-gas reservoirs in ultra-deep basins across the world. Breakthroughs are continuously reported around the world in the course of deep exploration. First, the drilling depth continues to increase, the maximum being deeper than $10,000 \mathrm{~m}$, as exemplified by the deepest well with $12,200 \mathrm{~m}$ drilling depth, SG-3 exploratory well. The deepest oil reservoir discovered so far is the Tiber clastic rock oil reservoir (1,259 $\mathrm{m}$ underwater and 8,740 $\mathrm{m}$ underground). The depth of gas wells continues to increase, and the deepest gas reservoir discovered so far $(8,309-8,322 \mathrm{~m})$ is a Silurian basin gas reservoir in the Anadarko Basin. Second, the manageable formation temperature and formation pressure in drilling operations are also continuously increasing. So far, the highest temperature encountered is $370{ }^{\circ} \mathrm{C}$ and the highest pressure encountered is $172 \mathrm{MPa}$ (Table 3).
According to USGS and World Petroleum Investment Environment Database, from 1945 to 2014, the world's normal petroleum resource has increased from 96 billion ton in 1945 to 630 billion ton in 2014, the annual average increase being as high as $8.06 \%$ (Fig. 2a), and the natural gas resource has also increased from 260 trillion $\mathrm{m}^{3}$ in 1986 to 460 trillion $\mathrm{m}^{3}$ in 2013 , the annual average increase being as high as $2.85 \%$ (Fig. 2b). Over the past years, the world has shown robust momentum for deep petroleum exploration. The number of oil-gas reservoirs discovered keeps growing fast (Fig. 3). According to data provided by Kutcherov et al. (2008), more than 1,000 hydrocarbon fields have been developed at depths of $4,500-8,103 \mathrm{~m}$, the original recoverable oil reserve of which contributes $7 \%$ of the world's total amount and the natural gas reserve makes up $25 \%$. According to IHS data, as of 2010 , for the 4,500-6,000 m deep hydrocarbon fields in the world, the proved recoverable residual oil reserve is 83.8 billion ton or $35.5 \%$ of the total recoverable oil reserve, and the natural gas is 65.9 billion ton oil equivalent or $44.4 \%$ of the total productive natural gas reserve; for the $6,000 \mathrm{~m}$ or deeper hydrocarbon fields in the world, the proved recoverable residual oil reserve is 10.5 billion ton or $4.45 \%$ of the total productive oil reserve, and the natural gas is 7 billion ton oil equivalent or $4.7 \%$ of the total productive natural gas reserve (Fig. 4).

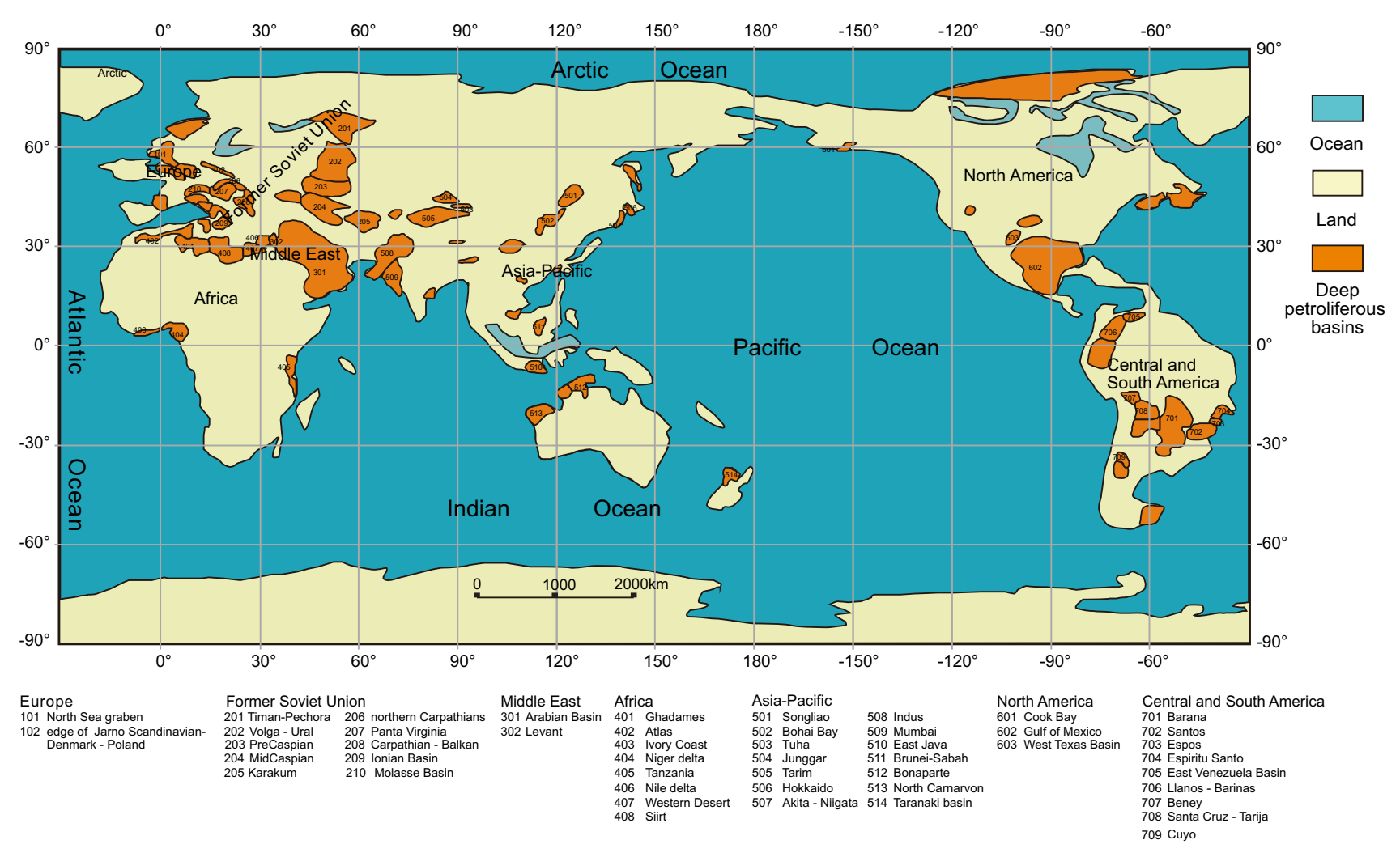

Fig. 1 Horizontal distribution of major deep petroliferous basins in the world 
Table 3 Geological characteristics of world representative deep oil-gas reservoirs known so far

\begin{tabular}{|c|c|c|c|c|}
\hline Feature & Name & Year & Parameters & Region \\
\hline Deepest well & SG-3 exploratory well & 1992 & $\begin{array}{l}\text { Completion depth } \\
12,200 \mathrm{~m}\end{array}$ & $\begin{array}{l}\text { Kola Peninsula, } \\
\text { Russia }\end{array}$ \\
\hline Deepest oil reservoir & Tiber clastic rock oil reservoir & 2009 & $\begin{array}{l}\text { Buried depth } \\
8,740 \mathrm{~m}\end{array}$ & $\begin{array}{l}\text { Gulf of Mexico } \\
\text { abyssal basin, USA }\end{array}$ \\
\hline Deepest gas reservoir & Mills Ranch gas reservoir & 1977 & $\begin{array}{l}\text { Buried depth } \\
7,663-8,083 \mathrm{~m}\end{array}$ & $\begin{array}{l}\text { Western Interior } \\
\text { Basin, USA }\end{array}$ \\
\hline $\begin{array}{l}\text { Deep hydrocarbon reservoir with } \\
\text { highest porosity }\end{array}$ & $\begin{array}{l}\text { Gaenserndorf Ubertief oilfield Hauptdolomit } \\
\text { Formation gas reservoir }\end{array}$ & 1977 & $\begin{array}{l}\text { Porosity } 35 \%- \\
38 \%\end{array}$ & Vienna Basin, Austria \\
\hline $\begin{array}{l}\text { Deep hydrocarbon reservoir with } \\
\text { lowest porosity }\end{array}$ & Mora hydrocarbon reservoir & 1981 & $\begin{array}{l}\text { Porosity } 2.6 \%- \\
4 \%\end{array}$ & $\begin{array}{l}\text { Sureste Basin, } \\
\text { Mexico }\end{array}$ \\
\hline $\begin{array}{l}\text { Deep hydrocarbon reservoir with } \\
\text { highest permeability }\end{array}$ & $\begin{array}{l}\text { Platanal oilfield 4830-Cretaceous hydrocarbon } \\
\text { reservoir }\end{array}$ & 1978 & $\begin{array}{l}\text { Permeability } \\
7,800 \mathrm{mD}\end{array}$ & $\begin{array}{l}\text { Sureste Basin, } \\
\text { Mexico }\end{array}$ \\
\hline $\begin{array}{l}\text { Deep hydrocarbon reservoir with } \\
\text { lowest permeability }\end{array}$ & Wolonghe Huanglong structural belt gas reservoir & 1980 & $\begin{array}{l}\text { Permeability } \\
0.01 \mathrm{mD}\end{array}$ & Sichuan Basin, China \\
\hline $\begin{array}{l}\text { Deep gas reservoir with highest } \\
\text { temperature }\end{array}$ & $\begin{array}{l}\text { Satis hydrocarbon reservoir, Tineh Formation gas } \\
\text { reservoir }\end{array}$ & 2008 & $\begin{array}{l}\text { Temperature } \\
370{ }^{\circ} \mathrm{C}\end{array}$ & $\begin{array}{l}\text { Nile Delta Basin, } \\
\text { Egypt }\end{array}$ \\
\hline $\begin{array}{l}\text { Deep oil reservoir with lowest } \\
\text { temperature }\end{array}$ & $\begin{array}{l}\text { Sarutayuskoye oilfield Starooskolskiy Group oil } \\
\text { reservoir }\end{array}$ & 2008 & Temperature $47^{\circ} \mathrm{C}$ & Pechola Basin, Russia \\
\hline $\begin{array}{l}\text { Deep gas reservoir with highest } \\
\text { pressure }\end{array}$ & $\begin{array}{l}\text { Zistersdorf Ubertief } 1 \text { oilfield Basal Breccia gas } \\
\text { reservoir }\end{array}$ & 1980 & Pressure $172 \mathrm{MPa}$ & Vienna Basin, Austria \\
\hline $\begin{array}{l}\text { Deep hydrocarbon reservoir with } \\
\text { lowest pressure }\end{array}$ & $\begin{array}{l}\text { Akzhar East oilfield Asselian VIII (PreCaspian) } \\
\text { Unit hydrocarbon reservoir }\end{array}$ & 1988 & Pressure $8.4 \mathrm{MPa}$ & $\begin{array}{c}\text { Caspian Basin, } \\
\text { Kazakhstan }\end{array}$ \\
\hline
\end{tabular}

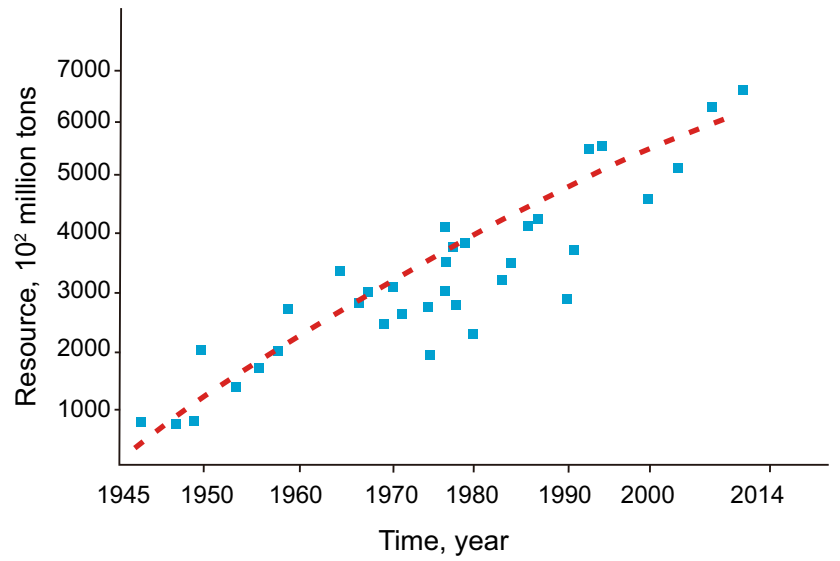

(a) The evaluation quantity of the world's conventional oil resources changes with time

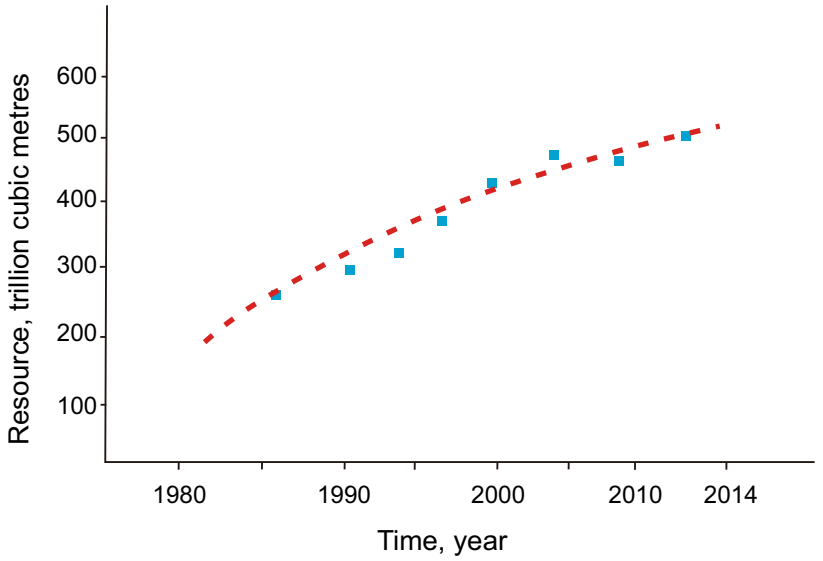

(b) The evaluation quantity of the world's conventional gas resources changes with time

Fig. 2 World petroleum evaluation result and variation as a function of time

\subsection{Exploration of deep oil-gas reservoirs in China}

China started deep petroleum exploration from the late 1970s, having discovered a number of large deep oil-gas fields in the deep parts of some large sedimentary basins including Tarim, Erdos, and Sichuan basins, and made important progresses in the deep parts of the Daqing, Zhongyuan, Dagang, and Shengli fields in East China's petroleum region (Feng 2006; Song et al. 2008; Wu and Xian 2006). With the nation's breakthroughs in deep and ultra-deep well drilling techniques and equipment, onshore petroleum exploration has continued to extend toward deep and ultra-deep levels (Sun et al. 2010); petroleum exploration has also undergone a transition from shallow to deep and further to ultra-deep levels. On July 28, 1966, China's first deep well, Songji-6 of Daqing (4,719-m well depth), was completed, marking the transition of China's drilling operation from shallow wells to middle and deep wells, and signaling that China's petroleum exploration was turning from shallow toward deep 


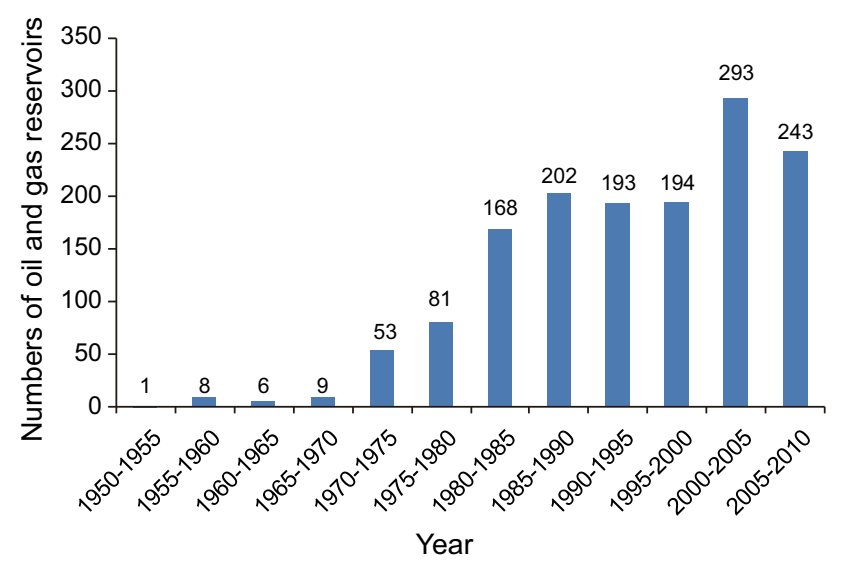

Fig. 3 Number of deep oil-gas reservoirs discovered in the world and its variation as a function of year

levels. From 1976, China's petroleum exploration marched toward ultra-deep levels. On April 30, 1976, China's first ultra-deep well, Nuji well in Sichuan $(6,011 \mathrm{~m}$ well depth), was completed, marking the entry of China's petroleum exploration into ultra-deep levels (Wang et al. 1998). So far, China has drilled deep wells in 15 large basins with sedimentary thicknesses larger than $5 \mathrm{~km}$ (Pang 2010). Of the 176 deep exploratory wells drilled in the Jizhong Depression (the average well depth is 4,521 m), 37 have yielded industrial petroleum flows. The exploratory well success rate has reached $21.4 \%$ (Tuo 2002). Of the 156 pay zone well intervals tested in the Tarim Basin, 58 have their bottom boundaries deeper than $5,000 \mathrm{~m}$ (Pang 2010). According to statistics, as of 2010, of the 47 petroliferous basins in China, seven deep basins have been discovered, out of which 210 deeper than $4,500 \mathrm{~m}$ oil-gas reservoirs have been identified. Shallow basins at a depth of 2,000 $\mathrm{m}$ or shallower are predominantly found in China's Inner Mongolia and Tibet; 2,000-4,500 m middle deep basins are typically located in the seas of East China; 4,500-6,000 m deep basins are

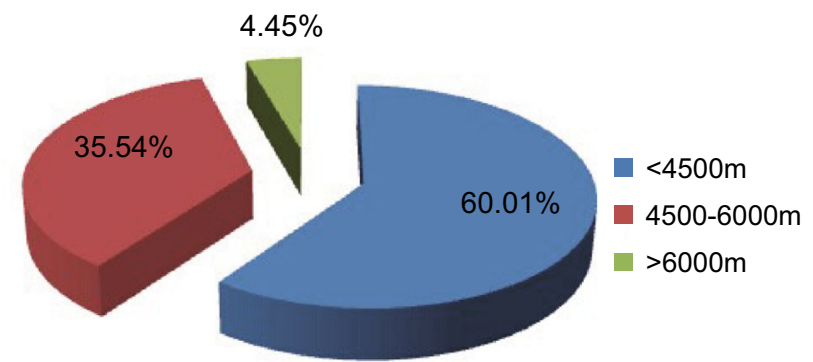

(a) The depth distribution of the world recoverable oil reserves distributed in Central China and Southern North China. China also has a huge stock of ultra-deep petroleum resources, having discovered some ultra-deep basins with buried depths of more than $6,000 \mathrm{~m}$, including the Tarim Basin and Songliao Basin. These are mostly located in Northwest and Northeast China (Fig. 5).

China is rich in deep petroleum resources with vast room for further exploration. According to a 2005 statistics of Shi et al., the deep oil resource within the mineral concession of CNPC is approximately $51.5 \times 10^{8} \mathrm{t}$ or $12 \%$ of the total; the deep natural gas reserve is $4.25 \times 10^{12} \mathrm{~m}^{3}$ or $19 \%$ of the total. Zhu and Zhang (2009) suggest that China's deep petroleum resource reserves are extremely non-uniform and mostly found in Xinjiang. In the Junggar Basin, the middle-shallow and deep oil geological resources are $9.7 \times 10^{8} \mathrm{t}$ or approximately $18 \%$ of the basin's total amount; the deep natural gas resource is $2,081 \times 10^{8} \mathrm{~m}^{3}$ or approximately $32 \%$ of the basin's total amount. Pang (2010) discovered after studies that the Tarim Basin has the richest oil resources in the deep part at $33.7 \times 10^{8}$ t or $56 \%$ of the basin's total oil resource, natural gas resources in the deep part at $29,244 \times 10^{8} \mathrm{~m}^{3}$ or $37 \%$ of the basin's total natural gas resource. Statistics indicate that China's deep petroleum resource is 30,408 million ton, which is $27.3 \%$ of the nation's total oil resource (Fig. 6a); its deep natural gas resource is 29,120 billion $\mathrm{m}^{3}$, which is $49.2 \%$ of the nation's total natural gas resource (Fig. 6b). Since 2000, China's petroleum exploration has continued to extend toward deep and ultra-deep levels. In the Junggar Basin, the ratio of deep exploratory wells increased from $3 \%$ in 2000 to $15 \%$ in 2013 (Fig. 7a). In the Tarim Basin, this ratio increased from $65 \%$ in 2000 to $92 \%$ in 2013 (Fig. 7b). The ratio of newly increased petroleum reserves in deep formations has also continued to rise. In the Tarim Basin, the ratio of deep oil increased from $66 \%$ in 2000 to $92 \%$ in 2013 (Fig. 8a); the ratio of deep natural gas also increased from $66 \%$ in 2004 to $92 \%$ in 2013 (Fig. 8b).

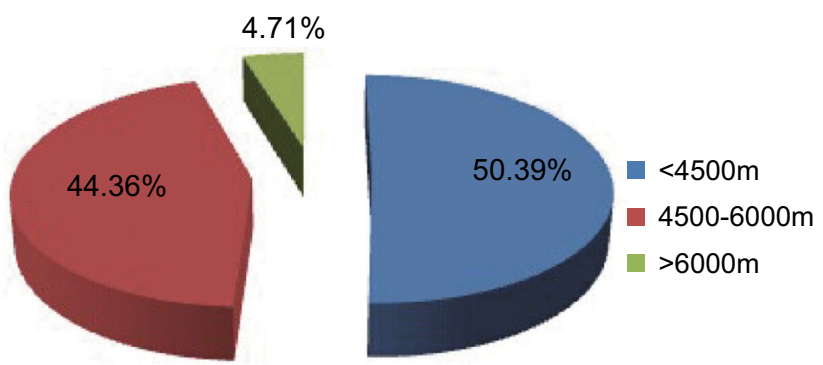

(b) The depth distribution of the world recoverable gas reserves

Fig. 4 Distribution of world recoverable oil and gas reserves at middle and deep depths of petroliferous basins 


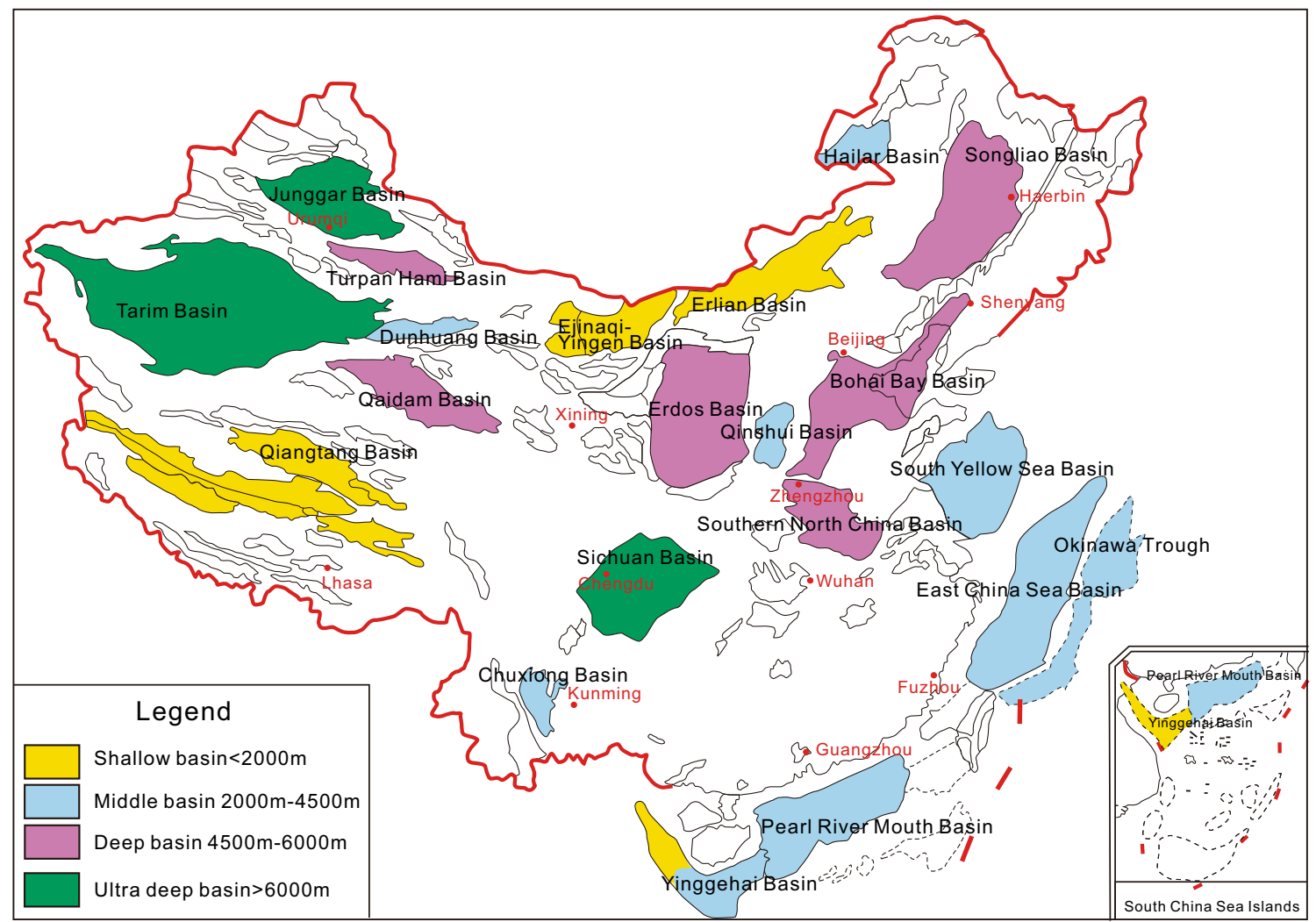

Fig. 5 Depth classification and horizontal distribution of petroliferous basins in China

\section{Geological features of deep oil-gas reservoirs}

Compared with middle or shallow petroliferous basins, deep basins have large buried depths and the features of high temperature, high pressure, low porosity, low permeability, complex structural styles, and highly variable sedimentary forms. These special properties have been responsible for the unique characteristics of deep basin oil-gas reservoirs compared with their middle or shallow counterparts. Many scholars (Zappaterra 1994; Dyman and Cook 2001; Liu et al. 2007a, b; Wang et al. 2012) have examined deep oil-gas reservoirs. Table 4 lists some typical hydrocarbon fields (reservoirs) discovered in deep petroliferous basins in the world, from which we can observe their differences and varieties in terms of formation age, lithology, buried depth, porosity, pressure, petroleum phase, trap type, and basin type.

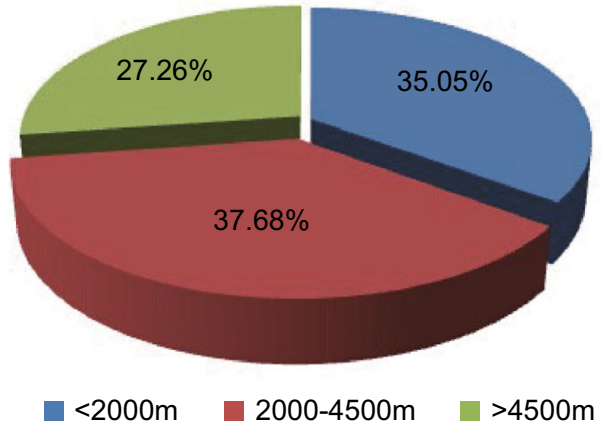

(a) The depth distribution of oil prospective resource

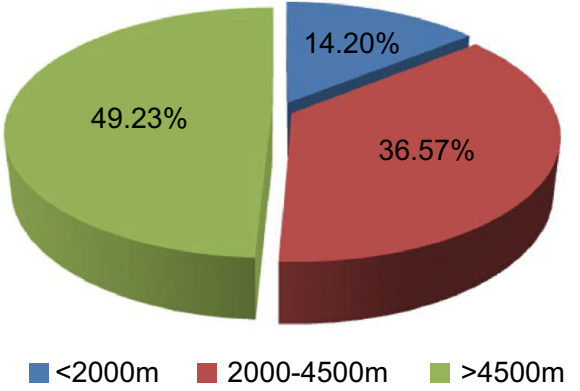

(b) The depth distribution of gas prospective resource

Fig. 6 Depth distribution of petroliferous basin resources in China 
Fig. 7 Depths of exploratory wells drilled in the Junggar and Tarim basins. a Number and depth of exploratory wells drilled in the Junggar Basin over time, b Number and depth of exploratory wells drilled in the Tarim Basin since 2000
Number of exploratory wells

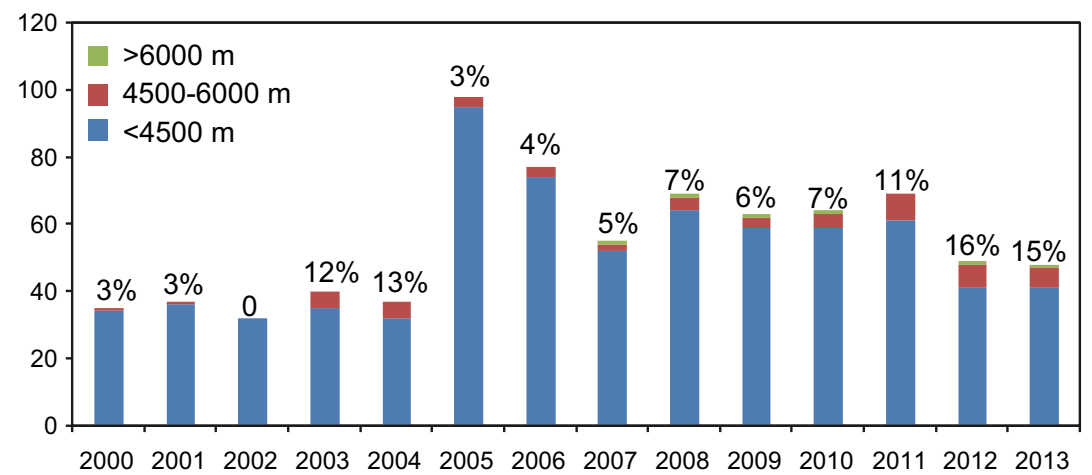

(a)

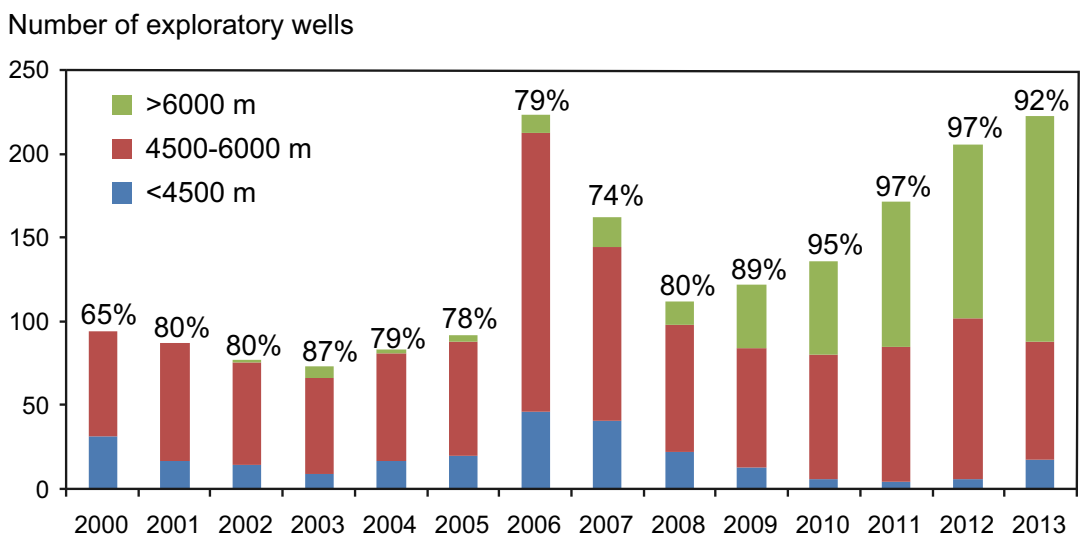

(b)
4.1 While oil-gas reservoirs have been discovered in many types of deep petroliferous basins, most have been discovered in low heat flux deep basins

Oil-gas reservoirs have been discovered in all types of deep petroliferous basins (Fig. 9). Based on the basin classification system of Ingersoll (1995), Bai and Cao (2014) classified 87 deep petroliferous basins into seven groups: continental rift, passive continental marginal, foreland, interior craton, fore-arc, back-arc, and strike-slip basins, of which the passive continental marginal basins (25) and foreland basins (41) are the richest in deep petroleum, followed by the rift basins (12). These three types contribute $47.7,46.4$, and $5.6 \%$ of the world's deep proven and probable (2P) recoverable petroleum reserves. The deep $2 \mathrm{P}$ recoverable petroleum reserves in the back-arc basins (2), strike-slip basins (3), and interior craton basin (1) contribute merely $0.3 \%$ of the world's total (Fig. 10).

As a matter of fact, the distribution divergences of deep oil-gas reservoirs in petroliferous basins are essentially decided by the geothermal gradients of the sedimentary basins. Compared with the higher geothermal gradient counterparts, lower geothermal gradient sedimentary basins contain far more deep petroleum resources since when they reached the same buried depth, they had lower pyrolysis temperatures, and source rocks were richer in residual organic matter and hence had greater ability to generate and preserve hydrocarbon. Figure 11 compares the deep hydrocarbon potentials of source rocks in basins with different geothermal gradients in China as a function of depth, from which we can observed that "hot" basins expelled less hydrocarbon indicating they make up a smaller proportion of deep petroleum resources than their "cold" counterparts. As the geothermal gradient increases, the ratio of deep petroleum resources reduces. According to geothermal gradient records of 405 deep oil-gas reservoirs across the world, $318 \%$ or $78.5 \%$ were discovered in deep basins with geothermal gradients of $1-2{ }^{\circ} \mathrm{C} / 100 \mathrm{~m} ; 79 \%$ or $19.5 \%$ were discovered in deep basins with geothermal gradients of $2-3{ }^{\circ} \mathrm{C} / 100 \mathrm{~m}$; and $8 \%$ or $2 \%$ were discovered in deep basins with geothermal gradients larger than $3{ }^{\circ} \mathrm{C} / 100 \mathrm{~m}$ (Fig. 12). In China, the geothermal gradient increases from the west toward the east. The number and reserves of deep oil-gas reservoirs discovered in West China basins is far larger than that discovered in East China basins (Fig. 13). 
Fig. 8 Proved deep oil and gas reserves in the Tarim Basin discovered each year since 2000. a Depth distribution of proved oil reserves in the Tarim Basin discovered each year since 2000, b Depth distribution of proved natural gas reserves in the Tarim Basin

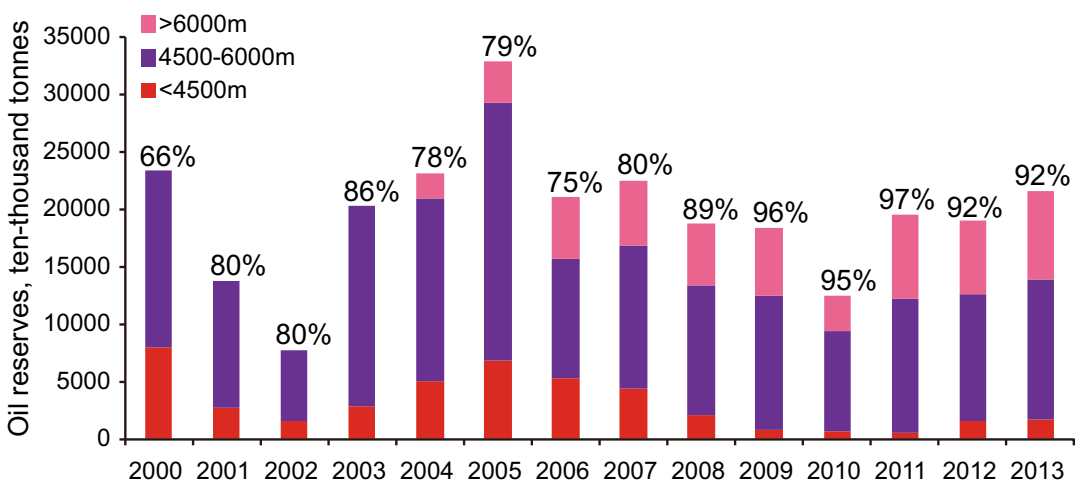

(a)

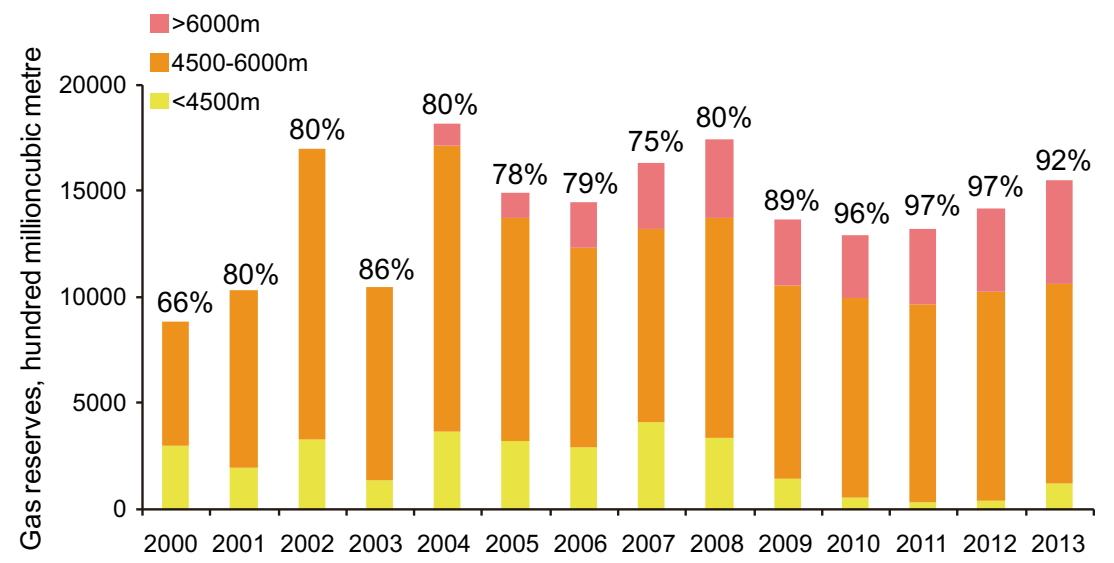

(b)
4.2 While many types of petroliferous traps are developed in deep basins, oil-gas-bearing features in deep basin traps are arousing increasing attention

Like their middle-shallow counterparts, deep basins also contain a variety of traps which, according to the conventional trap classification, include tectonic traps, stratigraphic traps, lithological traps, structural-lithological traps, structural-stratigraphic traps, and lithological-stratigraphic traps. Different types of traps differ significantly in terms of their reserves. After a statistical analysis on 837 deep oil-gas reservoirs in the USA, Dyman et al. (1997) discovered that structural traps and combination traps make up as much as $66.9 \%$. Only in Anadarko and California basins are there more lithological traps than structural ones (Fig. 14). Bai and Cao (2014), after summarizing the trap types and reserves of the world's deep oil-gas reservoirs, discovered that structural traps have $73.7 \%$ of the world's deep recoverable $2 \mathrm{P}$ petroleum reserves, with structurallithological traps and stratigraphic traps contributing $21.9 \%$ and $4.4 \%$, respectively (Fig. 15).

Recently, with the discovery of tight, continuous oil-gas reservoirs in Canada's Alberta Basin, the USA's Red
Desert Basin and Green River Basin, and China's Erdos, Sichuan, and Songliao basins, people have become more interested in these unconventional oil-gas reservoirs. First, these reservoirs have completely different genesis compared with conventional reservoirs, and their discovery has brought on a novel petroleum exploration field. Second, these reservoirs are widely and continuously distributed with vast resource potentials and great scope for petroleum exploration. Third, these reservoirs formed inside deep basin traps between the buoyancy accumulation threshold of a petroliferous basin and the basement of the basin. Their buried depths were quite large, but can be very shallow at present as a result of subsequent tectonic events in the basin. Deep basin traps are a special type of hydrocarbon trap in which the reservoir media have porosities smaller than $12 \%$, permeabilities smaller than $1 \times 10^{-3} \mu \mathrm{m}^{2}$, and throat radii smaller than $2 \mu \mathrm{m}$. Hydrocarbon was not subject to buoyancy in its accumulation, thus making it possible to spread continuously. The more developed the sources rocks were in a deep basin trap, the more continuous the reservoirs were distributed close to the source rocks and the richer the petroleum resources they provide. Figure 16 gives a typical conceptual model and shows the difference about the development 


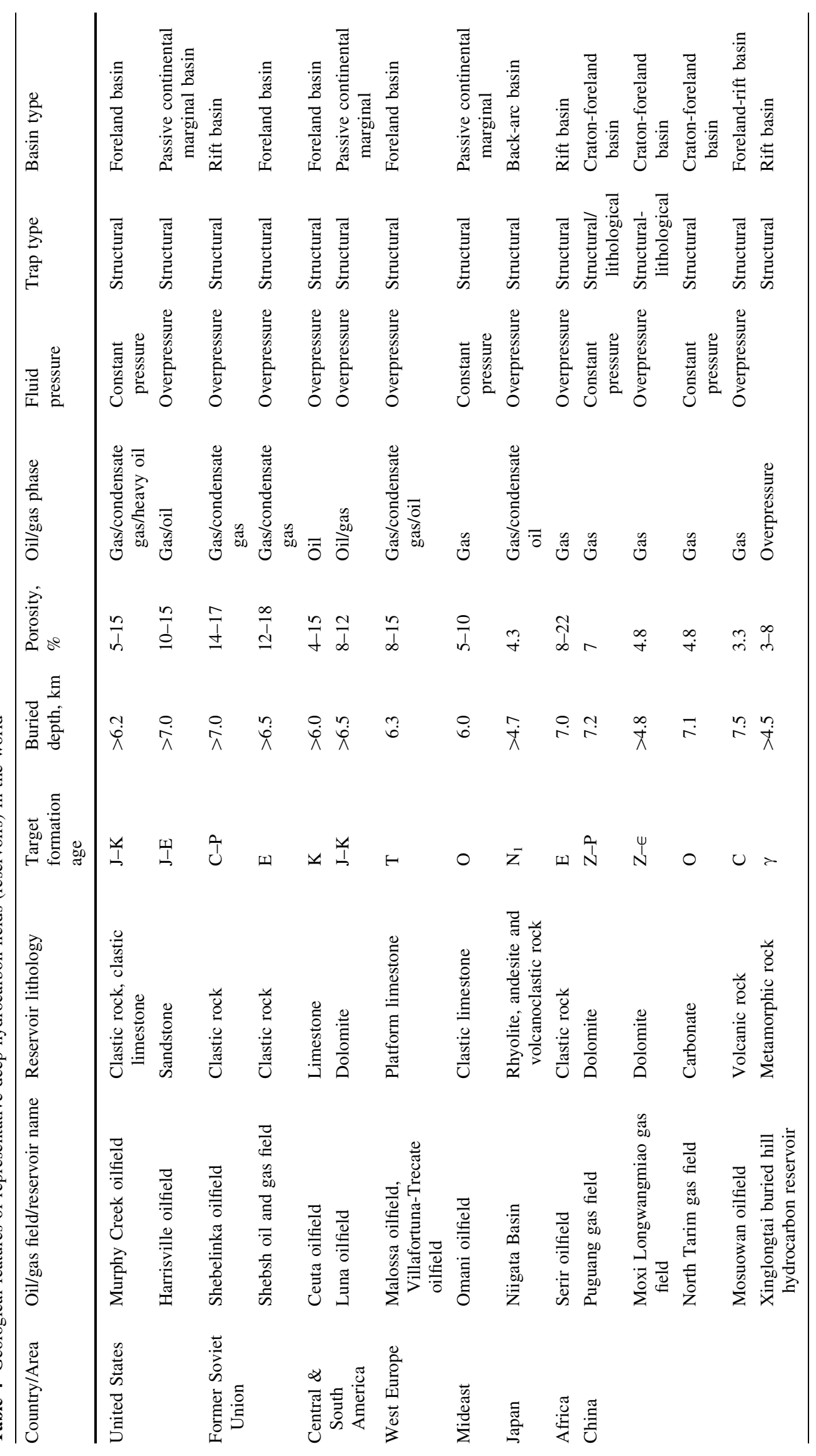




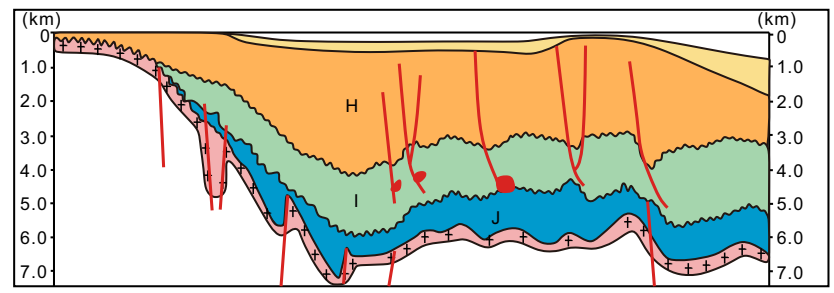

(a) The passive continental margin basin of the deep reservoirs in the Kamps Basin in Brazil

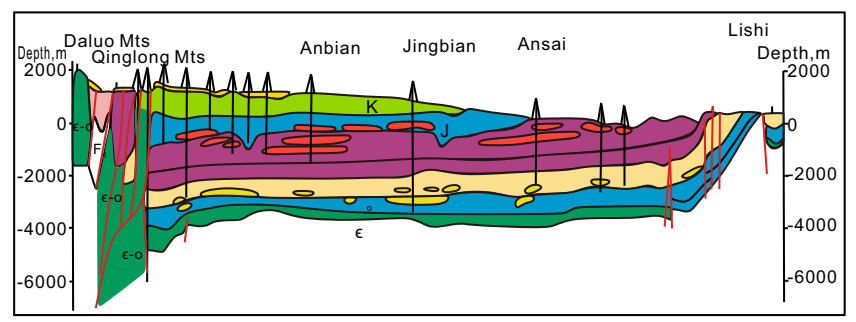

(c) The craton basin of the deep reservoirs in the Erdos Basin in China

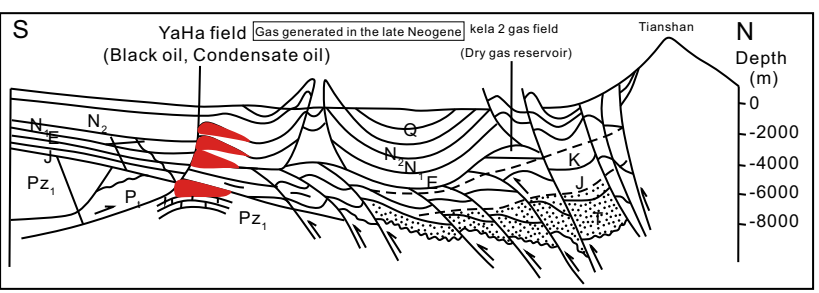

(b)The foreland basin of the deep reservoirs in the Kuqa Depression in China

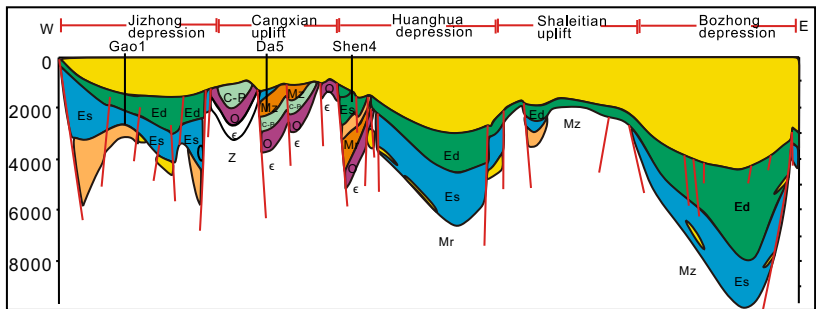

(d)The rift basin of the deep reservoirs in the Bohai Bay in China

Fig. 9 Deep oil-gas reservoirs developed in different types of basins (Li and Lü 2002; Li 2009)

Fig. 10 Deep hydrocarbon reservoir distribution in different types of basins in the world (Bai and Cao 2014)

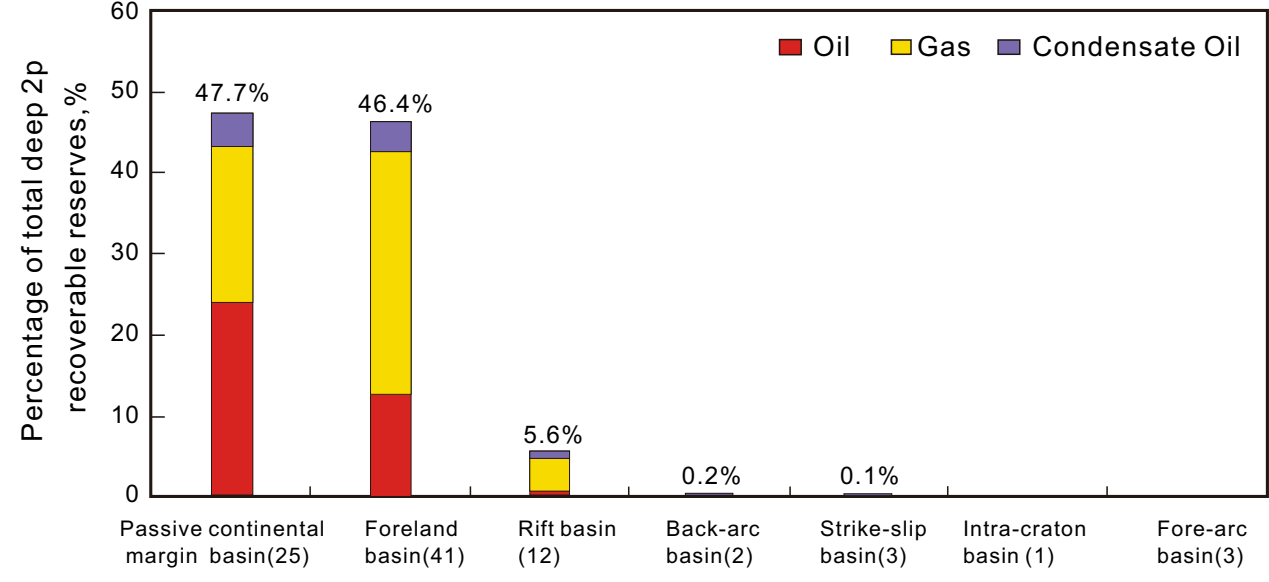

Type of basin and distribution of a deep basin trap-controlled hydrocarbon reservoir in a petroliferous basin and conventional traps.

\subsection{The composition of deep petroleum is widely} different with more natural gas than liquid oil and the natural gas ratio increases with the buried depth

The composition of deep petroleum in petroliferous basins varies and includes gaseous hydrocarbon, condensate gas, condensate oil, liquid hydrocarbon, and oil-gas coexistence. Phase statistics of 1,477 deep oil-gas reservoirs in the world demonstrate that oil-gas miscible phases contribute $54 \%$ and gas phases contribute $40 \%$. The oil phase makes up a very small proportion of $6 \%$ (Fig. 17). Generally, as the formation depth increases, natural gas makes up a larger proportion in deep petroleum and overtakes liquid hydrocarbon as the prevailing type of petroleum resources. Figure 18 shows how the oil and natural gas reserves discovered from different formations of East China's Bohai Bay Basin and West China's Tarim and Junggar basins vary as a function of depth. By and large, the ratio of older deep basin gas reservoirs increases due to pyrolysis of crude oil as a result of extended high temperature exposure of the oil reservoir in deep basins, or thermal cracking in the source rocks when they reached high maturity (Dyman et al. 2001). The Hugoton gas field 


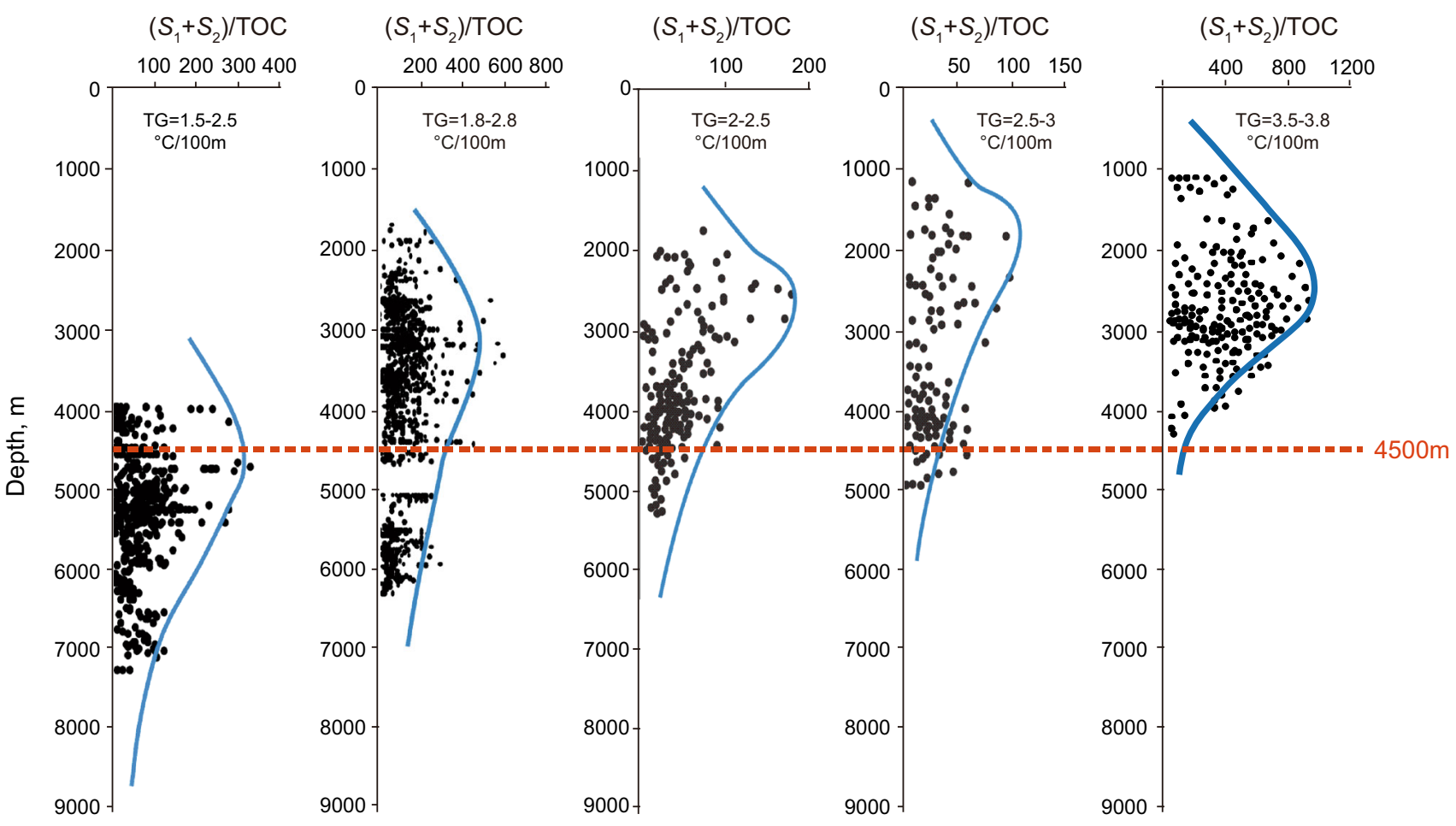
(a) Tarim Basin area
(b) Kuqa Depression
(c) Sichuan Basin
(d) Ordos Basin
(e) Jiyang Depression

Fig. 11 Comparison of hydrocarbon potentials of deep source rocks in basins in China with different geothermal gradients

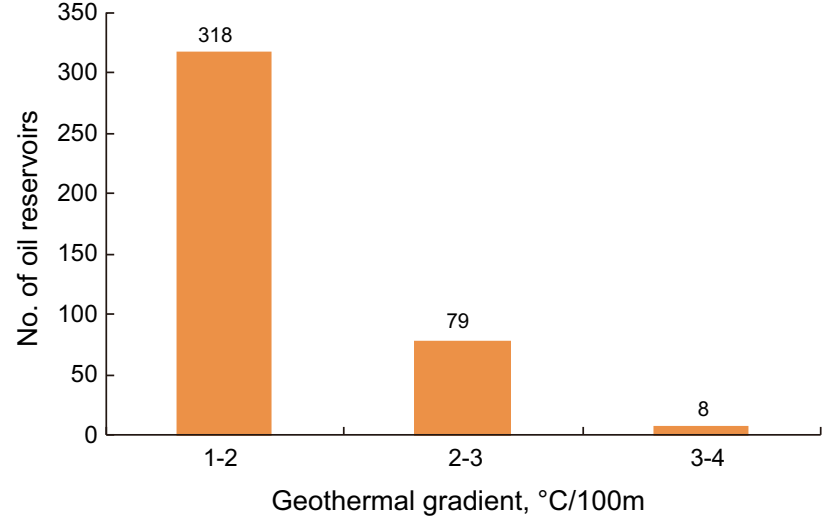

Fig. 12 Number of deep oil-gas reservoirs discovered in basins in the world with different geothermal gradients

and Mills Ranch in the USA's Anadarko Basin, for example, are pure gas fields. Many deep gas reservoirs in China's petroliferous basins also originated from earlier oil or oil-gas reservoirs that were cracked into gas under high temperatures, as exemplified by the large Puguang carbonate gas field (Du et al. 2009), the large Kela-2 gas field (Jia et al. 2002), and the Hetian gas field (Wang et al. 2000). Huge liquid or condensate oil reservoirs have also been discovered in a number of deep basins such as the

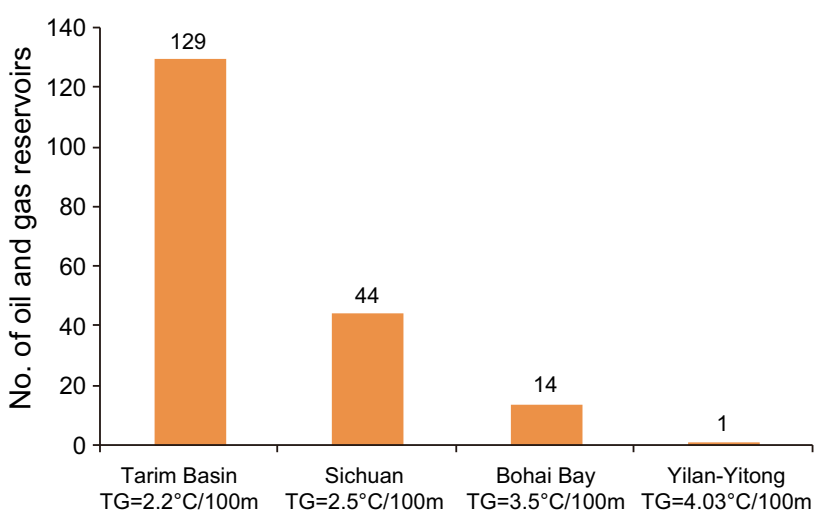

Fig. 13 Number of deep oil-gas reservoirs discovered in basins in China with different geothermal gradients

USA's Rocky Mountain Basin, where gas wells make up only $34 \%$ of the deep exploratory wells while most are oil wells and no pyrolysis has taken place deeper than $6,000 \mathrm{~m}$. This is often because the low subsurface temperature or high pressure of the formation had prevented the crude oil from coming to its threshold pyrolysis temperature (Svetlakova 1987). A lot of factors can be related to deep basin petroleum phases. These include (1) the type of the original organic matter; (2) temperature and pressure; and (3) subsequent adjustment or reformation. 


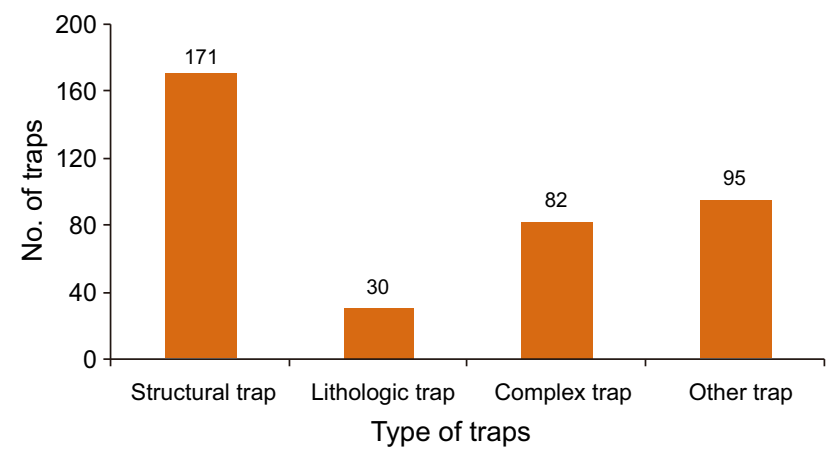

Fig. 14 Trap types of deep oil-gas reservoirs in the USA (Dyman et al. 1997)

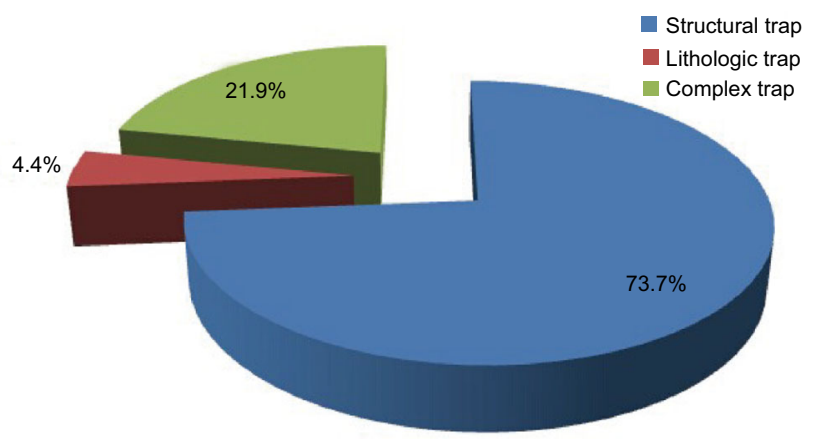

Fig. 15 Deep petroleum reserves in petroliferous basins in the world with different trap types

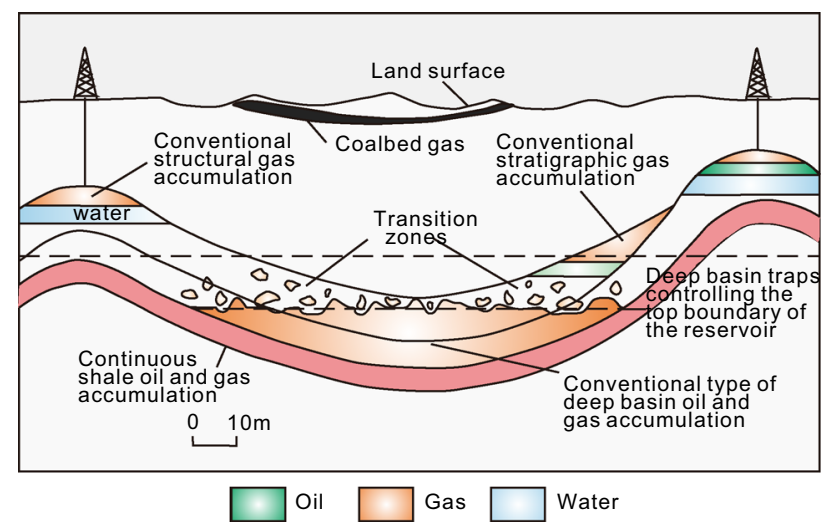

Fig. 16 Difference and comparison of conventional traps versus deep basin traps in petroliferous basins and their petroleum-control features

4.4 Residual organic matter in deep source rocks reduces but the hydrocarbon expulsion rate and efficiency continuously increase with the buried depth

As far as deep source rocks are concerned, they have much smaller measured residual hydrocarbon amount and hydrocarbon potential than their middle-shallow counterparts, and both reduce with the increase of the buried depth.

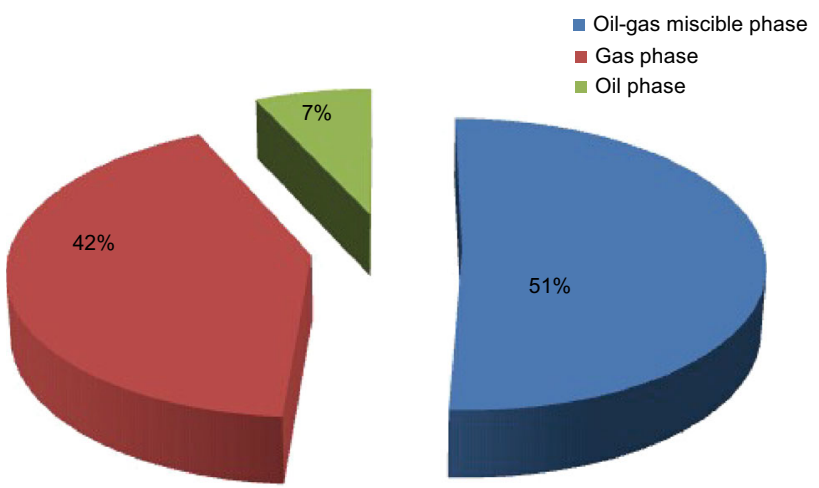

Fig. 17 Phase distribution of deep petroleum in petroliferous basins in China

They appear to have the following characteristics: (1) the residual hydrocarbon amount per unit parent material in the source rocks (total organic carbon, TOC) is represented by $S_{1} /$ TOC or "A"/TOC (Dickey 1975; Hao et al. 1996; Durand 1988). The residual hydrocarbon amount in deep source rocks first increases then reduces with the increase of the depth or $R_{\mathrm{o}}$ and was already very small in deep basins (Fig. 19); (2) the hydrocarbon potential is represented by the $\mathrm{H} / \mathrm{C}$ atomic ratio, $\mathrm{O} / \mathrm{C}$ atomic ratio, and hydrogen index (Tissot et al. 1974; Tissot and Welte 1978; Jones and Edison 1978; Baskin 1997; Zhang et al. 1999). The H/C atomic ratio and $\mathrm{O} / \mathrm{C}$ atomic ratio (Fig. 20) and hydrocarbon index HI (Fig. 21) reduce with the increase of the buried depth; and (3) the hydrocarbon potential index of source rocks is represented by $\left(S_{1}+S_{2}\right) /$ TOC (Zhou and Pang 2002; Pang et al. 2004). When the TOC is more than $0.1 \%$, the hydrocarbon potential index of deep source rocks shows a "big belly" profile of increasing followed by reducing with the increase of the depth or $R_{\mathrm{o}}$ (Fig. 22). In a word, as the buried depth increases and the hydrocarbon potential of source rocks gradually reduces, the accumulated oil-gas volume and hydrocarbon expulsion efficiency of source rocks appear to increase gradually with the increase of the buried depth (Fig. 23), reflecting the increase in the contribution made by source rocks to oilgas reservoirs. This indicates that the quality and effectiveness of source rocks should be judged by investigating how much hydrocarbon was generated and expelled by source rocks rather than by relying on how much hydrocarbon or how much hydrocarbon potential is left of the source rocks.

4.5 While there are many types of rocks in deep hydrocarbon reservoirs, most of them are clastic rocks and carbonate

Deep target formations in petroliferous basins contain a variety of rocks, though clastic rocks and carbonate are the 


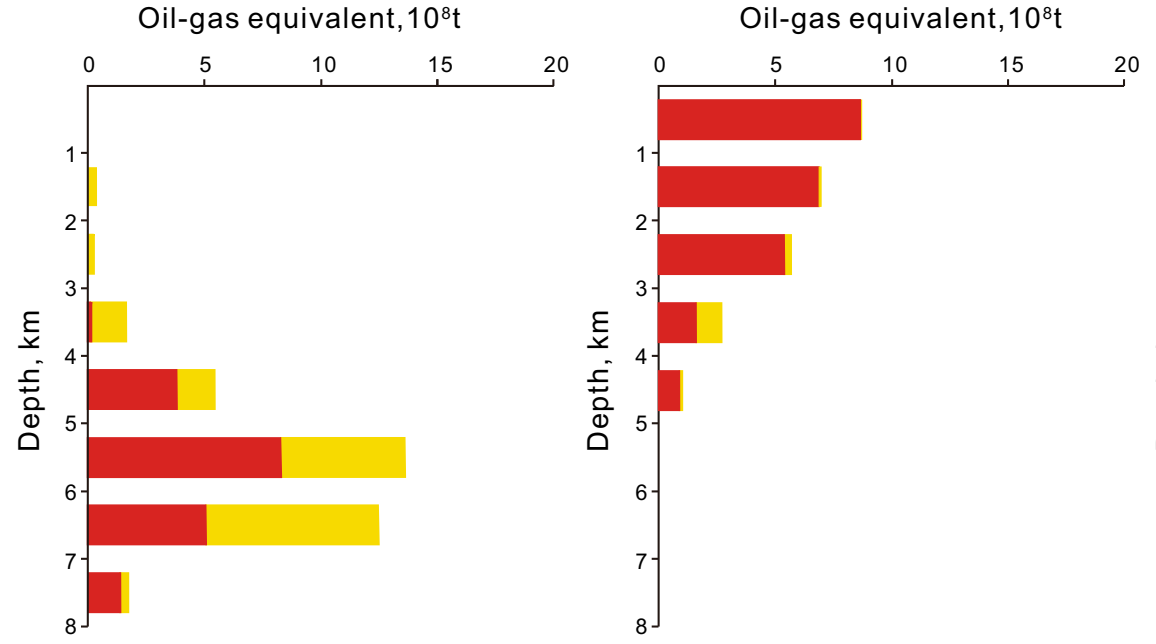

(a) Tarim Basin

(b)Junggar Basin
Oil-gas equivalent, $10^{8} \mathrm{t}$

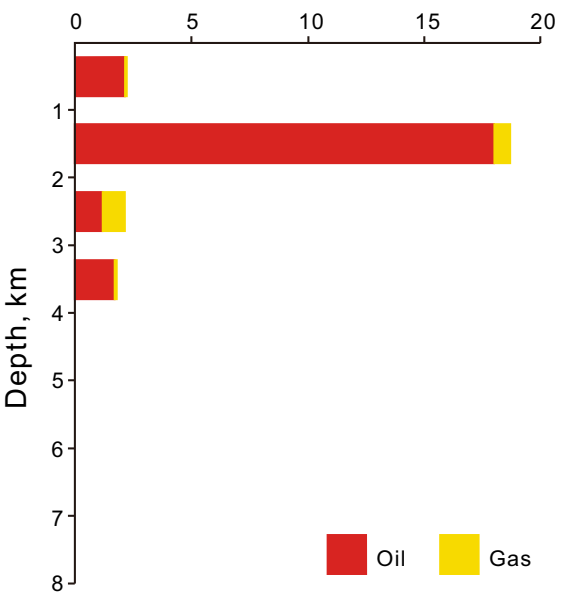

(c) Bohai Bay Basin

Fig. 18 Petroleum reserves of petroliferous basins in China as a function of buried depth

predominant types of deep hydrocarbon reservoirs discovered so far, with certain amounts of volcanic and metamorphic rocks too. Among clastic reservoirs, fractured sandstone reservoirs are the most favorable. Carbonate reservoirs include limestone and dolomite, with carbonate reservoirs extensively found in brittle fractures and karst caves taking the largest proportion. As of 2010, of the 1,477 deep oil-gas reservoirs discovered across the world, $1,035 \%$ or $70.1 \%$ were located in clastic reservoirs, $429 \%$ or $29.0 \%$ were in carbonate reservoirs, and $13 \%$ or
$0.88 \%$ were in magmatic and metamorphic reservoirs (Fig. 24).

According to the latest nationwide petroleum resource evaluation made by the Ministry of Land and Resources (2005), deep hydrocarbon reservoirs discovered in China are predominantly carbonate and sandstone reservoirs (Fig. 25). Widespread marine carbonate reservoirs occur in Central West China basins and are responsible for a series of large marine carbonate hydrocarbon fields represented by Central and North Tarim hydrocarbon fields

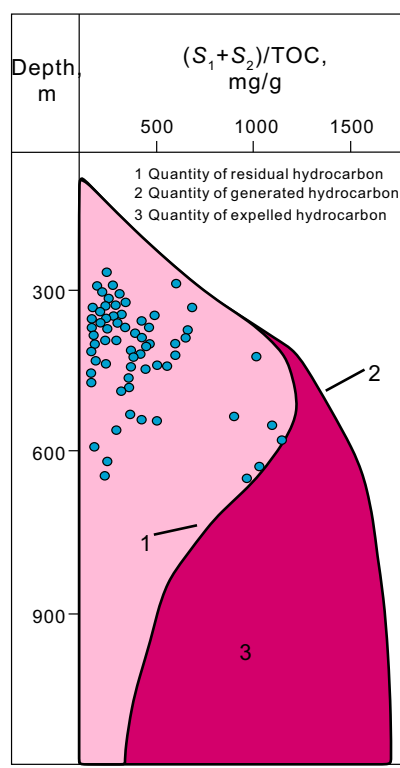

(a) Upper Ganchaigou Formation

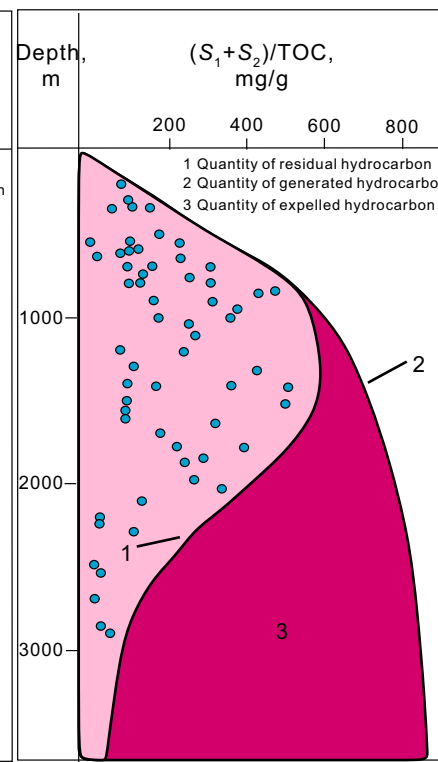

(b) Upper Youshashan Formation of Tertiary

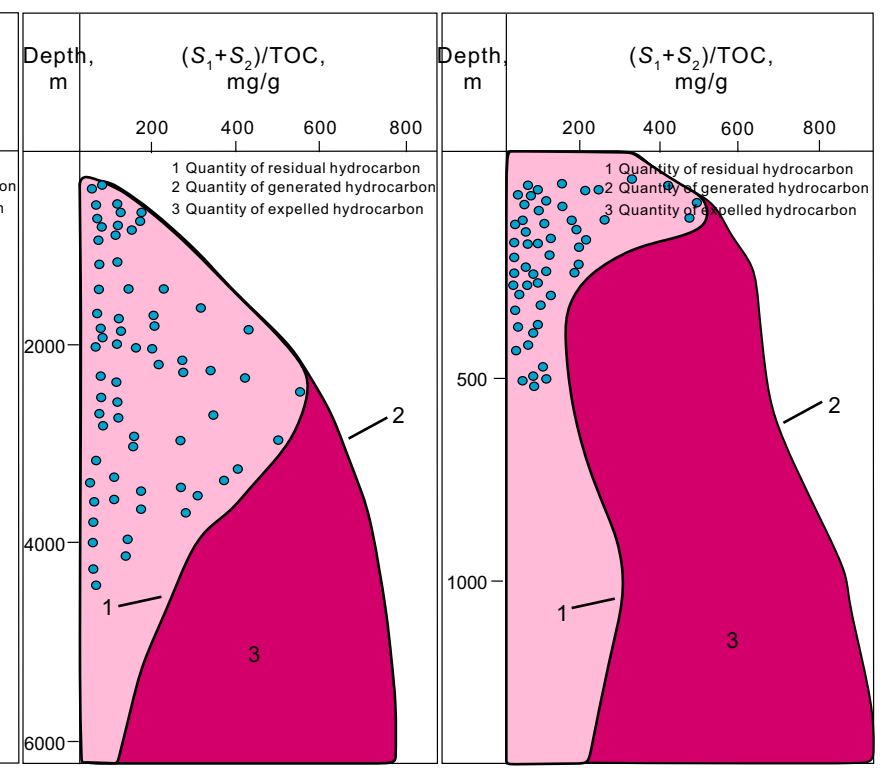

(c) Jurassic

(d) Quaternary

Fig. 19 Hydrocarbon generation, residual hydrocarbon, and hydrocarbon expulsion of source rocks in the Qaidam Basin as a function of buried depth 
Fig. 20 Kerogen $H / C$ atomic ratio and $O / C$ atomic ratio of source rocks in the Tarim Basin platform area. a Change of $H /$ $C$ atomic ratio, b change of $O /$ $C$ atomic ratio

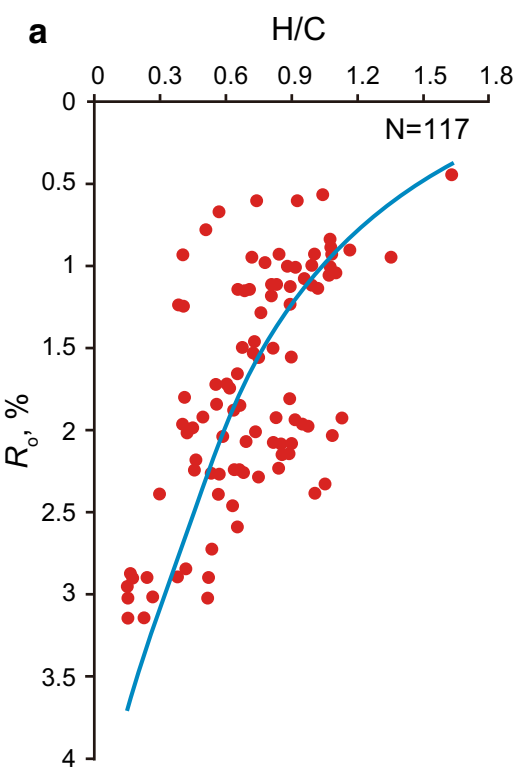

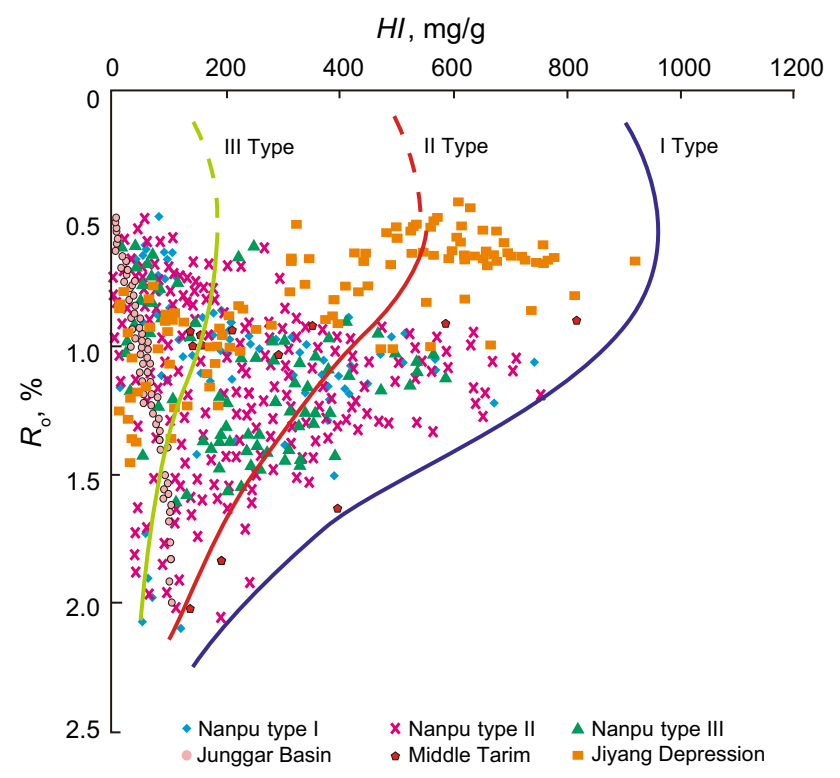

Fig. 21 Hydrogen indices of different types of source rocks as a function of thermal evolution level of the parent material

in the Tarim Basin, East and Central Sichuan reef-flat carbonate hydrocarbon fields. In the northwestern flank of the Junggar Basin, the Kuqa Depression of the Tarim Basin and the Xujiahe Formation of the Sichuan Basin, sandstone oil-gas reservoirs in clastic rocks are the predominant type. Besides, a lot of deep volcanic oil-gas reservoirs are also contained in the deep part of the Junggar and Songliao basins. Deep oil-gas reservoirs in bedrock metamorphic rocks have been discovered in places like the Liaohe Depression of the Bohai Bay Basin.
4.6 The age of deep hydrocarbon reservoirs is widely different, but those recently discovered are predominantly Paleogene and Upper Paleozoic

Oil-gas reservoirs in deep petroliferous basins are similar to their middle or shallow counterparts in terms of formation distribution. The ages of the reservoirs cover a wide range. Most of the deep oil-gas reservoirs discovered so far, however, are in five formation systems: Neogene, Paleogene, Cretaceous, Jurassic, and Upper Paleozoic, the deep $2 \mathrm{P}$ recoverable petroleum reserves of which account for $12.8 \%, 22.3 \%, 18.3 \%, 12.8 \%$, and $22.2 \%$ of the world's totals, respectively (Fig. 26). This suggests that the deep petroleum is mainly in Neogene and Upper Paleozoic formations. Also, as the reservoir ages become older, the ratio of deep natural gas in the total deep petroleum reserve tends to increase accordingly.

After summarizing the reservoir ages of oil-gas reservoirs in China's deep petroliferous basins (Table 5), we discovered that the reservoir ages of deep oil-gas reservoirs in Central and West China basins are predominantly Paleozoic, meaning the reservoirs are quite old; those in East China basins are predominantly Paleogene or Cretaceous, and reservoir ages of oil-gas reservoirs in the bedrock are predominantly Precambrian.

4.7 The porosity and permeability of deep hydrocarbon reservoirs are widely different, but they vary with the lithology and buried depth

The porosities and permeabilities of target formations for deep oil-gas reservoirs in petroliferous basins vary widely, ranging from high-porosity, high-permeability (with 


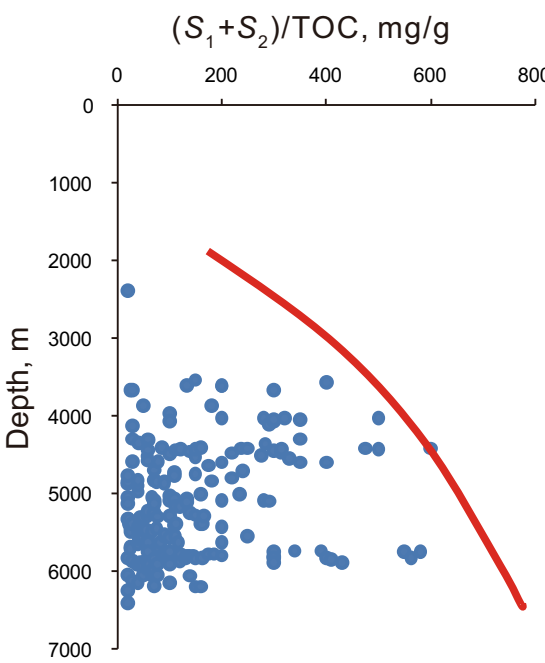

(a) $\mathrm{TOC} \leq 0.1$

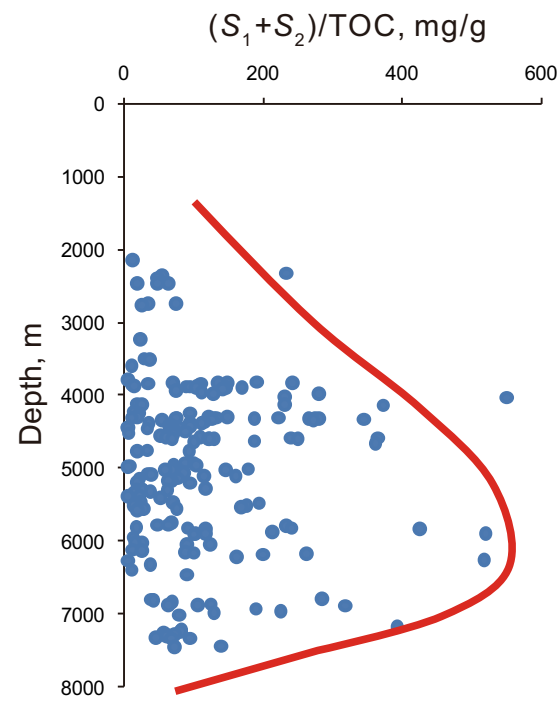

(d) $0.3 \leq \mathrm{TOC} \leq 0.4$
$\left(S_{1}+S_{2}\right) / T O C, \mathrm{mg} / \mathrm{g}$

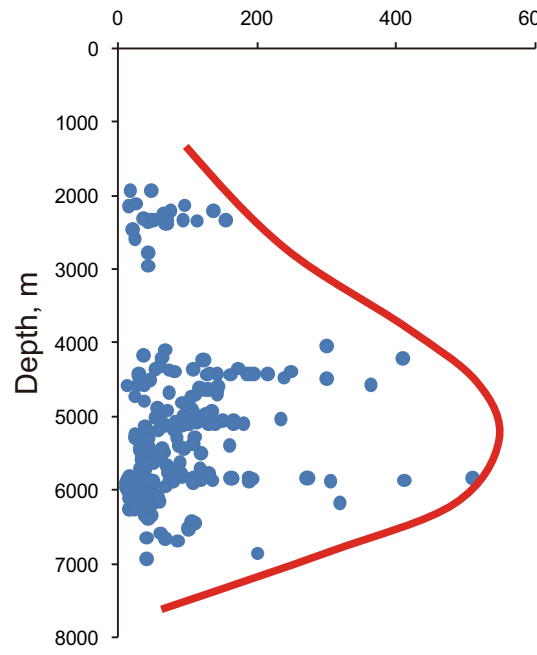

(b) $0.1 \leq \mathrm{TOC} \leq 0.2$

$\left(S_{1}+S_{2}\right) / T O C, \mathrm{mg} / \mathrm{g}$

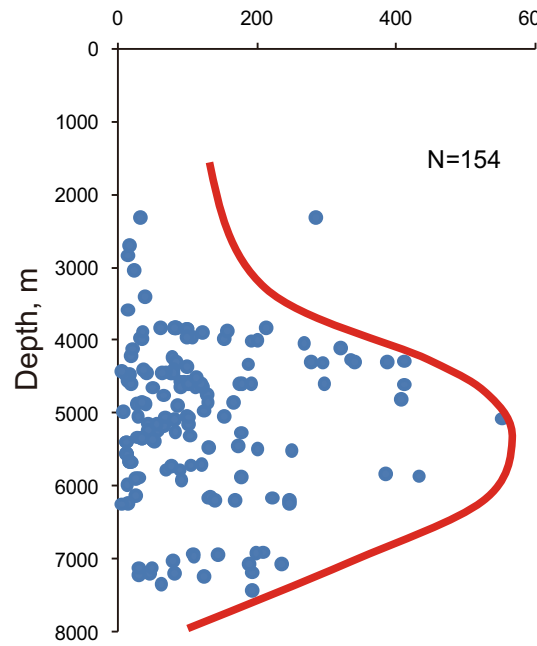

(e) $0.4 \leq T O C \leq 0.5$
$\left(S_{1}+S_{2}\right) / T O C, \mathrm{mg} / \mathrm{g}$

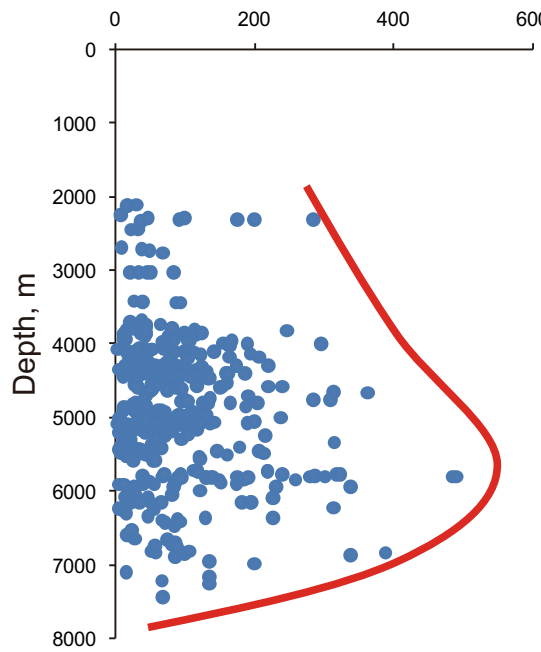

(c) $0.2 \leq \mathrm{TOC} \leq 0.3$

$$
\left(S_{1}+S_{2}\right) / \text { TOC, } \mathrm{mg} / \mathrm{g}
$$

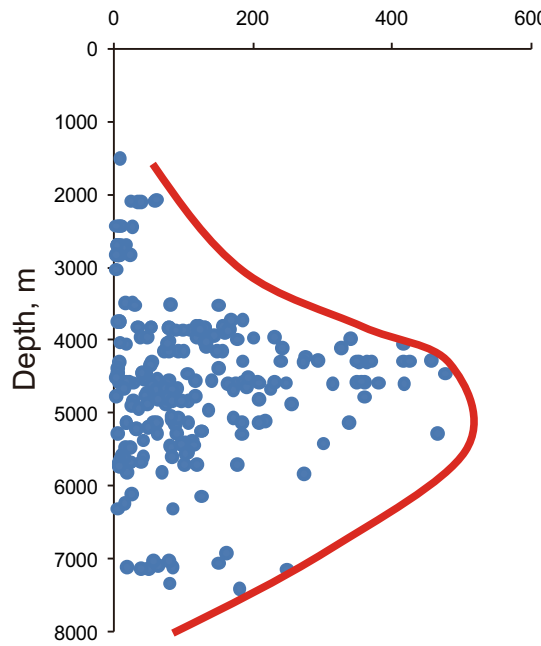

(f) $\mathrm{TOC}>0.5$

Fig. 22 Hydrocarbon potential of Cambrian-Ordovician carbonate source rocks in the Tarim Basin

porosity of $38 \%$ and permeability of $7,800 \mathrm{mD}$ ) highquality reservoirs to low-porosity, low-permeability (with porosity lower than $5 \%$ and permeability less than $0.1 \mathrm{mD}$ ) tight reservoirs. High-porosity, low-permeability or low-porosity, high-permeability petroliferous reservoirs have also been identified. Deep drilling records across the world demonstrate that as the reservoir depth increases, the compaction effect and consequently the diagenesis intensify, so the porosity of deep rocks tends in general to decrease. The porosities of the world's deep petroliferous basins are mostly in the 10\%-12\% range (Wang et al. 2012). A summary of the porosities and permeabilities of 20,717 oil-gas reservoirs across the world as a function of depth revealed that the porosities and permeabilities of these reservoirs tend to decrease with the increase of depth overall (Fig. 27), though this rule varies from one lithology to another in different areas. Clastic reservoirs, for example, show obvious porosity and permeability decreases in some reservoirs, but the porosity of other reservoirs varies little in deep or ultra-deep formations (Fig. 28), while carbonate reservoirs do not show obvious decreases in their reservoir properties as the depth increases (Fig. 29) due to their high rock brittleness, high compaction stability, and good solubility. The porosities of volcanic reservoirs do not vary much with depth (Fig. 30). The various petroliferous basins in China do not present the same characteristics. Figure 31 compares the reservoir porosity variations of different petroliferous basins in China as a function of 


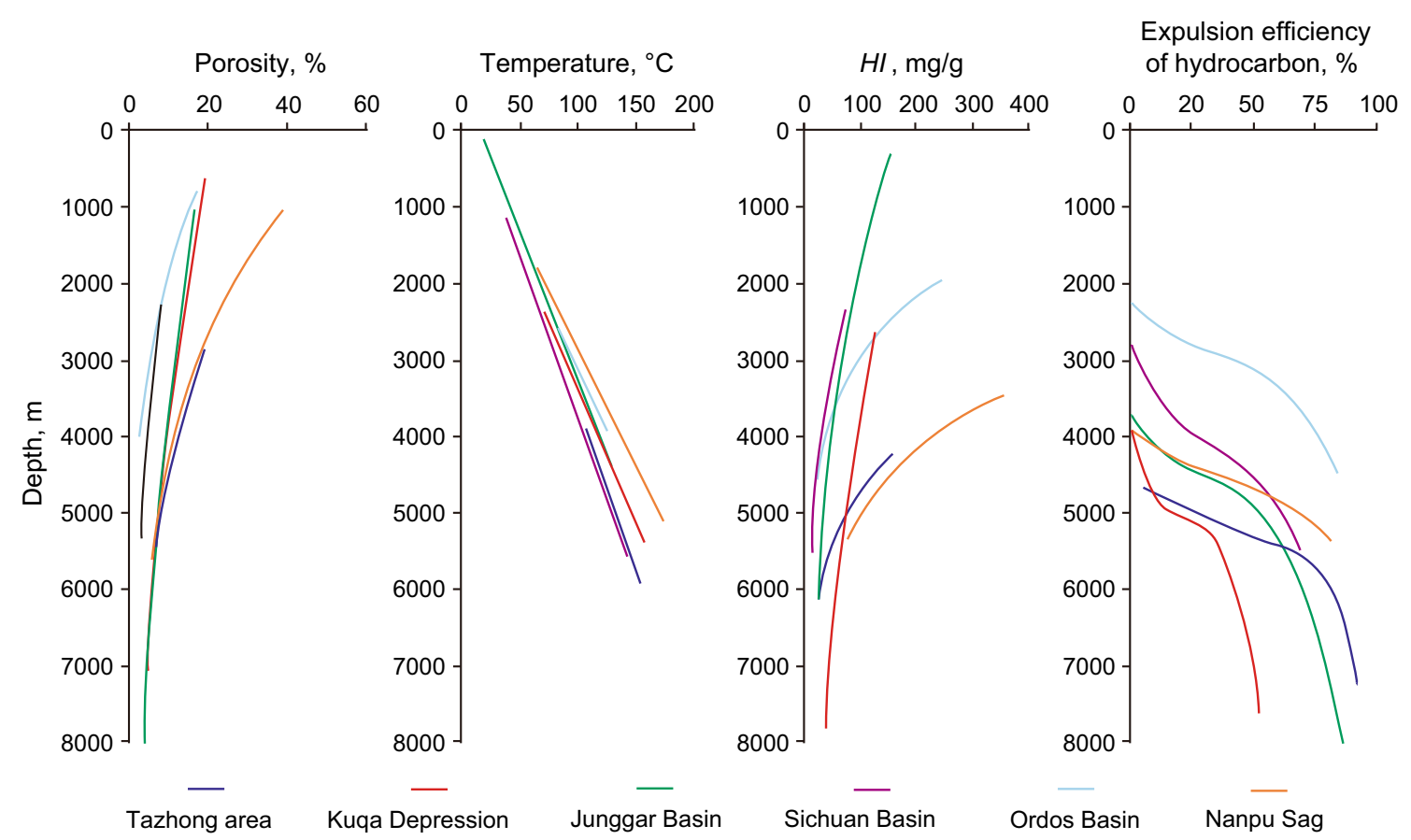

Fig. 23 Hydrocarbon expulsion efficiency of representative petroliferous basins in China as a function of depth

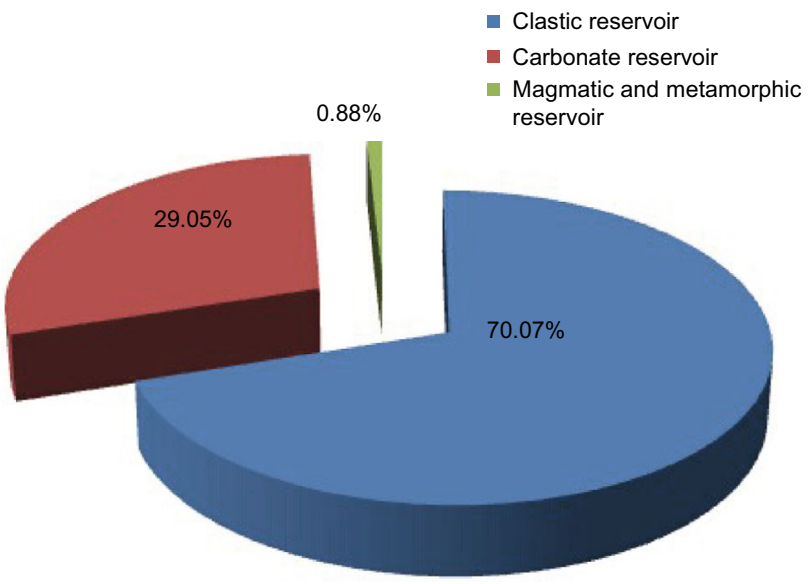

Fig. 24 Distribution of reservoir lithologies of deep oil-gas reservoirs in the world

depth. It shows that the porosity of sandstone reservoirs decrease with an increase in buried depth, while the porosity is in general retained in carbonate and volcanic rocks until below $6,500 \mathrm{~m}$.

4.8 The temperatures of deep oil-gas reservoirs differ widely, but they typically vary with the buried depth and geothermal gradient

The temperature range of oil reservoirs in deep petroliferous basins has exceeded that of liquid hydrocarbon (windows) supposed by traditional kerogen theory $\left(60-120{ }^{\circ} \mathrm{C}, R_{\mathrm{O}}=0.6 \%-1.35 \%\right)$ : the highest oil reservoir temperature discovered in the world so far is more than $200{ }^{\circ} \mathrm{C}$. Compared with their middle-shallow counterparts, deep oil-gas reservoirs have even higher temperatures which vary even more widely. Statistics of the temperatures and pressures of 428 deeper-than-4,500 m oil-gas reservoirs in the world (Fig. 32) show that the temperatures of deep oil-gas reservoirs can be $200{ }^{\circ} \mathrm{C}$ maximum and those of a couple of gas reservoirs are more than $370{ }^{\circ} \mathrm{C}$, compared with the lowest hydrocarbon reservoir temperature of $47{ }^{\circ} \mathrm{C}$. Even at the same depth, the temperatures of deep oil-gas reservoirs vary from one type to another, such as the petroliferous basins in China, those in the east are mostly extensional basins that are typically hot basins with an average geothermal gradient of approximately $4{ }^{\circ} \mathrm{C} / 100 \mathrm{~m}$ and oil reservoirs deeper than $4,500 \mathrm{~m}$ being hotter than $180{ }^{\circ} \mathrm{C}$; the extrusion basins in the west and the craton basins in the center, to the contrary, have lower geothermal gradients and are typical cold basins (Liu et al. 2012) with an average geothermal gradient of approximately $2.5{ }^{\circ} \mathrm{C} / 100 \mathrm{~m}$. At the same depth of $4,500 \mathrm{~m}$, the temperature in the center and west is less than $120^{\circ} \mathrm{C}$. The temperature difference is approximately $60{ }^{\circ} \mathrm{C}$. Figure 33 compares the geothermal gradients of some of the representative basins in China as a function of time, from which we can observe that, at the same depth, the formation temperature tends to increase from west toward east, reflecting the eastward increase of the geothermal gradient or heat flux. 


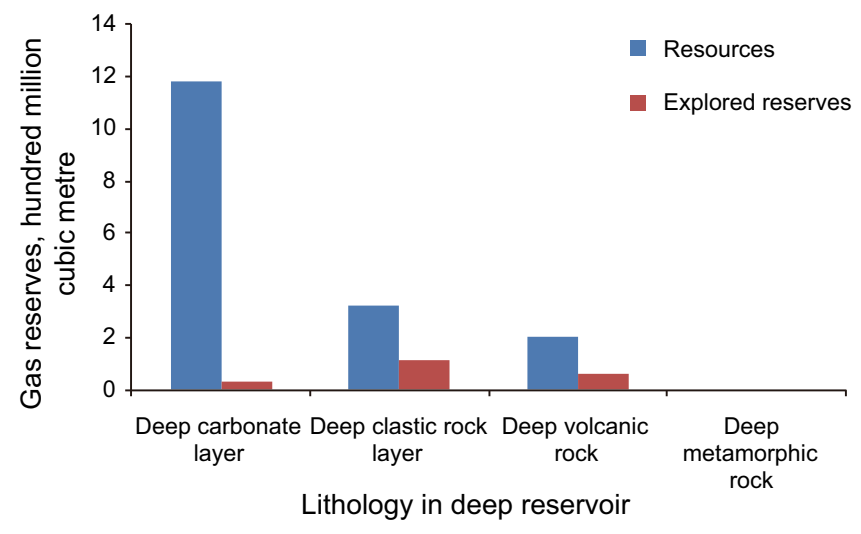

(a) Lithology distribution of gas reservoir

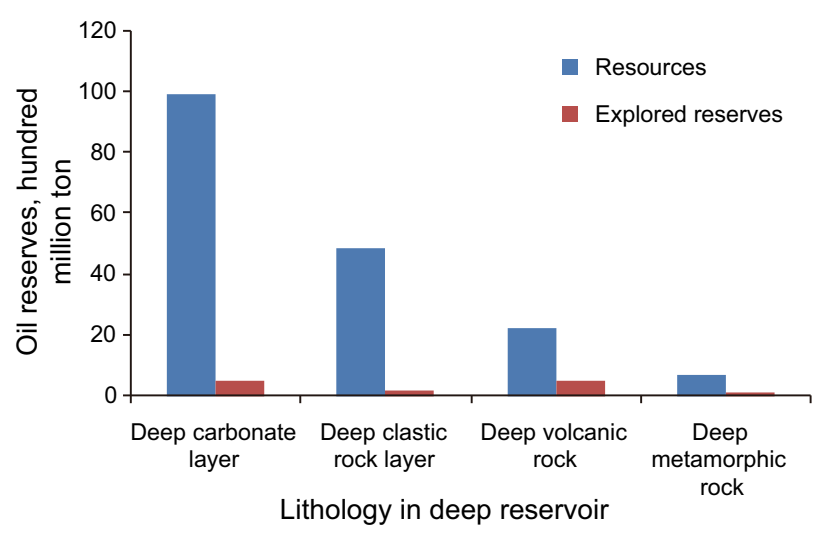

(b) Lithology distribution of oil reservoir

Fig. 25 Distribution of reservoir lithologies of deep oil-gas reservoirs in China

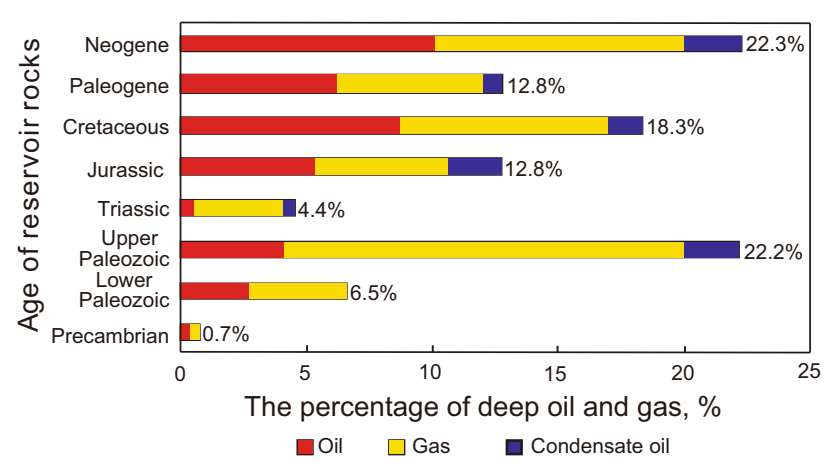

Fig. 26 The age distribution of deep hydrocarbon reservoirs in the world (Bai and Cao 2014)

4.9 The pressure of deep oil-gas reservoirs typically varies with the buried depth, genesis, and evolution period

Oil-gas reservoirs formed under high porosities and high permeabilities in middle-shallow petroliferous basins are typically buoyancy controlled, thereby generally displaying high pressures. Oil-gas reservoirs discovered in deep basins, however, have complex genesis, thereby displaying diverse pressures (Fig. 34). Statistics of the pressure records of 16,552 oil-gas reservoirs in the world revealed significant pressure differences among deep oil-gas reservoirs. The highest of the majority is $130 \mathrm{MPa}$, with a few outliers as high as $172 \mathrm{MPa}$, while the lowest is merely 8.4 MPa (Fig. 35).

Abnormal high pressures are generally contained in deep tight structural gas reservoirs and tight lithological gas reservoirs, like the Sichuan Xiaoquan gas reservoir which has abnormally high pressures with a pressure coefficient of 1.6-2.0 (Guan and Niu 1995), and the Fuyang tight oil reservoir in Songliao which also displays abnormally high pressures with a pressure coefficient larger than 1.6. Deep oil-gas reservoirs with normal pressures also exist, like the 13 Lunnan buried hill oil reservoirs in the Tarim Basin that have the pressure coefficients between 1.03 and 1.14; and the Lunnan-17 well, Lunnan-30 well, Lunnan-44 well, and Jiefang-123 well oil reservoirs that have coefficients of $1.137,1.130,1.143$, and 1.148 , defining them as normal pressure oil reservoirs (Gu et al. 2001). Low-pressure oil-gas reservoirs are typically found in tight syncline sandstone gas reservoirs, like the tight sandstone hydrocarbon reservoirs discovered in Canada's Alberta Basin (Masters 1979), the tight sandstone hydrocarbon reservoirs discovered in the USA's Red Desert (Spencer 1989), and the tight sandstone hydrocarbon reservoirs in the USA's Green River Basin. The same occurs in the upper Paleozoic tight sandstone reservoirs in China's Erdos Basin and the tight sandstone gas reservoirs discovered in the Jurassic of the Tuha Basin (Fig. 36). In the main, deep oil-gas reservoirs have complex pressures; abnormally high, normal, and abnormally low-pressure hydrocarbon reservoirs can all be found in deep oil-gas reservoirs. So far, the complex hydrocarbon accumulation areas formed by coexistence of the three pressure categories are increasingly found in basins. Research (Pang et al. 2014a) shows that the pressure of deep oil-gas reservoirs is decided by their genesis mechanism and genesis process. Normal oil-gas reservoirs formed in free fluid dynamic fields in high-porosity, high-permeability media generally have high pressure, while unconventional oil-gas reservoirs formed in limited fluid dynamic fields in low-porosity, low-permeability media generally end up with negative pressure, though they appeared to show high pressure during hydrocarbon accumulation into reservoirs. Normal oil-gas reservoirs formed in the early years in petroliferous basins, as the depth increased, superimposed or compounded with the unconventional oil-gas reservoirs originated from the deep part before, eventually giving rise to 
Table 5 Chronological distribution of deep hydrocarbon reservoir strata in China's petroliferous basins

\begin{tabular}{|c|c|c|c|c|c|c|}
\hline Basin & Oil/gas field name & $\begin{array}{l}\text { Target } \\
\text { formation } \\
\text { depth, m }\end{array}$ & $\begin{array}{l}\text { Formation } \\
\text { lithology }\end{array}$ & $\begin{array}{l}\text { Proved oil } \\
\text { reserve, } \\
10^{4} \mathrm{t}\end{array}$ & $\begin{array}{l}\text { Proved natural } \\
\text { gas } \\
\text { reserve, } 10^{8} \mathrm{~m}^{3}\end{array}$ & $\begin{array}{l}\text { Target } \\
\text { formation age }\end{array}$ \\
\hline \multirow[t]{4}{*}{ Tarim Basin } & Central Tarim gas field & $4,500-6,200$ & Carbonate & 38,600 & 1,020 & Ordovician \\
\hline & Halahatang oilfield & $5,900-7,100$ & Carbonate & 20,812 & - & Ordovician \\
\hline & Donghetang oilfield & $>6,000$ & Clastic rock & 3,323 & - & Carboniferous \\
\hline & Kuche deep gas region & $5,000-8,000$ & Clastic rock & - & 6,448 & Cretaceous \\
\hline Junggar Basin & Xiazijie oilfield & 4,800 & Volcanic rock & 1,548 & 34 & Permian \\
\hline \multirow[t]{2}{*}{ Sichuan Basin } & Longgang gas field & $2,800-7,100$ & Carbonate & - & 730 & Permian \\
\hline & $\begin{array}{l}\text { Moxi Longwangmiao gas } \\
\text { field }\end{array}$ & $4,500-5,500$ & Dolomite & - & 4,404 & $\begin{array}{l}\text { Sinian, } \\
\text { Cambrian }\end{array}$ \\
\hline \multirow{2}{*}{$\begin{array}{c}\text { Bohai Bay } \\
\text { Basin }\end{array}$} & Qishan gas field & $4,500-5,500$ & Clastic rock & - & 95 & Paleogene \\
\hline & Xinglongtai gas field & $4,500-5,500$ & $\begin{array}{l}\text { Metamorphic } \\
\text { rock }\end{array}$ & 0.75 & - & Archaeozoic \\
\hline Songliao Basin & Changling gas field & $4,500-5,000$ & Volcanic rock & - & 640 & Cretaceous \\
\hline
\end{tabular}
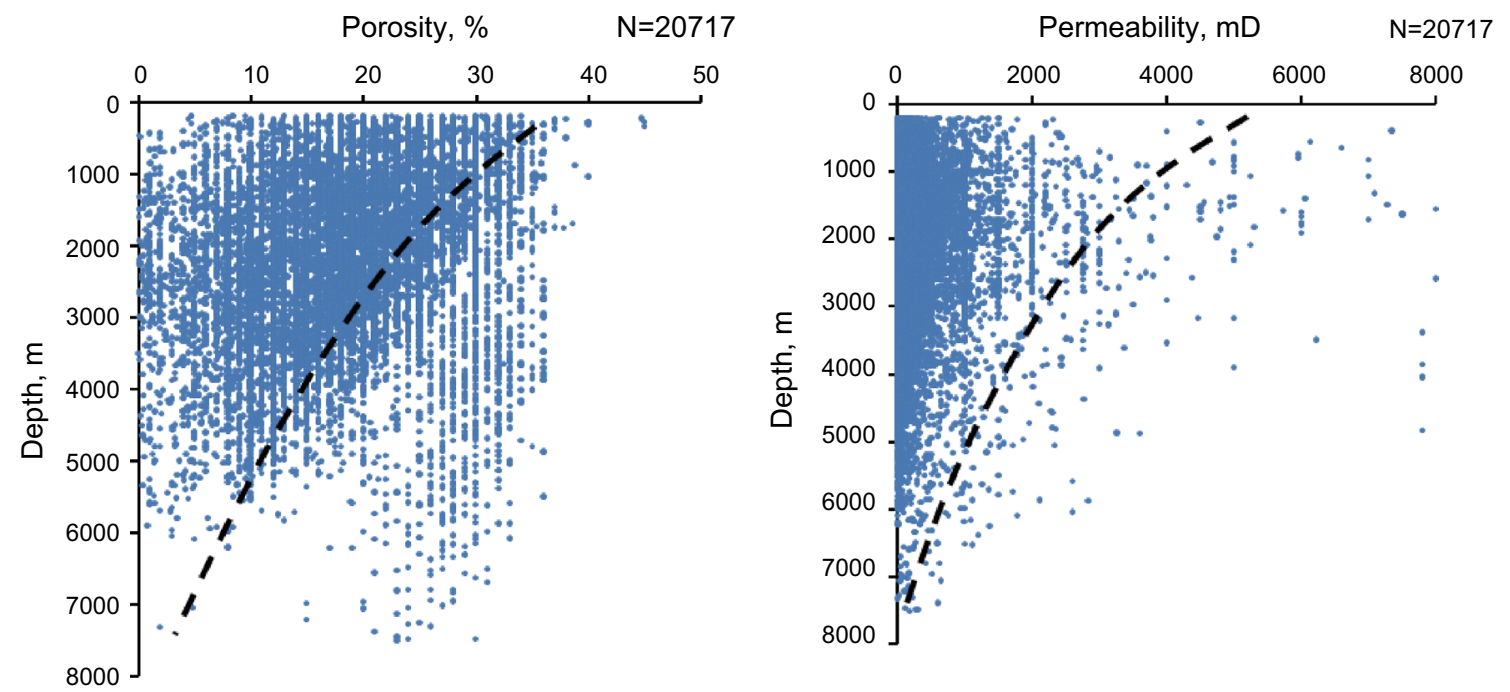

Fig. 27 Reservoir properties as a function of depth of petroliferous basins in the world
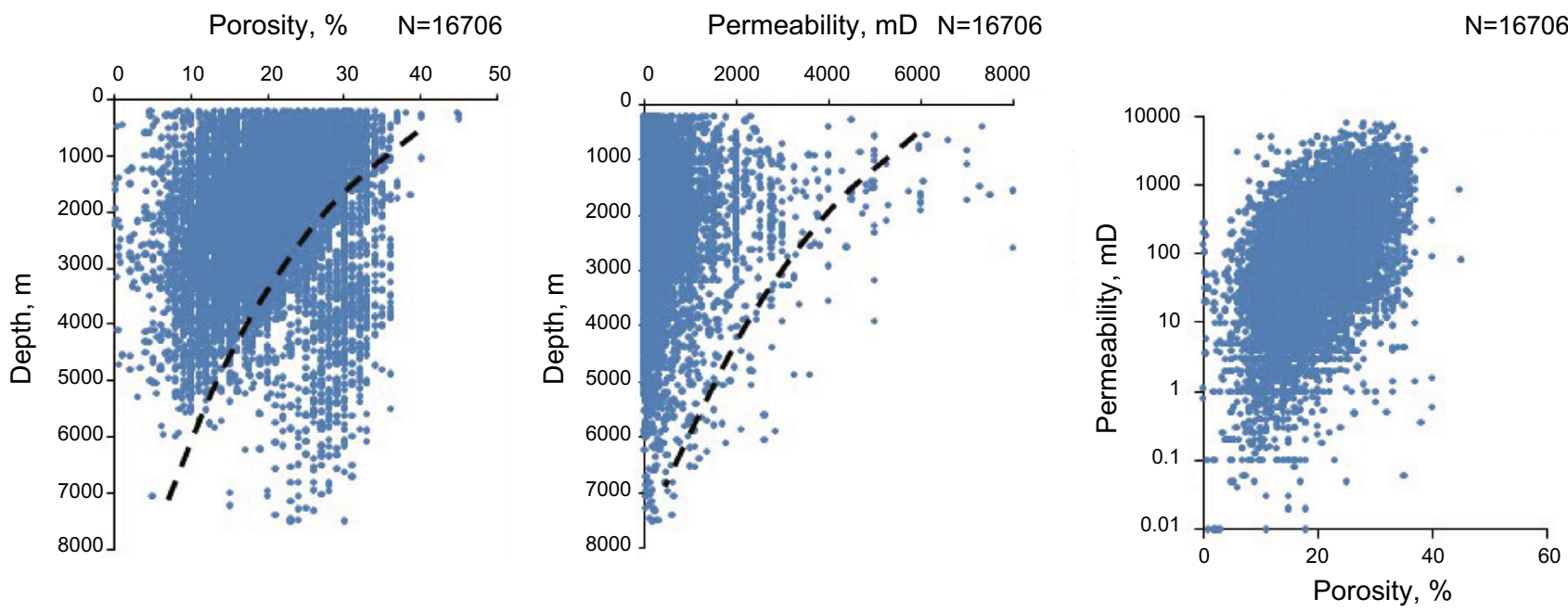

Fig. 28 Reservoir properties of clastic rocks as a function of buried depth of petroliferous basins in the world 

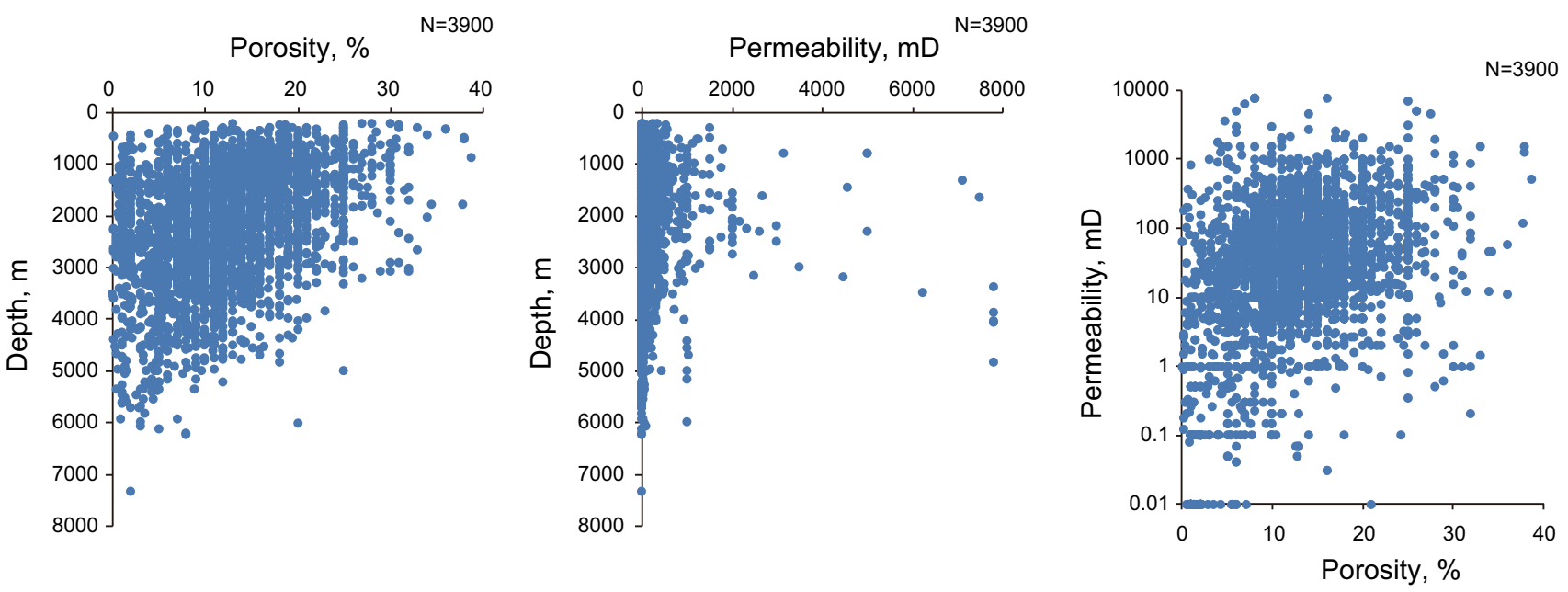

Fig. 29 Reservoir properties of carbonate as a function of buried depth of petroliferous basins in the world
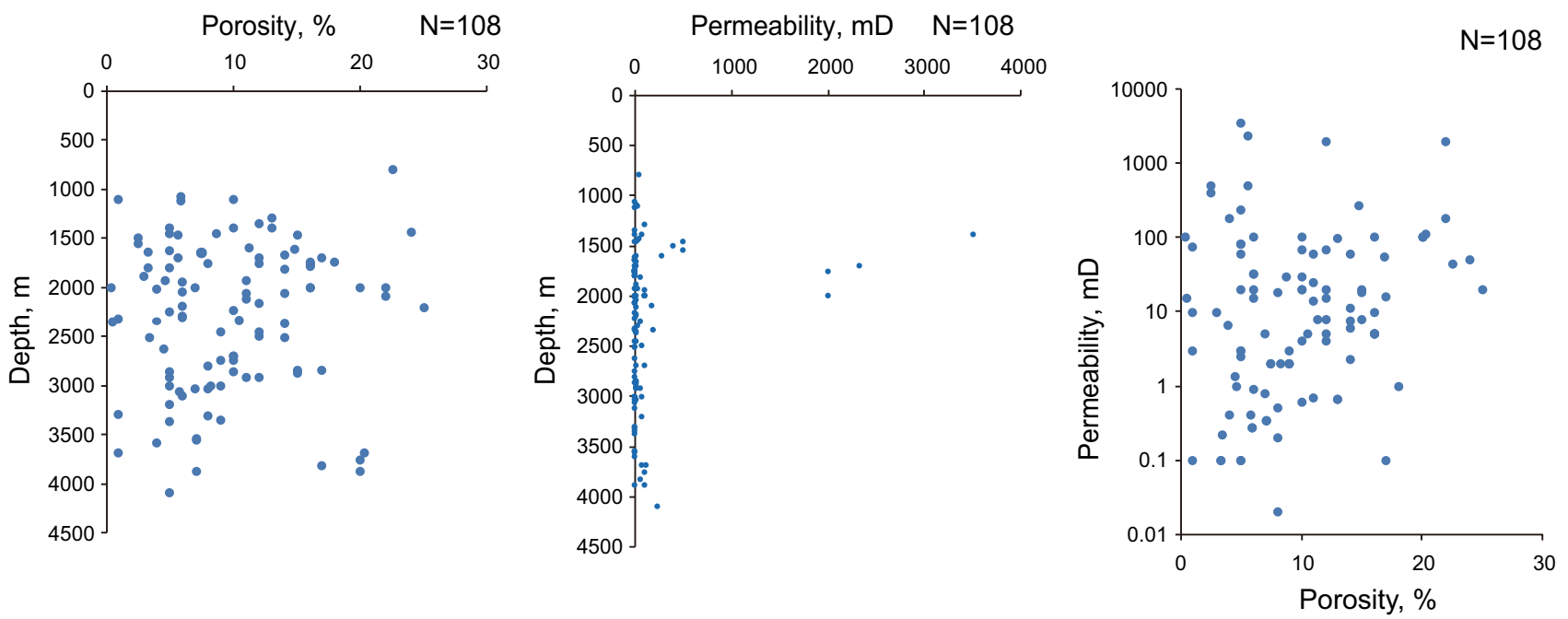

Fig. 30 Reservoir properties of volcanic and metamorphic rocks as a function of buried depth of petroliferous basins in the world

superimposing or compounded, continuous oil-gas reservoirs, among which there can be high-pressure petroliferous reservoirs coexisting with low-pressure petroliferous reservoirs.

\subsection{Deep oil-gas reservoirs may exist with or without a cap, and those without a cap are typically of unconventional genesis}

Forming a hydrocarbon reservoir without relying on a cap is the unique geological feature of deep hydrocarbon entrapment. Conventional petroleum geological theory assumes that a cap is an indispensable geological element for the formation and preservation of any hydrocarbon reservoir; without a cap, it would be impossible for hydrocarbon to gather into a reservoir in any high-porosity, high-permeability media, since buoyancy would cause the hydrocarbon to percolate upward to the basin surface. For deep hydrocarbon entrapment, however, as far as the reservoir media were commonly tight, a cap is not indispensable (Fig. 37). The realities underlying this phenomenon are the particular fluid dynamic fields and material equilibrium conditions of deep oil-gas reservoirs: (1) deep reservoirs, if commonly tight, had poor porosities and permeabilities and limited pore throat radii, so hydrocarbon had to overcome great capillary pressures and the hydrostatic pressures of the overlying water columns when it tried to charge into the reservoir; (2) for deep oilgas reservoirs, buoyancy was no longer the primary drive for hydrocarbon migration; they expelled pore water and expanded their own area by relying on the hydrocarbon volume increase and finally became continuous oil-gas reservoirs; and (3) the sources of tight continuous oil-gas reservoirs formed from deep basins were close to the 


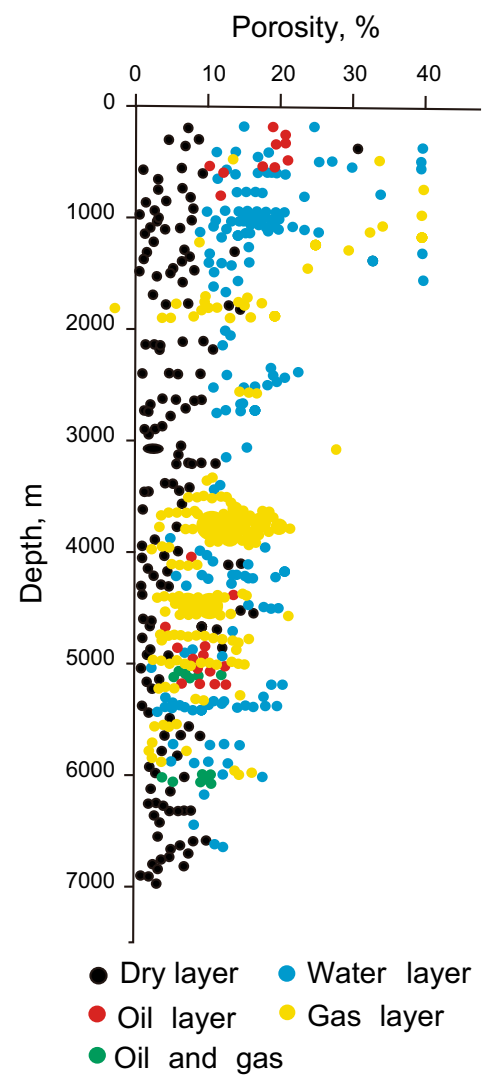

(a) Kuqa clastic rock

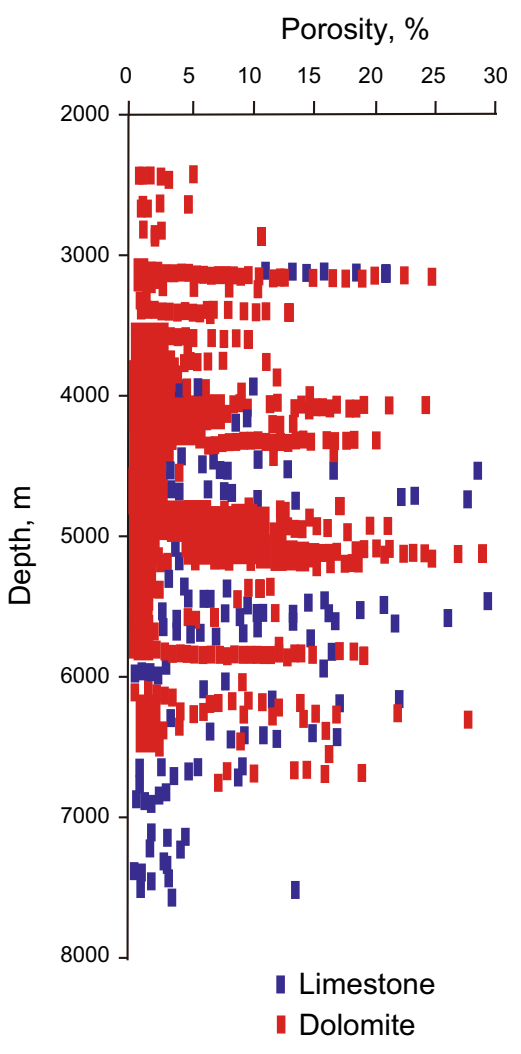

(b) Tarim and Sichuan carbonate

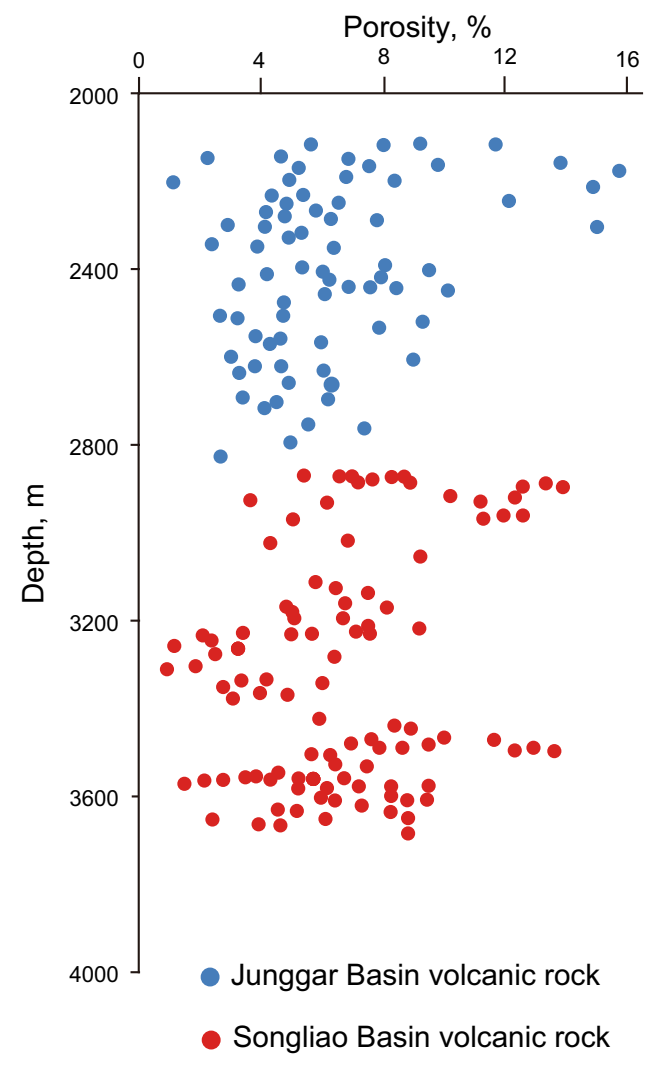

(c) Junggar and Songliao Basin volcanic rocks

Fig. 31 Porosities of target strata with different lithologies as a function of depth of petroliferous basins in China

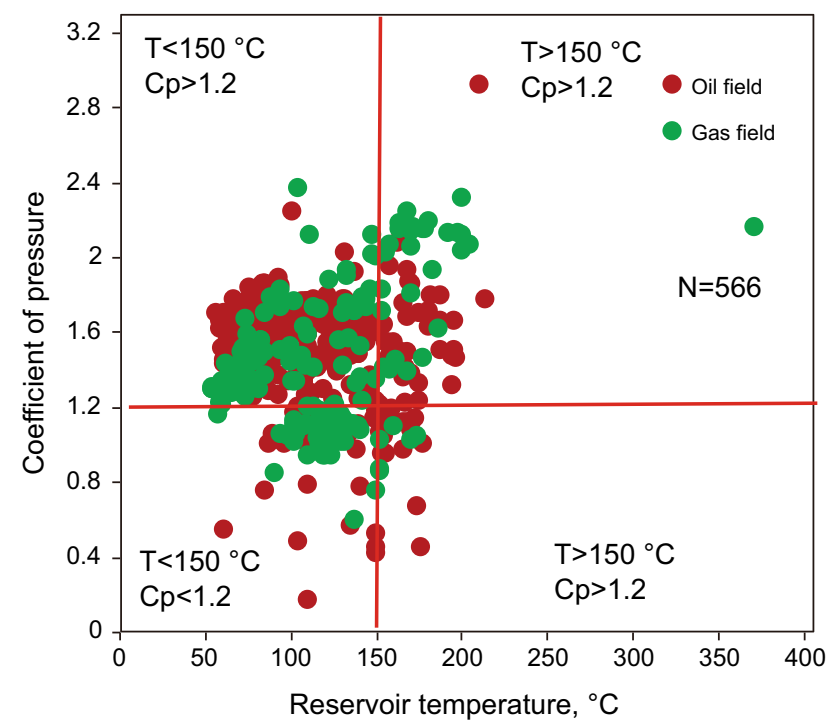

Fig. 32 Scatter diagram of temperatures and pressure coefficients of deep hydrocarbon fields of petroliferous basins in the world

reservoir, keeping the hydrocarbon under constant diffusion-accumulation equilibrium, thus enabling them to be preserved for a long time under structural stability.
Deep oil-gas reservoirs can be developed without a cap, but oil-gas reservoirs without a cap are generally found in areas with tight reservoirs and stable tectonism, like deep depressions and slope areas of the basin.

\section{Major progress in deep hydrocarbon reservoir research}

Deep hydrocarbon reservoirs are attracting the attention of more and more companies and scholars at home and abroad and a series of research achievements have been made in the past ten years. The major research achievements and progresses are described as follows:

\subsection{Multiple deep hydrocarbon sources in petroliferous basins and the formation mechanisms}

Traditionally, hydrocarbon researchers believed that hydrocarbon was formed from thermal degradation of organic matter under appropriate temperatures $\left(60-135^{\circ} \mathrm{C}\right)$ and pressure (burial depth 1,500-4,500 m) in sedimentary basins (Hunt 1979; Tissot and Welte 1978). But the formation mechanism of deep hydrocarbons in a high- 
Fig. 33 Formation temperatures of petroliferous basins in different parts of China as a function of buried depth
Fig. 34 Comparison of pressures and genesis of conventional gas reservoirs versus deep basin oil-gas reservoirs (Pang et al. 2006)

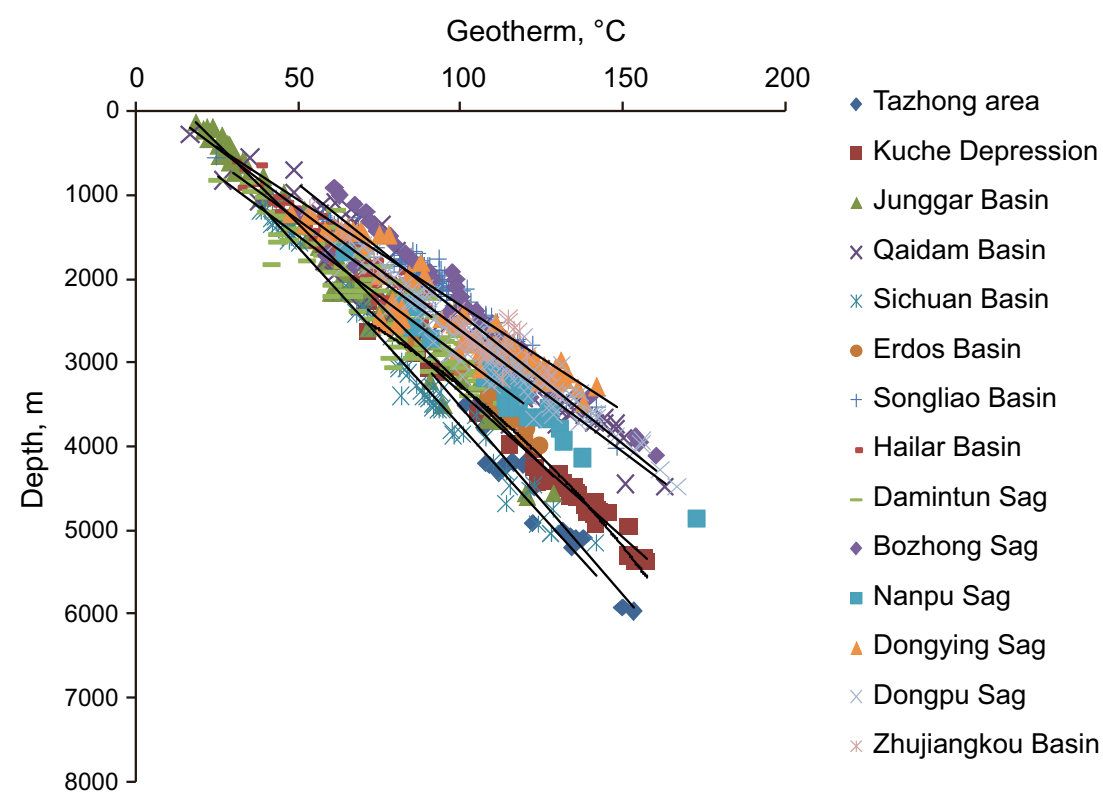

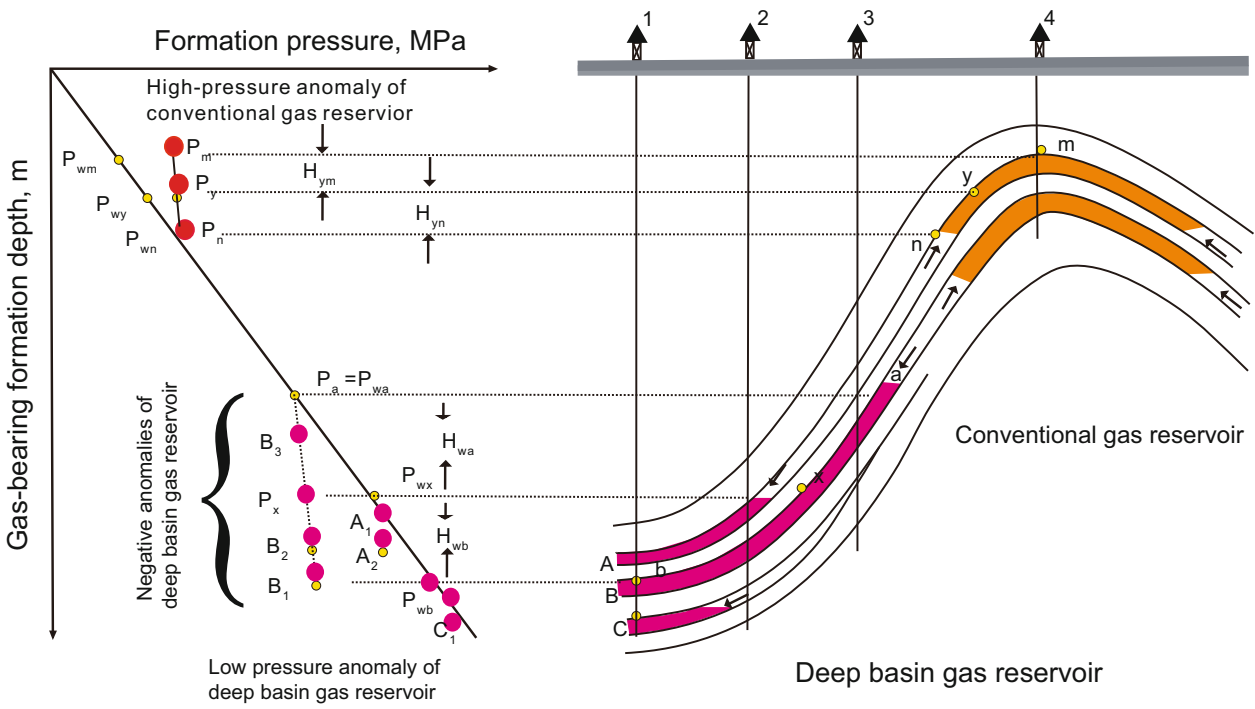

temperature and high-pressure environment is far more complicated than it was thought to be. So far, four hydrocarbon generation modes have been proposed by scholars.

\subsubsection{Successive generation of gas from deep organic matter}

The theory of successive generation of gas from organic matter solved the problem of generation and expulsion of natural gas from highly and over-mature source rocks deep down in hydrocarbon basins (Zhao et al. 2005). The "successive generation of gas" mechanism means the conversion of gas-generating matrix and succession of gasgenerating time and contribution in the gas-generating process (Fig. 38), including two aspects: 1) the generation of gas from thermal degradation of kerogen and cracking of liquid hydrocarbon and soluble organic matter in coal, which occurs successively in terms of gas generation and contribution; and 2) part of the liquid hydrocarbon generated in the thermal degradation of kerogen is expelled from source rocks to form oil reservoirs, but most of the liquid hydrocarbon remains dispersed in the source rocks, where it is thermally cracked in the highly to over-mature areas so that the source rocks still have great gas-generating potential. 

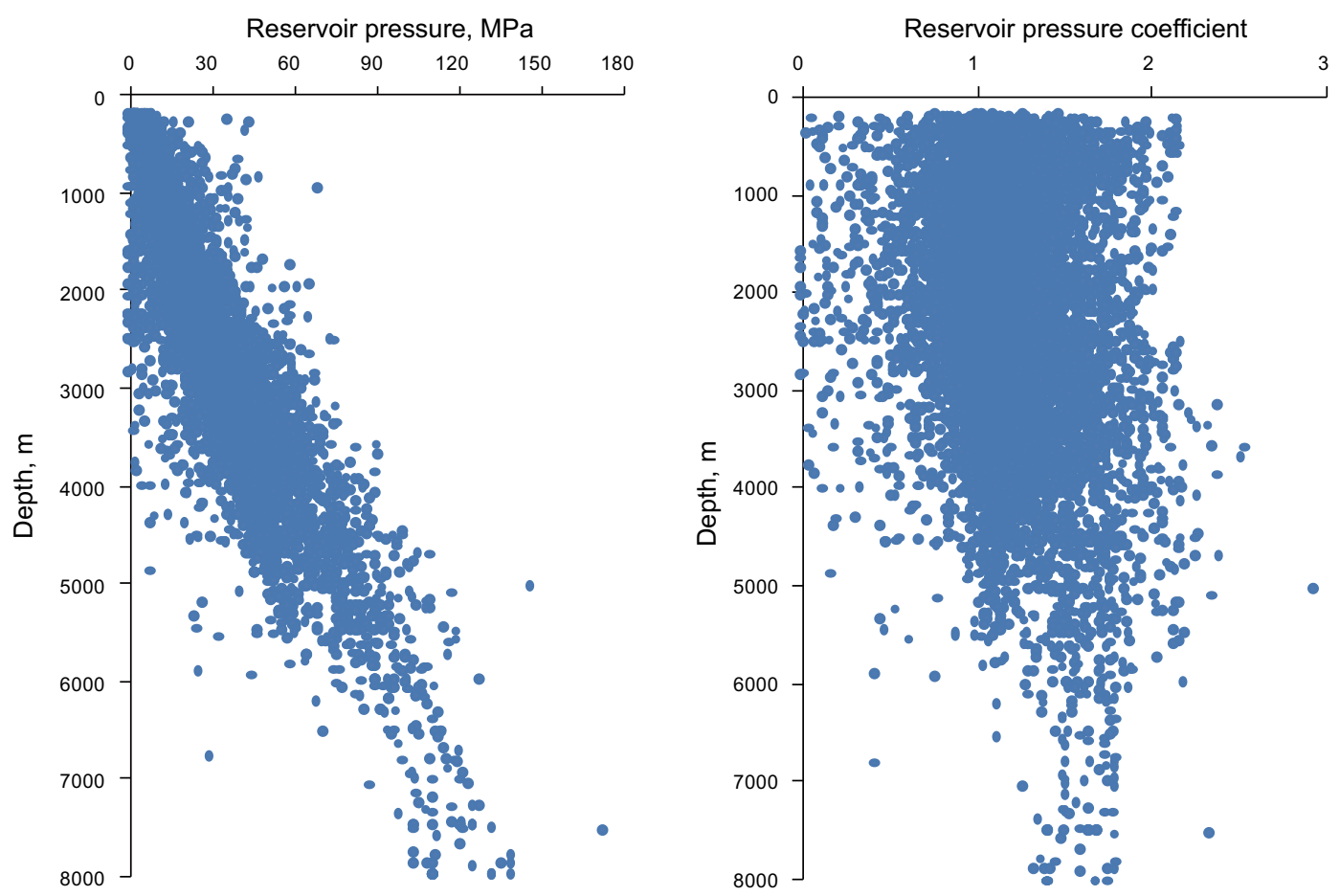

Fig. 35 Hydrocarbon reservoir pressures of petroliferous basins in the world as a function of buried depth
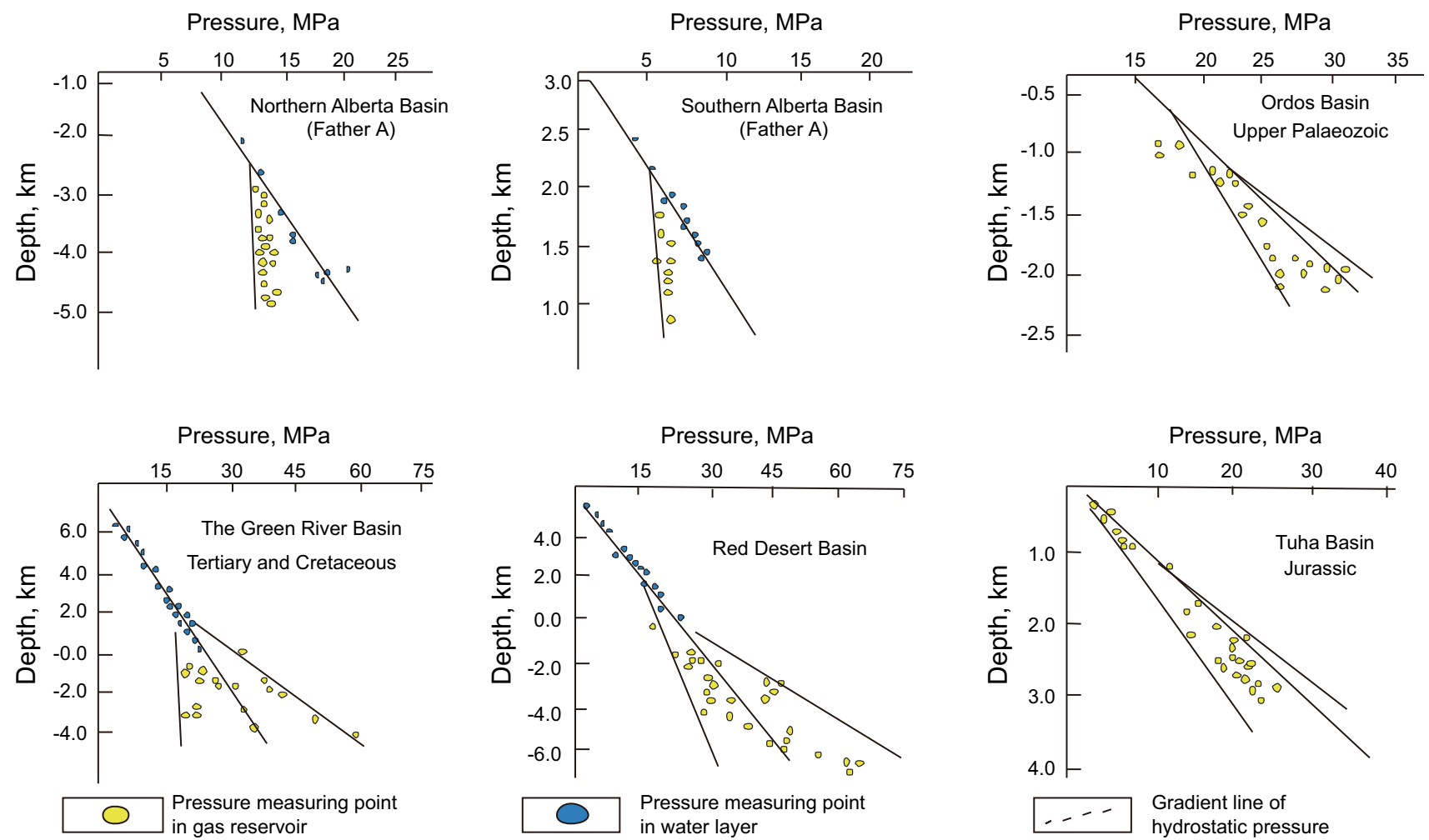

Fig. 36 Reservoir pressures of deep tight sandstone oil-gas reservoirs in representative petroliferous basins in China and elsewhere as a function of depth 


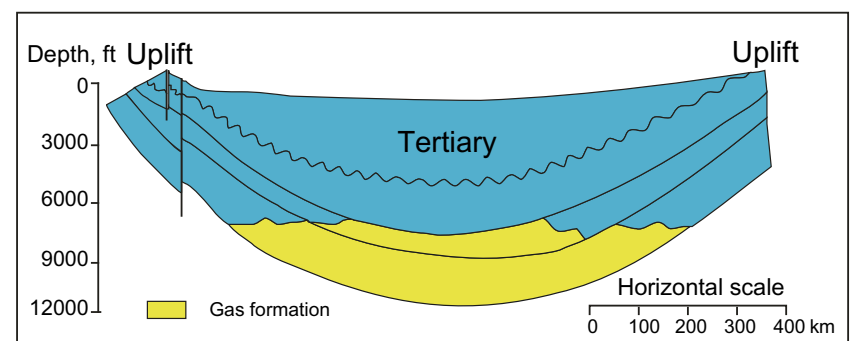

(a) American Red Desert Basin

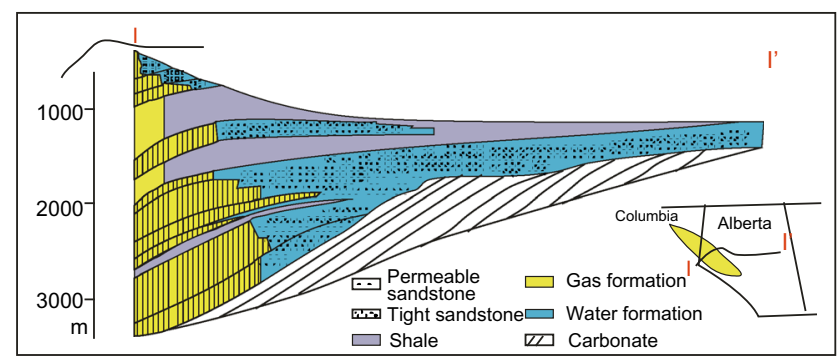

(c) Canadian Alberta Basin

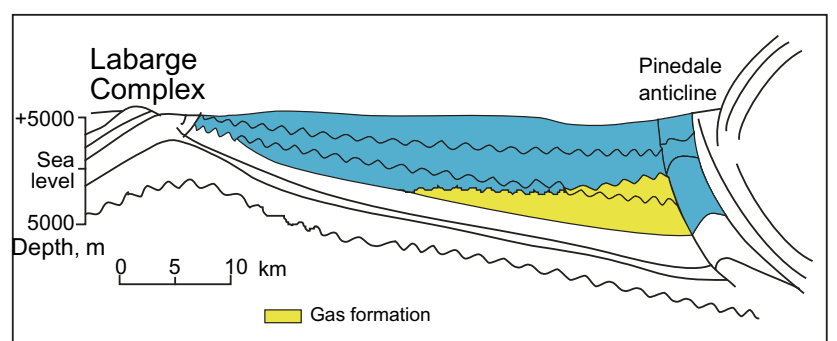

(b) American Green River Basin

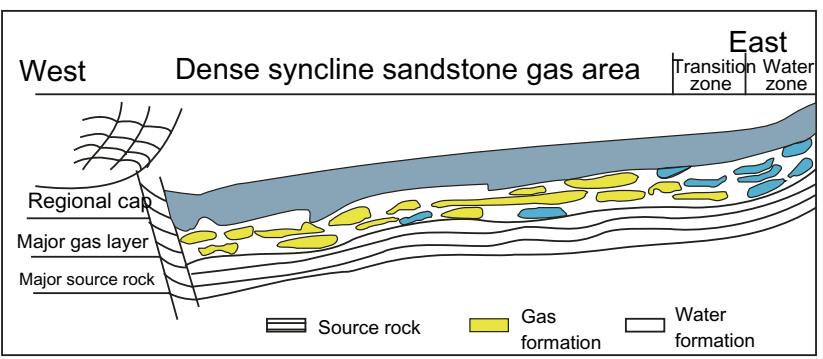

(d) Chinese Ordos Basin

Fig. 37 Reservoir pressures of a few known tight sandstone oil-gas reservoirs in China and worldwide

\subsubsection{Hydrocarbon generation from hydrogenation of deep organic matter}

The generation of hydrocarbons from thermal evolution of organic matter not only needs heat but also hydrogen. The injection of hydrogen-rich fluids into a sedimentary basin will definitely have a great impact on the generation of hydrocarbon. Jin et al. conducted a simulation test with olivine, zeolite, and source rocks, finding that the methane yield increased by $2-3$ times after the source rocks interacted with the zeolite and olivine. According to analysis of hydrocarbon generated in low-maturity source rocks in the Dongying Sag and the Central Tarim region by Jin et al. (2002) by means of hydrogenation thermal simulation, the effect of hydrogenation on hydrocarbon generation for Type $\mathrm{II}_{2}$ kerogen is distinct after the peak hydrocarbongenerating period, while the effect on humic-type kerogen is distinct in all periods. The effect of hydrogenation on source rocks with poor hydrogen kerogen is more distinct (Fig. 39).

\subsubsection{Hydrocarbon generation and expulsion from deep asphalt cracking}

Paleo-reservoirs, if damaged, may produce asphalt, and asphalt may be cracked under high temperature to generate lighter hydrocarbons.

Gong et al. (2004) collected asphaltic sand formed by bio-degradation in the Silurian from the Tarim Basin, and used a high-pressure reaction vessel to investigate the effects of heat on the compositions, isotopes, and physical properties of the sand (Fig. 40). The results indicated that heat had an effect on the compositions and structure of the Silurian asphaltic sand during later-stage burial in the Tarim Basin. The asphaltic sand produces gas at high temperature, and the cracked gas has lighter carbon isotopes: there are less compositions of $\mathrm{C}_{6+}$ and above, and it is dominated by light oil; the gas yield is low at low temperature but increases substantially after $400{ }^{\circ} \mathrm{C}$ and reaches its peak at $550{ }^{\circ} \mathrm{C}$.

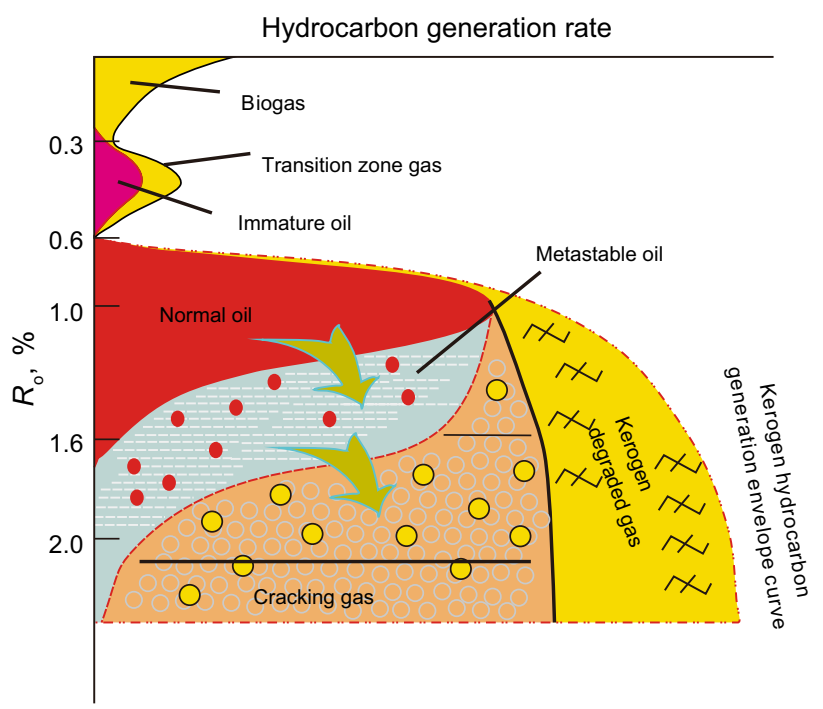

Fig. 38 Successive generation of gas from organic matter (Zhao et al. 2005) 


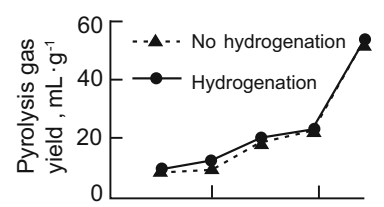

(a)

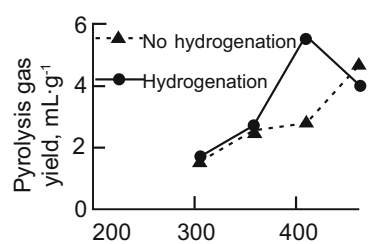

(b1)

Simulated experiment temperature, ${ }^{\circ} \mathrm{C}$

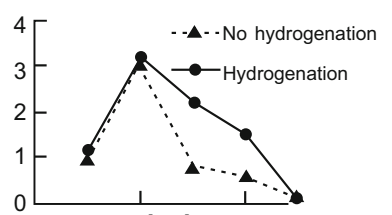

$\left(a_{2}\right)$

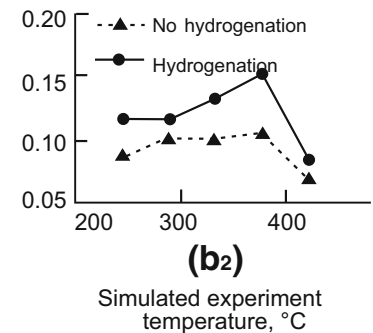

Fig. 39 Simulation test results comparison of different types of source rocks under hydrogenated and non-hydrogenated conditions (Jin et al. 2002). a Source rock from Sha-3 member at well Fan 15 in the Dongying Sag (Type $\mathrm{II}_{2}$ kerogen, water added) and b Carboniferous source rocks from Central Tarim well He6 (Type III kerogen, water not added)

Huang et al. (2012) obtained the yield curves of the asphalt degradation products (oil and gas) under different temperatures and further evolution process by using artificial and geological samples (Fig. 41). The hydrocarbongenerating process of asphaltic sandstone was divided into three stages: (1) evaporative fractionation stage $\left(R_{\mathrm{o}}<0.9 \%\right)$, during which the light components of crude oil escaped from damaged paleo-reservoirs to form heavy oil (or asphalt), which could not provide sufficient supply to new hydrocarbon reservoirs; (2) Cracking stage 1 $\left(R_{\mathrm{O}}=0.9 \%-1.8 \%\right)$, during which oil precipitation increased abruptly and reached a peak, and the yield of hydrocarbon gas increased. It was an important hydrocarbon supply stage in the burial process of asphaltic sandstone (heavy oil); (3) Cracking stage $2\left(R_{\mathrm{O}}>1.8 \%\right)$, during which large amounts of large molecule hydrocarbons were decomposed and hydrocarbon gas was given off. With the rise of temperature, the amount of liquid hydrocarbon in the expelled hydrocarbon components decreased substantially and large amounts of hydrocarbon gas was generated, followed by a substantial decrease of the residual hydrocarbon, and the generation of large amounts of methane. It was an important gas supply stage.

\subsubsection{Hydrocarbon generation and expulsion from deep source rocks with low TOC}

Pang et al. (2014b) believed that deep-buried poor source rocks with low total organic carbon (TOC) concentration can be regarded as effective source rocks. They generate mass hydrocarbons in the long evolution of geological history, which makes a great contribution to hydrocarbon accumulation. Pang et al. (2014b) obtained the evolutionary charts of TOC of carbonate source rocks based on the hydrocarbon expulsion threshold theory through simulation by using the material balance method (Fig. 42). As shown in the charts, a) the original TOC of source rocks decreases with an increase of $R_{\mathrm{O}}$. The TOC has a minor increase first and then decreases substantially until a balance is reached. The sharp decrease occurs when $R_{\mathrm{O}}=0.5 \%-2.0 \%$, and the TOC of Type I, II, and III source rocks decreases by $62 \%, 48 \%$, and $25 \%$, respectively. This is consistent with the period of generation and expulsion of large amounts of hydrocarbon during the thermal evolution of organic matter. b) The abrupt TOC decrease of different types of source rocks occurs at different times. For source rocks of Type I, II, and III organic matter, the abrupt TOC decrease occurs when $R_{\mathrm{o}}=0.5 \%, 0.7 \%$, and $0.9 \%$, respectively. This may be related to the increasing hydrocarbon expulsion threshold depth of the sources rocks. Many scholars studied the hydrocarbon yield of poor hydrocarbon carbonate source rocks through thermal experiments (Qin et al. 2005; Hao et al. 1993; Cheng et al. 1996; Fan et al. 1997; Xie et al. 2002; Hu et al. 2005; Liu et al. 2010b). According to the test results, the source rocks yielded large amounts of hydrocarbon. The maximum oil and gas yield was $40.4-482.6 \mathrm{~kg} / \mathrm{t}$ TOC and $115-4,226 \mathrm{~m}^{3} /$ $\mathrm{t}$ TOC, respectively. This indicates the source rocks in the deep basins with low TOC concentration are the result of the mass generation and expulsion of hydrocarbons and can be taken as effective source rocks under certain conditions. Pang et al. (2014b) pointed out, for deep source rocks that have yielded large amounts of hydrocarbon in basins, if the regional hydrocarbon prospects are identified and evaluated by using residual organic abundance indices (TOC), it will lead to errors; for highly to over-matured source rocks buried deep in basins, more source rocks are poor in hydrocarbon and the errors will be more obvious. Therefore, residual hydrocarbon indices cannot be used directly to identify and evaluate deep-buried effective source rocks. If TOC is used as a basic index to identify and evaluate source rocks, comparisons should be made in the same geological conditions (Pang et al. 2014b). Figure 43 shows the charts of TOC recovery coefficient under different geological conditions in accordance with the material balance theory, we can conclude that the TOC recovery coefficient of argillaceous source rocks $\left(R_{\mathrm{O}}>2.0 \%\right)$ varies with different parent material types; the TOC recovery coefficient of parent material I, II, III type reaches 2.6, $1.75,1.25$ respectively; while for carbonate source rocks the TOC recovery coefficient can reach $2.65,7.80,1.30$ respectively. The chart allows comparison of TOC of source rocks under different geological conditions on an equal footing. The criteria for evaluation of effective source rocks based on hydrocarbon expulsion thresholds of 
Fig. 40 Curves of $n$-alkane carbon isotopes under different experimental temperatures (Gong et al. 2004)

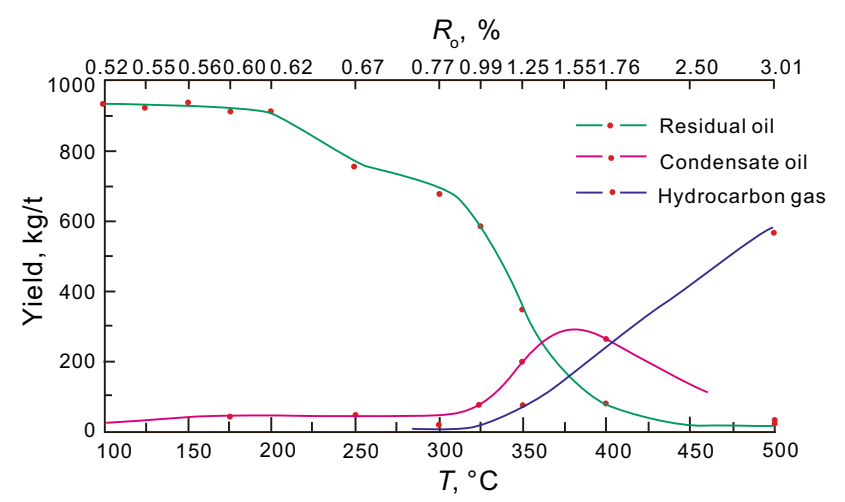

(a) Artificial samples

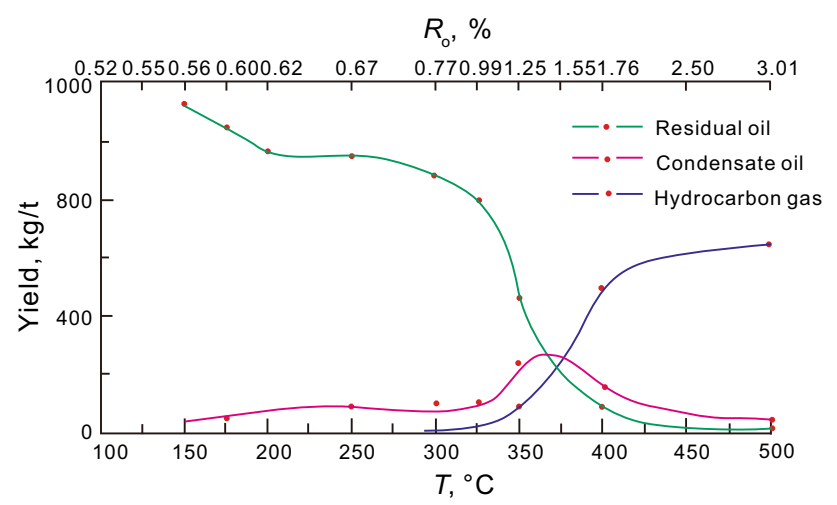

(b) Geological samples

Fig. 41 Hydrocarbon yield curves of asphaltic sand under different temperatures (Huang et al. 2012)

deep source rocks in basins are listed in Table 6. With the criteria, Pang et al. (2014b) identified and evaluated an effective Cambrian-Ordovician source rock in the Central Tarim region. According to the results, the thickness of the effective source rocks is 47 to 129 meters more than that evaluated using the TOC $=0.5 \%$ criterion, and the scope of distribution is increased by $7 \mathrm{~km}^{2}$, total oil yield increased by 182,500 million tons, and total reserves increased by 9,300 million tons, accounting for $38.1 \%$ of the total resource. This reflects the importance of research on effective source rocks with low TOC.

\subsection{Deep-buried high-porosity and high-permeability reservoirs, the formation and distribution of which are related to structural changes and underground fluid activities}

The porosity and permeability of deep hydrocarbon reservoirs in basins are usually low. The deeper the reservoirs are, the smaller the porosity and permeability will be. In actual geological conditions, the porosity and permeability of deep effective reservoirs vary significantly. Research results indicate that the formation of deep-buried highporosity and high-permeability reservoirs is closely related to structural changes and evolution as well as fluid activities. In general, more faults and disconformities are developed in regions with stronger structural activities. Faults not only serve as pathways for hydrocarbon migration, but also improve the reservoir quality. Fault developed regions generally have favorable porosity and permeability. As shown in Fig. 44, most hydrocarbon reservoirs so far discovered in the Tarim region are distributed in fault regions. This is particularly true for carbonate reservoirs, which are developed near faults (Fig. 44a). Disconformities also serve as pathways for hydrocarbon migration, and improve the geological conditions of reservoirs by weathering and leaching. As shown in Fig. 45, reservoirs near disconformities have high porosity and permeability. High-quality carbonate reservoirs are usually distributed within 200-300 $\mathrm{m}$ from an unconformity. Sedimentary fluids have decisive effects on the granular 


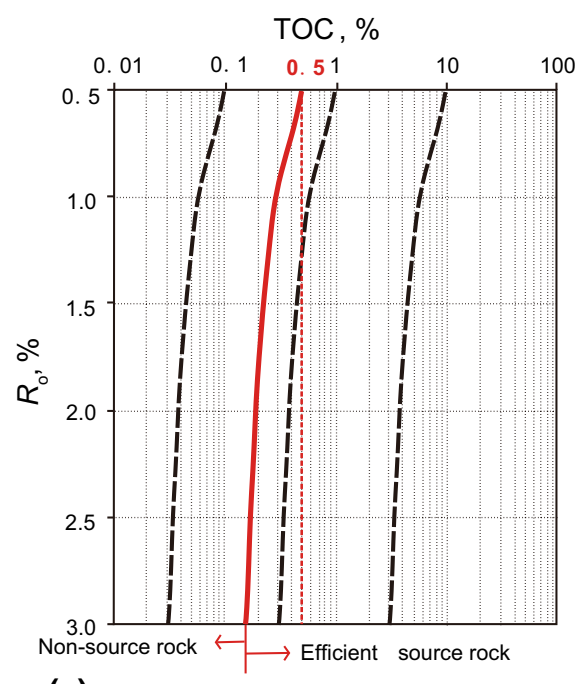

(a) With type I organic hydrocarbon source rocks

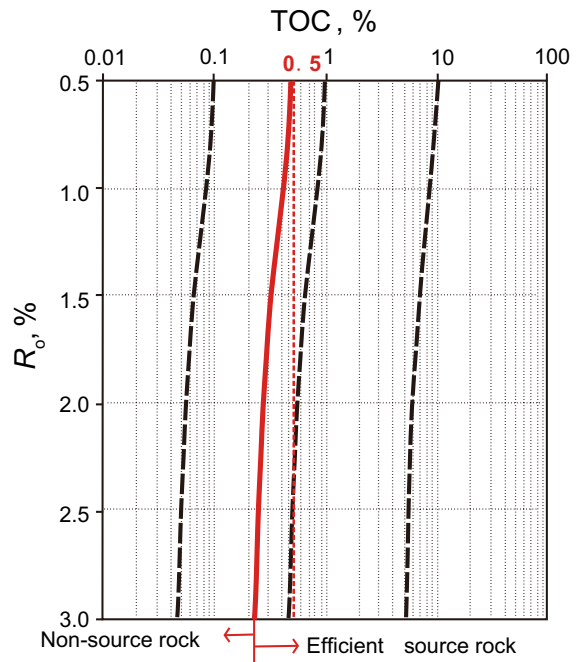

(b) With type II organic hydrocarbon source rocks

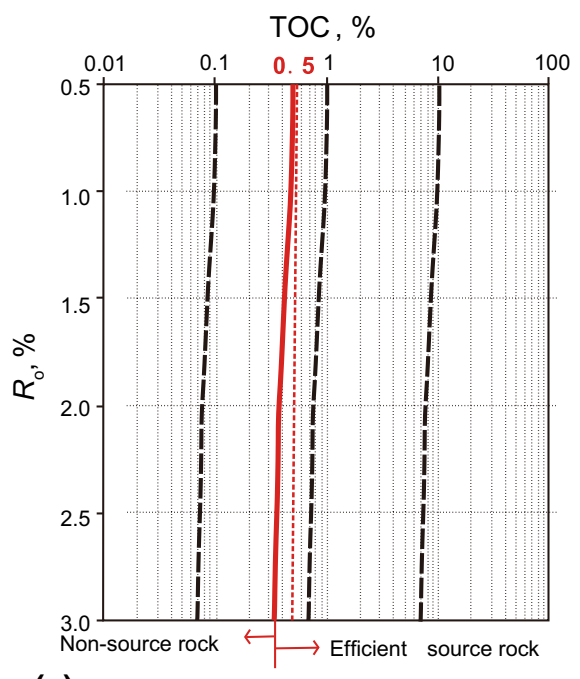

(c) With type III organic hydrocarbon source rocks

Fig. 42 Evolutionary charts of TOC of different carbonate source rocks of deep petroliferous basins (Pang et al. 2014b) structure and composition of reservoirs, and influence the strain response and the formation of fractures and cavities in the rock-forming process. Surface fluids may change the physical properties of surface rocks, enabling the rocks to accept external fluids and providing conditions for solution-pore type reservoirs reconstructed by external fluids after being buried. Underground hot fluids are favorable for secondary pore formation in deep reservoirs and the accumulation of gas and oil may take place in the dissolution pores and cavities, fractures, and cracks.

The formation of deep effective reservoirs is usually affected by a range of factors. For example, organic matter generates organic acids in the process of thermal evolution. The organic acids dissolve some minerals in the surrounding rocks to form secondary pores and improve the porosity of deep reservoirs. In the fast subsidence-sedimentation of sedimentary basins, overpressure systems may develop in shallow and high-porosity strata to reduce the effective stress, and thus reducing the compaction and restraining the pressure dissolution. At the same time, the fluids in the overpressure systems have poor fluidity, which retards the formation and cementation of rocks. That is why deep-buried overpressure reservoirs usually have high porosities. In summary, the high porosities of deep-buried overpressure reservoirs in basins are the result of the following combined effects: reduced compaction under low effective stress, retarded cementation due to low-fluidity fluids, and dissolution of minerals by organic acids. Therefore, multi-factor integrated research is required for the evaluation of deep-buried effective reservoirs.

Deep-buried high-quality clastic reservoirs developed over different periods in basins in China are related to such factors as abnormally high pressure, early hydrocarbon charging, thermal convection, gypsum-salt effects, and sandstone and mudstone interbeds ( $\mathrm{Li}$ and $\mathrm{Li}$ 1994; Gu et al. 1998; Zhong and Zhu 2003). Dissolution, early longterm shallow burial and late short-term deep burial, abnormally high pressure, and early hydrocarbon charging are key factors influencing the formation of deep-buried high-quality clastic reservoirs in China (Shi and Wang 1995; Yang et al. 1998; Li et al. 2001; Zhong et al. 2008). Many researchers realized that the formation and evolution of high-porosity and high-permeability carbonate reservoirs are related to the epidiagenesis, dissolution of organic acids, dolomitization, abnormally high pressure, modification of thermal fluids, and hydrocarbon charging (Surdam et al. 1989; Davies and Smith 2006; Fan 2005; Li et al. 2006; Zhu et al. 2006).

As research on deep-buried marine facies carbonate reservoirs goes on and exploration breakthroughs are continuously made in China, geologists have achieved a better understanding of the formation mechanisms of secondary pores in carbonate reservoirs. Previous researchers 
TOC recovery coefficient $K$ of muddy source rocks

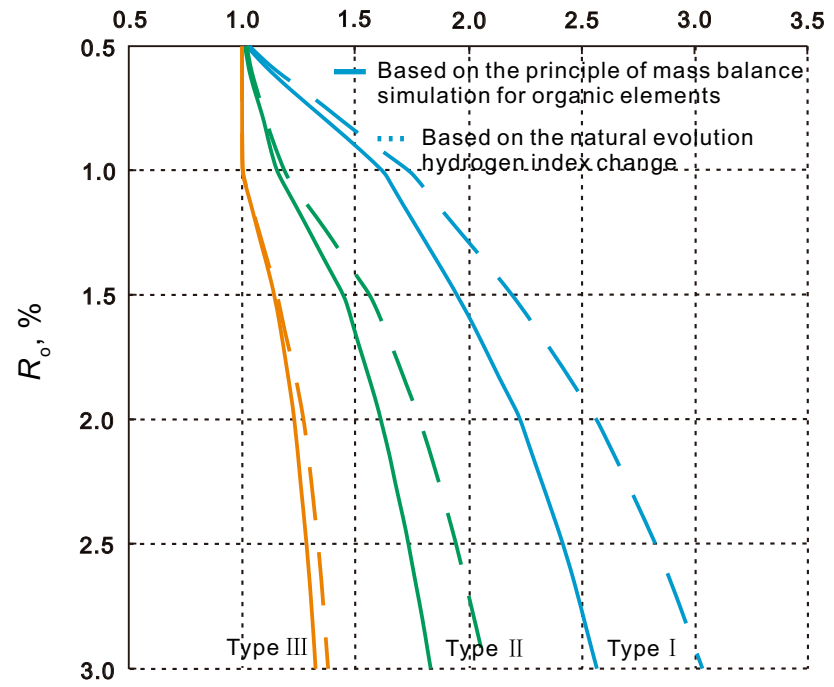

(a) The TOC recovery coefficient plot of different kerogen in muddy source rocks
TOC recovery coefficient $K$ of carbonate source rocks

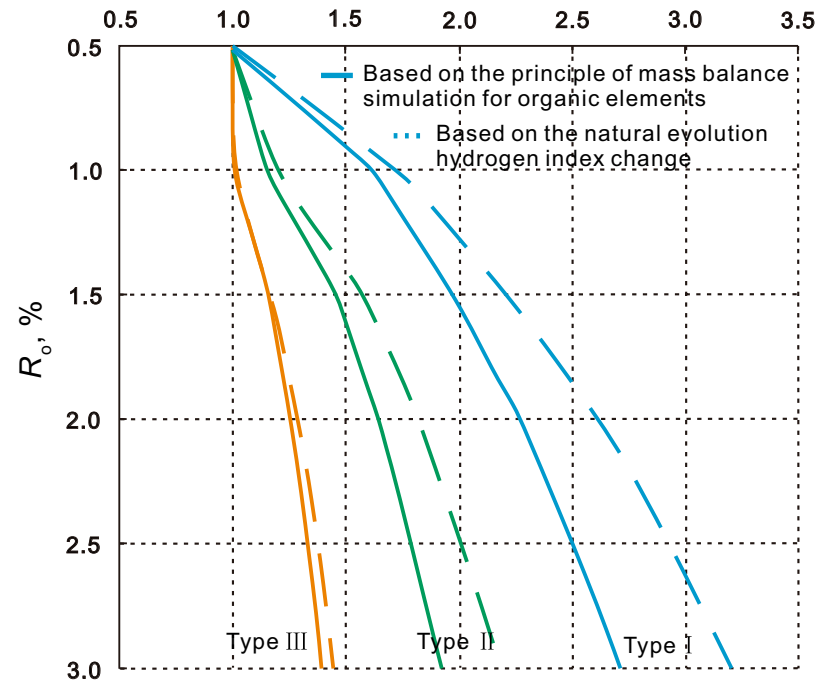

(b) The TOC recovery coefficient plot of different kerogen in carbonate source rocks

Fig. 43 Charts of restored TOC of source rocks under different geological conditions of petroliferous basins (Pang et al. 2014b)

Table 6 Revised TOC thresholds criterion for evaluation of effective source rocks

\begin{tabular}{|c|c|c|c|c|c|c|}
\hline \multirow[t]{2}{*}{ Evolutionary period } & \multicolumn{3}{|c|}{ Muddy source rock } & \multicolumn{3}{|c|}{ Carbonate source rock } \\
\hline & I & II & III & I & II & III \\
\hline Immature $\left(R_{\mathrm{o}}<0.5 \%\right)$ & 0.50 & 0.50 & 0.50 & 0.50 & 0.50 & 0.50 \\
\hline Mature $\left(R_{\mathrm{o}}=0.5 \%-1.2 \%\right)$ & 0.35 & 0.45 & 0.47 & 0.30 & 0.40 & 0.45 \\
\hline Highly mature $\left(R_{\mathrm{o}}=1.2 \%-2.0 \%\right)$ & 0.25 & 0.35 & 0.45 & 0.20 & 0.30 & 0.40 \\
\hline Over-mature $\left(R_{\mathrm{o}}>2.0 \%\right)$ & 0.20 & 0.30 & 0.40 & 0.15 & 0.25 & 0.35 \\
\hline
\end{tabular}

insisted that secondary pores in deep-buried carbonate reservoirs were formed as a result of the dissolution of the carbonate rock exposed to the air, and many scholars focused on paleo-dissolution reservoirs, ignoring the role of karstification (dissolution) in improving the permeability and storage properties of deep-buried carbonate reservoirs (Zhu et al. 2006). In recent years, the fluid-rock interaction in deep-buried hydrocarbon-bearing carbonate reservoirs has attracted the attention of more and more scholars (Land and MacPherson 1992; Fisher and Boles 1990; Williams et al. 2001; Zhang et al. 2005b). As deep-buried karst is not controlled by the base level of erosion on the surface, many substances could induce water-rock reactions, such as acidic water and gases produced in the process of thermal evolution of organic matter; hot water produced by magmatic activities, compaction or diagenesis; acidic gases from deep strata in basins; and hydrogen sulfide gas produced in thermochemical or microbe reduction of sulfatebearing carbonate rocks (Luo 2003). Pan et al. (2009) believed, based on samples from outcrops and drilling in the Central Tarim region, that hydrothermal karst reservoirs may be an important type of reservoir, which has been ignored in the exploration for Lower Paleozoic carbonate hydrocarbon reservoirs in the Tarim Basin, and that there might be high-quality reservoirs along the faults, the main pathways for the migration of hydrothermal fluids, and fault-associated dissolution fractures and cavities. Li et al. (2010) studied the Mid-Lower Ordovician carbonate reservoirs in the Tahe region in the Tarim Basin. According to the research results, carbonate reservoirs might have experienced strong cementation in the normal process of deep burial diagenesis, but there were hardly any signs of dissolution. The modification of the reservoirs might be related to late epikarstification and structural-thermal fluid processes (Fig. 46). Generally, the epikarstification was followed by the structural-thermal fluid processes. The development and distribution of the latter might be related to the fault-fissure system and early epikarst system. According to the research results on the Ordovician carbonate reservoirs in the Tarim Basin by Lin et al. (2012), four dynamic mechanisms were involved in the structural modification of the reservoirs and the formation of fissures 
and cavities: (1) penecontemporaneous surface water karstification of carbonate rocks to form dissolution cavities, (2) raised surface fresh water karstification of the reservoir to form dissolution cavities, (3) deep hydrothermal fluid karstification of reservoir to form dissolution cavities, and (4) stress-induced faulting to form fissures (Fig. 47). Zhu et al. (2006) discovered in studying the deep-buried high-quality carbonate reservoirs in the Sichuan Basin that, besides the dolomitization and deep dissolution that controlled the formation of the porous oolitic dolomite in the Feixianguan Formation, strongly corrosive materials produced in the TSR (thermochemical sulfate reduction) boosted the dissolution of dolomite, leading to the formation of porous permeable spongy oolitic dolomite dissolution bodies, which played a constructive role in the formation of the reservoirs. The above research achievements indicated that the deep fluids in basins might be closely associated with the formation of high-quality carbonate reservoirs.
Fig. 45 Weathering crust and hydrocarbon distribution in the basinplatform region, Tarim Basin and the porosity-permeability features in reservoirs (Du et al. 2010)

\subsection{Capillary pressure difference}

between inside and outside the target formation is the main force resulting in hydrocarbon accumulation in deep reservoirs

Forces involved in the formation of hydrocarbon reservoirs in hydrocarbon basins mainly include buoyancy, fluid pressure and dynamic force, expansive force of molecular volume, capillary force, molecule adsorption force, and intermolecular binding force (Pang et al. 2000). Under the action of buoyancy, natural gas migrates along migration pathways into traps in the upper part of a structure (White 1885). Under the action of the expansive force of gaseous molecules, natural gas migrates in a piston-type and accumulates in the lower part of a structure, with gas

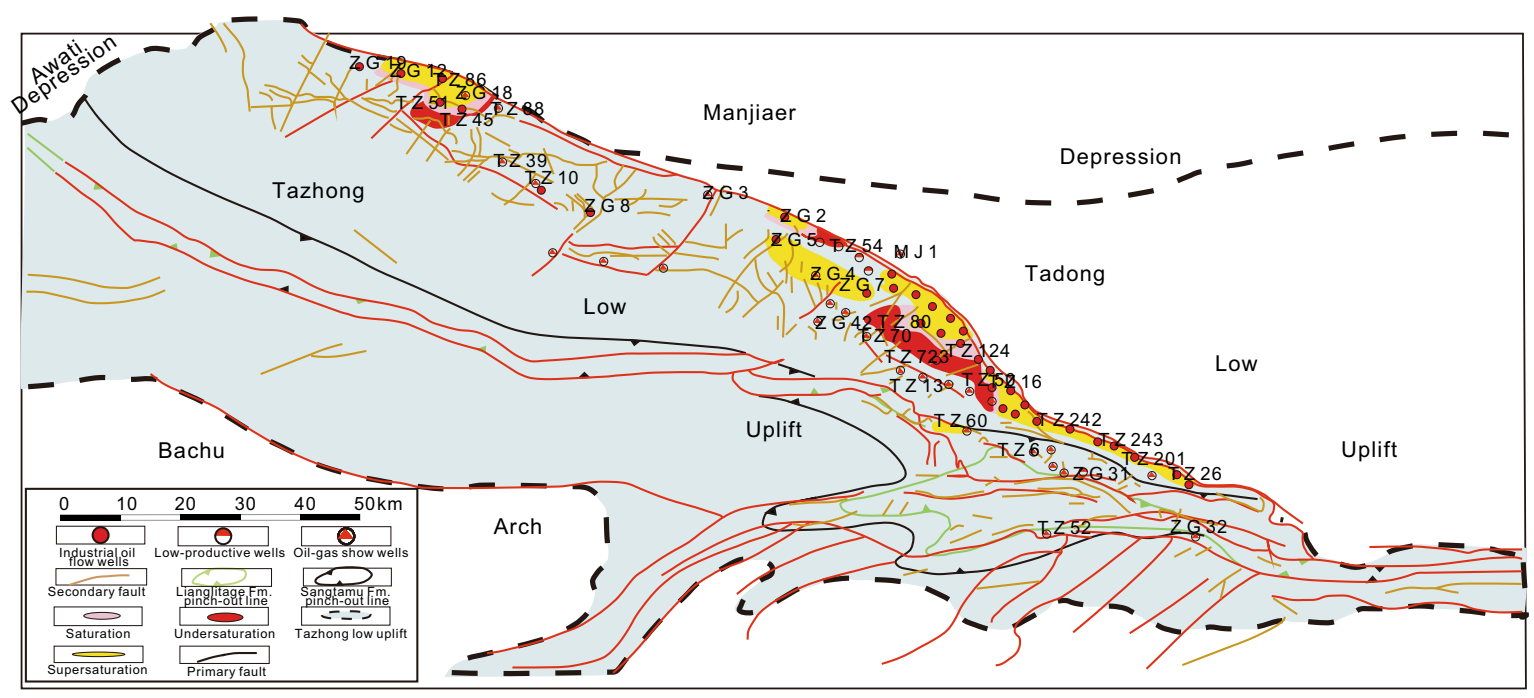

(a)

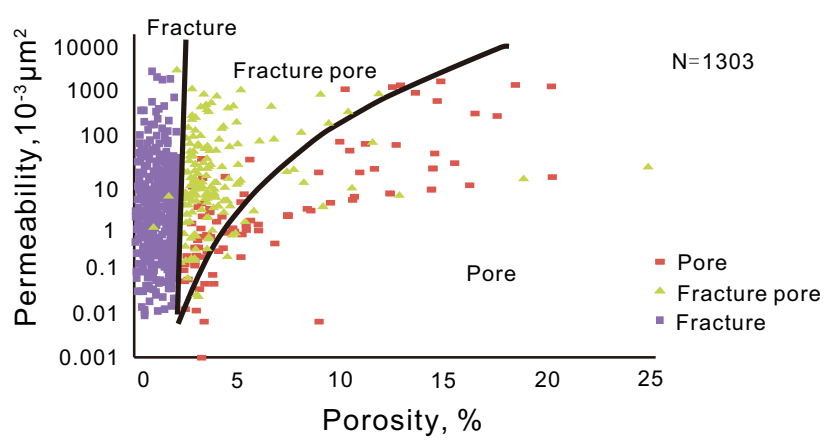

(b) The relationship between porosity and permeability in middle Tarim carbonate

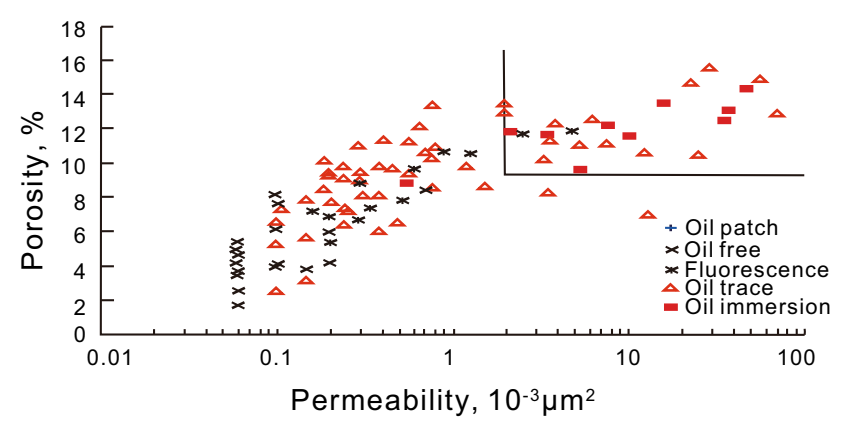

(c) The relationship between porosity and permeability in middle Tarim clastic rocks

Fig. 44 Faults and hydrocarbon distribution in the Central Tarim Basin and the porosity-permeability features in reservoirs 


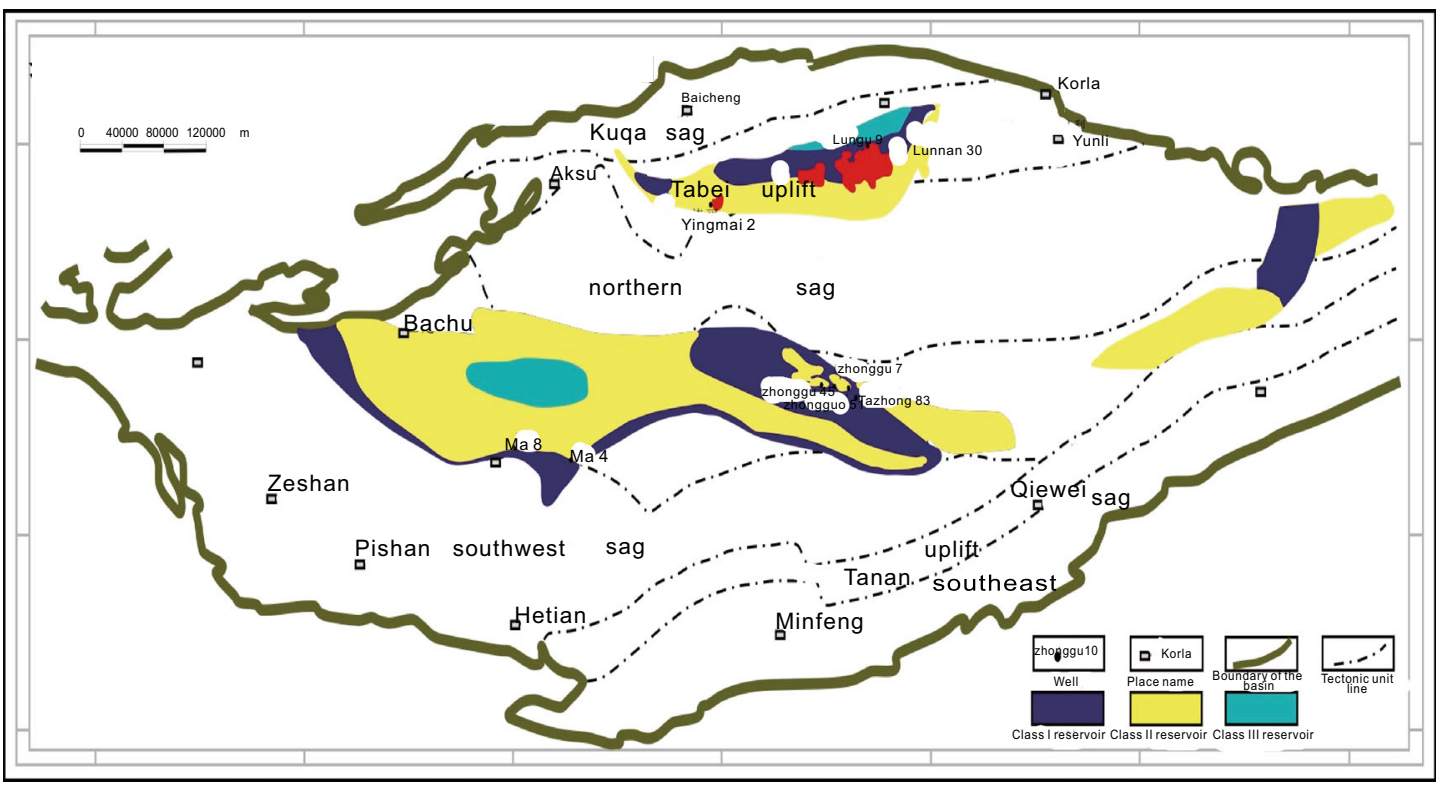

(a) Relationship between porosity distribution and distance to the weathering crust in the Yingshan Formation, Tazhong region

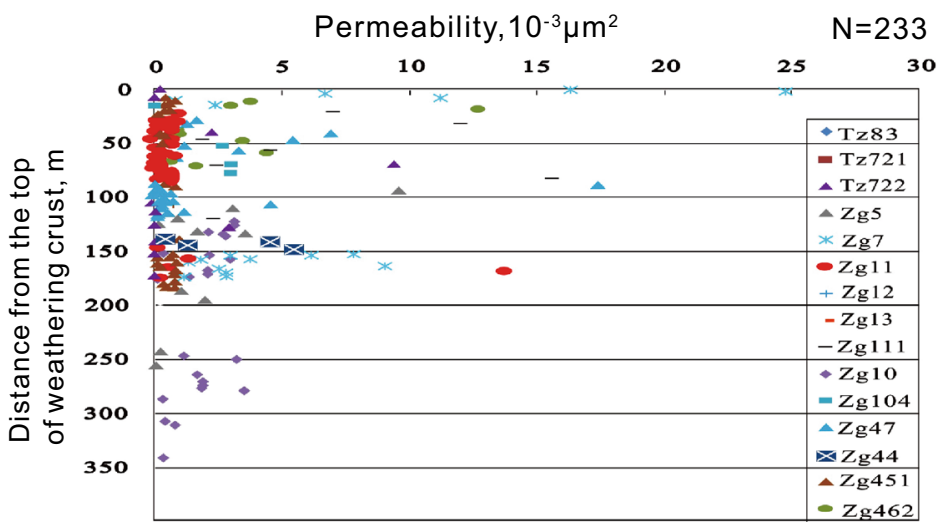

(b) The relationship between permeability of the Yingshan Formation and the distance from the top of weathering crust in Tazhong

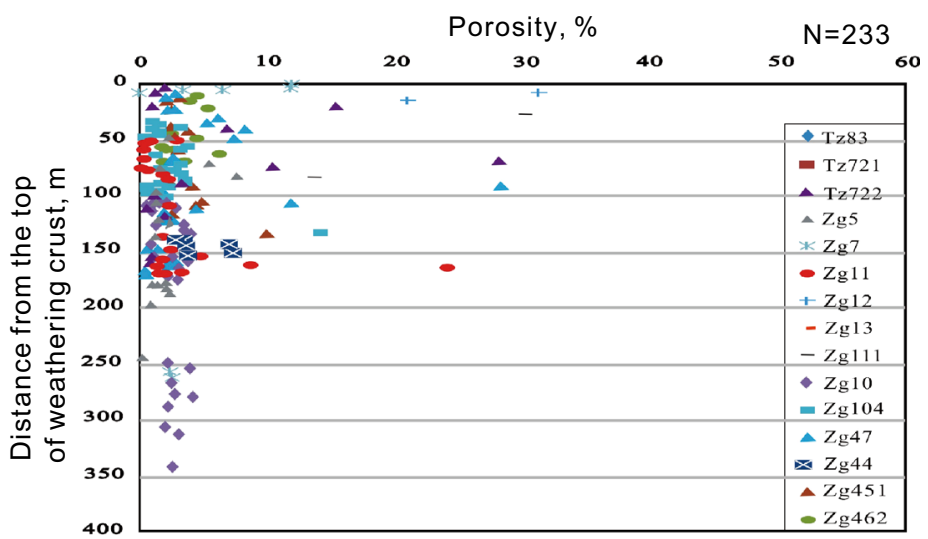

(c) Relationship between porosity distribution and the distance to the weathering crust in Yingshan Formation, Tazhong region 
topped by water (Pang et al. 2003). Due to the capillary pressure difference between sandstone and mudstone, natural gas migrates into lens-type sandstones with larger pores, and accumulates at the top of the lens under the action of buoyancy to form a reservoir (Chen et al. 2004).

The temperature and pressure in the shallow strata of sedimentary basins are low and the rock porosity and permeability are relatively high, so the accumulation and migration of hydrocarbon are primarily controlled by buoyancy. But in the deep strata, the temperature and pressure are high and the rocks are relatively tight, so the accumulation and migration of hydrocarbon are controlled by a combination of forces. There are a variety of hydrocarbon reservoirs in the deep strata of sedimentary basins. In addition to conventional reservoirs in highporosity and high-permeability strata, there are a large number of unconventional reservoirs in tight strata. Many hydrocarbon reservoirs have been discovered in the lowporosity carbonate and sandstone strata of the Junggar Basin and Tarim Basin (Fig. 48). With the ongoing research, geologists are gaining a better understanding of the formation mechanisms of deep hydrocarbon reservoirs. Capillary pressure that causes surface potentials has been considered to resist the flow of underground fluids. But since Magara (1978) puts forward the idea that capillary pressure is the primary power for hydrocarbon migration from source rocks to reservoirs, more and more scholars have realized that capillary pressure difference between mudstone and sandstone is an important factor in the formation of hydrocarbon reservoirs (Barker 1980; Magara 1978; Pang et al. 2000; Chen et al. 2004; Zhao et al. 2007; Li et al. 2007), and particularly that lithological traps such as sandstone lenses and pinch-outs are in a direct contact with deep mudstones in the part of basins. Therefore, capillary pressure difference might be one of the key forces for the formation of lithological hydrocarbon reservoirs included in sources rocks or in contact with source rocks. Surface potential is more significant to the formation of deepburied lithological hydrocarbon reservoirs (Huo et al. 2014a). In the sand-mud contact zone, there is capillary pressure difference between sandstone and mudstone as
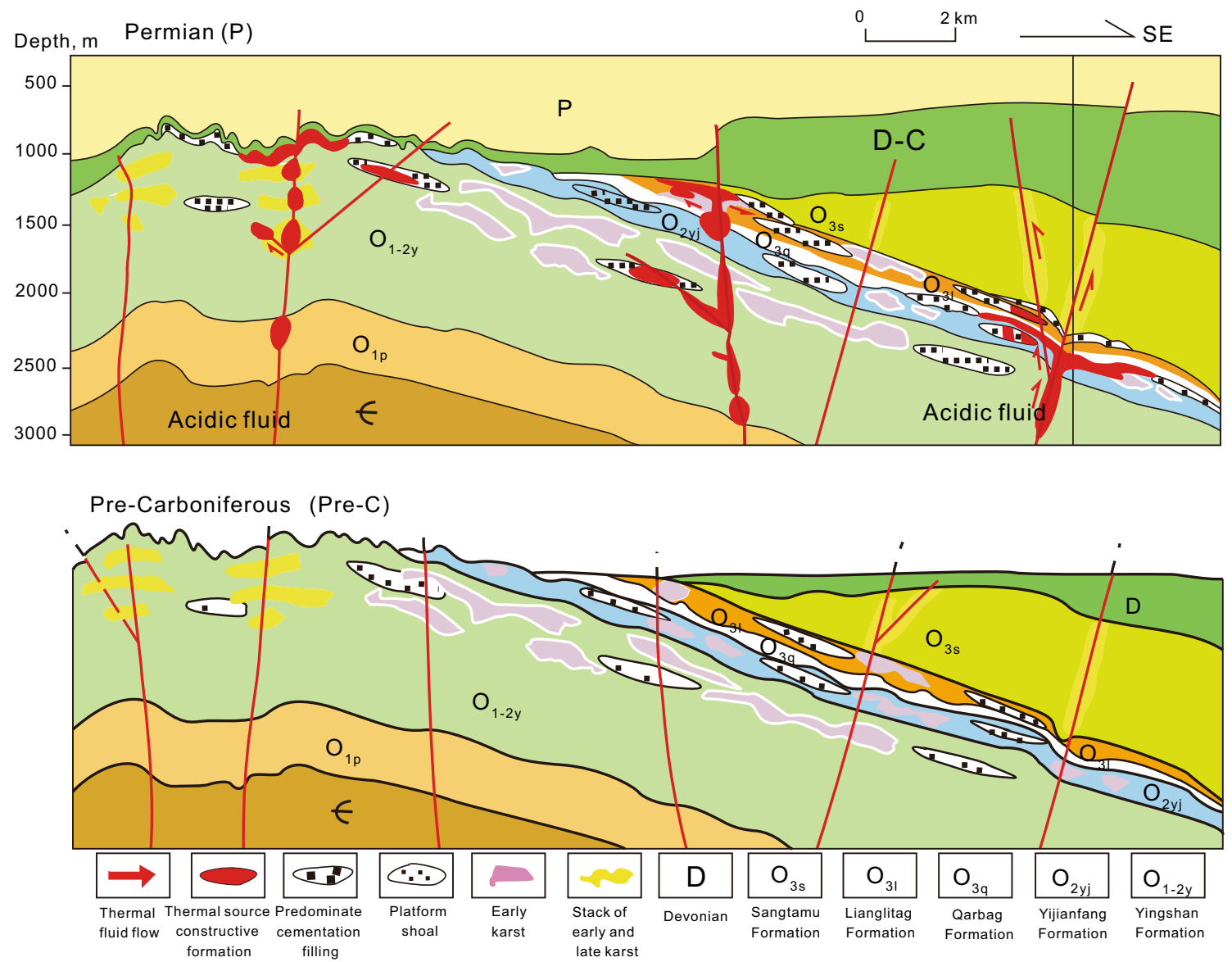

Fig. 46 Structures-fluid effect of Ordovician carbonate and controlling mode of reservoir distribution in the Tahe region, Tarim Basin (Li et al. 2010). Early karst: Mid-Late Ordovician-Silurian
(Caledonian); Superposition of early and late-period karst: superposition of Mid-Late Ordovician-Silurian karst (Caledonian) + Late Devonian karst (Hercynian) 
Fig. 47 Cavities and fissures formed as a result of structural changes of carbonate reservoirs in the Tarim Basin (Lin et al. 2012). a Dissolution cavities, b Fissures
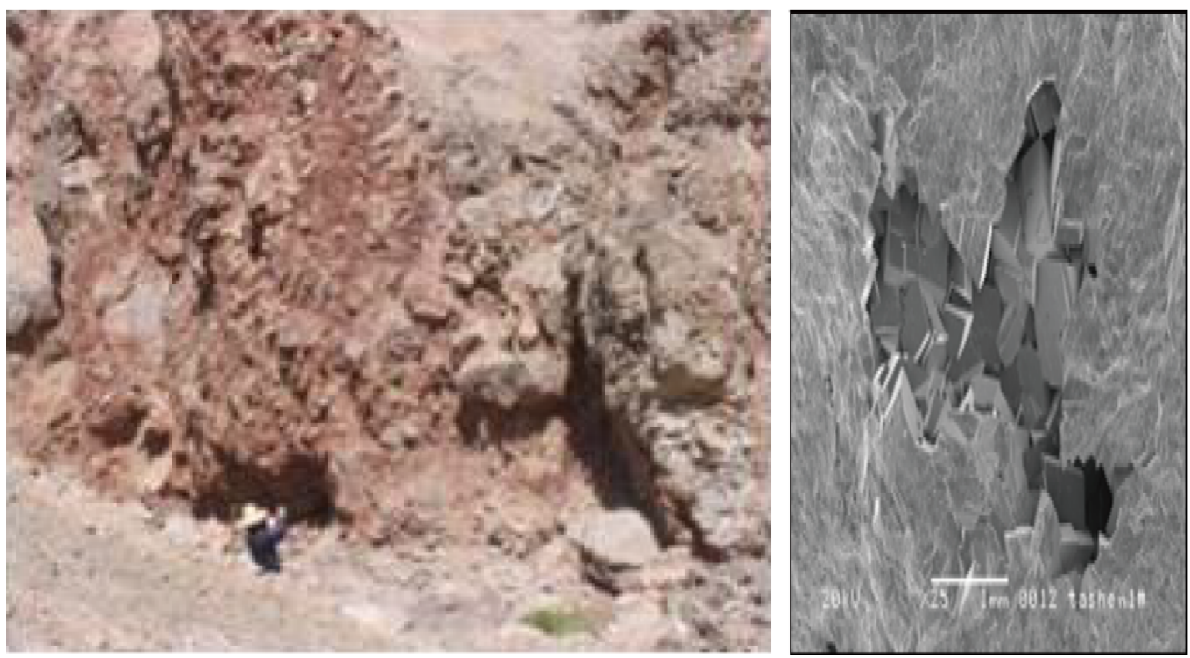

(a)

TS1

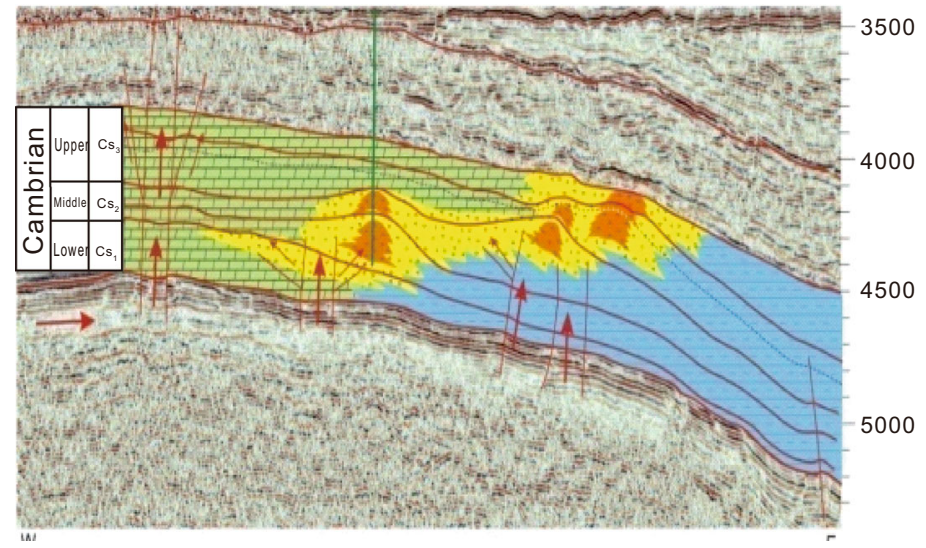

(b) former has bigger pores than the latter. Pang et al. (2006) and Wang et al. (2013) through the physical experiments concluded that the greater the capillary pressure difference is between the inner sandstone and outer mudstone in a trap, the better hydrocarbon accumulation conditions will be in the sandstone (Fig. 49). Under strata conditions, as the wall rock is compacted, the pore throat radius of the wall rock is much smaller than that of isolated sand bodies. Due to the capillary pressure difference between them, hydrocarbon migrates inwards. So, capillary pressure difference might be one of the key factors that led to the migration of hydrocarbon from the wall rock into the isolated sand bodies. A large number of tight reservoirs were developed in the deep strata of basins. The research of Pang et al. (2006) showed that hydrocarbon was not affected or less affected by buoyancy in tight media. The surface potential or capillary pressure difference between reservoir and external strata is a key factor affecting the accumulation of hydrocarbon in tight media (Fig. 50). The pressure difference has the following effects: (1) hydrocarbon migrates from the source rock into the reservoir due to capillary pressure difference. The greater the difference between the inner and outer capillary pressure or between the inner and outer surface potential, the higher the saturation of hydrocarbon in the reservoir, and the better the gasbearing properties. (2) Due to capillary pressure difference, hydrocarbon in the tight reservoir migrates from a low-porosity and low-permeability rock to a high-porosity and high-permeability rock to form hydrocarbon-rich "sweet spots". (3) When faulting or fissuring occurs in a tight reservoir, the capillary force will decrease and the surface potential will drop, causing capillary pressure difference and the accumulation of hydrocarbon to fault zones and formation of "sweet spots". Exploration practice has proved that there are large numbers of hydrocarbon-rich "sweet spots" in the extensive, continuous tight sandstone reservoirs in the deep strata of 
basins, and most of them were formed due to faulting and fissuring in late periods.

\subsection{Three dynamic boundaries of deep hydrocarbon reservoirs}

The accumulation and migration of gas and oil are controlled by many geological conditions, including temperature, pressure, source of oil and gas, migration path, traps, etc. The formation and distribution of deep oil-gas reservoirs are mainly constrained by three force balance boundaries in terms of the dynamic mechanics. The first dynamic boundary is buoyancy-controlled threshold. It is the upper boundary of formation and distribution of unconventional tight reservoirs. The buoyancy-controlled threshold is the maximum depth of non-buoyancy-driven hydrocarbon migration in a hydrocarbon basin. The formation and distribution of hydrocarbon reservoirs in hydrocarbon basins are controlled by the dynamic boundary formed by different thresholds (Pang 2010; Pang et al. 2014a). The buoyancy-driven hydrocarbon accumulation threshold is a new geological concept in relation to buoyancy-driven hydrocarbon accumulation (White 1885). Pang et al. (2014a) maintained that the buoyancy-driven hydrocarbon accumulation threshold is the threshold beyond which buoyancy will have less effect on the accumulation of hydrocarbon in highly compacted strata as the burial depth increases. Generally, it is characterized by porosity,

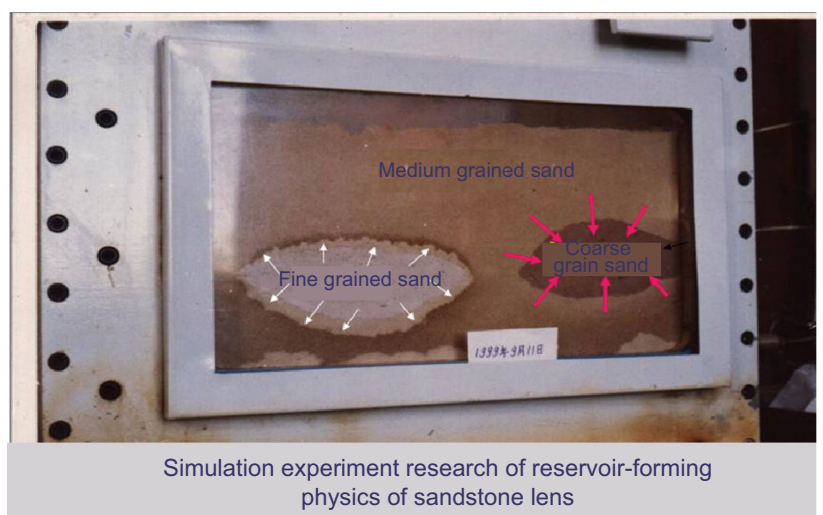

Fig. 49 Physical experiments simulating the formation of a sandstone lens reservoir (Pang et al. 2006; Wang et al. 2013)

pore throat radius, and permeability geological parameters of strata at certain burial depths (Fig. 51).

With respect to the causes of the buoyancy-controlled threshold, scholars have different views. Masters held that buoyancy-controlled threshold is caused by the relative variation of permeability of strata (Masters 1979); other scholars argued that geological conditions such as diagenetic difference (Cant 1986), fault seals (Cluff and Cluff 2004) and force equilibrium mechanisms (Berkenpas 1991) are the causes. These views may be used to explain the phenomena of non-buoyancy-controlled hydrocarbon accumulation in some basin areas, but cannot explain it in a

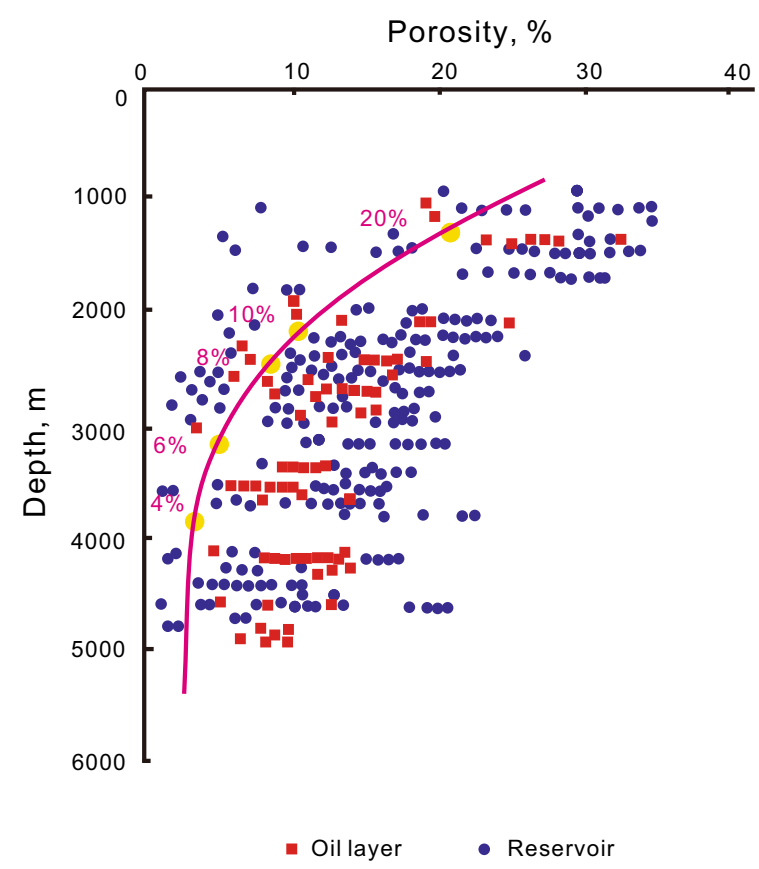

(a) Clastic rocks in the Junggar Basin

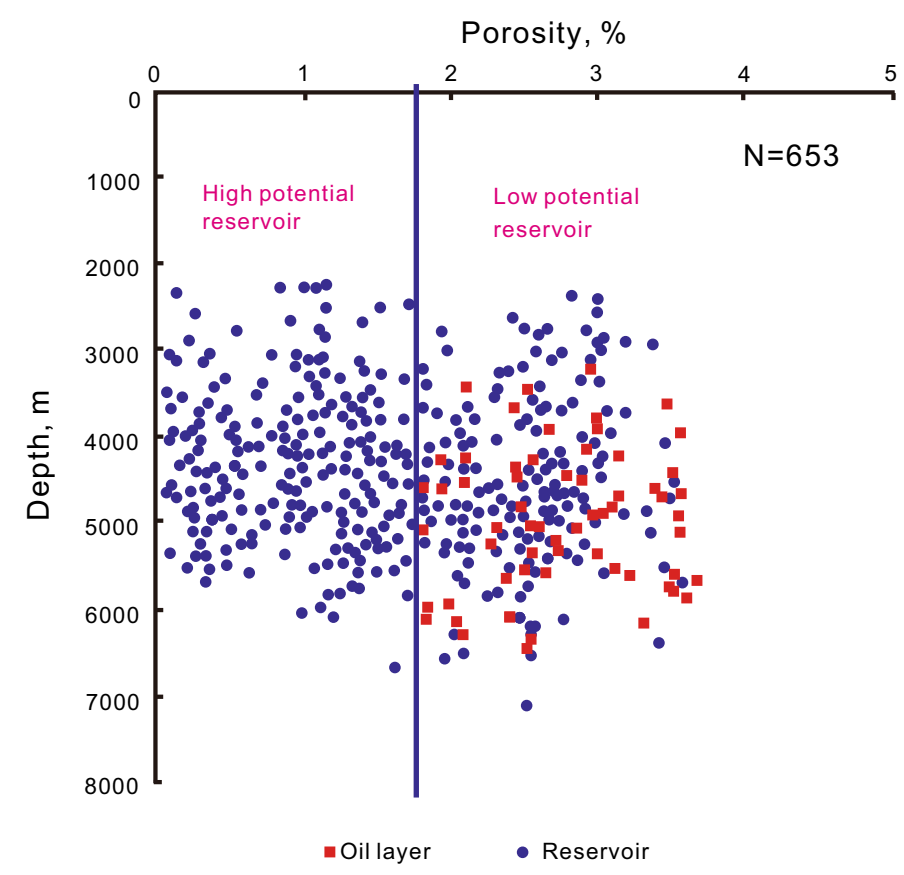

(b) Carbonate rocks in the Junggar Basin

Fig. 48 Diagram of effective porosity in different reservoirs changes as a function of burial depth 
broader sense. Through physical simulation experiments (Fig. 52), Pang et al. (2013, 2014a) believed that there exists an equilibrium of forces affecting the migration of natural gas at the buoyancy-controlled threshold. Charge pressure is the dynamic force and capillary force and overlying water pressure are the resistances. The equilibrium between the driving force for upward migration of hydrocarbon $\left(P_{\mathrm{e}}\right)$ and capillary force in tight media $\left(P_{\mathrm{c}}\right)$ and overlying static water pressure $\left(P_{\mathrm{w}}\right)$ is the dynamic mechanism of buoyancy-driven hydrocarbon accumulation thresholds. Figure 52 shows the physical simulation experiment results of buoyancy-controlled threshold in a tapered glass tube; it can be quantified by the dynamic equilibrium equation $P_{\mathrm{e}}=P_{\mathrm{w}}+P_{\mathrm{c}}$. Similar results have been obtained based on the physical simulation experiment using a thick tube filled with sandstone of different sizes (Pang et al. 2014a).
The fundamental reason why hydrocarbon in deep tight strata of hydrocarbon basins is not controlled by buoyancy is that the sum of rock capillary force and overlying static water pressure is greater than the pressure in the hydrocarbon reservoir. When the pressure in the hydrocarbon reservoir is greater than the sum of the two forces, buoyancy will cause hydrocarbons to migrate upwards to the surface or scatter. The equilibrium of forces is the dynamic mechanism of buoyancy-controlled threshold, which can be expressed in Eqs. (1)-(3):

$P_{\mathrm{e}}=P_{\mathrm{w}}+P_{\mathrm{c}}$

where $P_{\mathrm{e}}$ is oil reservoir pressure, which can be expressed as follows:

$P_{\mathrm{eg}}=\frac{z \times \rho_{\mathrm{g}}}{M_{\mathrm{g}}} \times R \times T \times 1.01 \times 10^{2}$
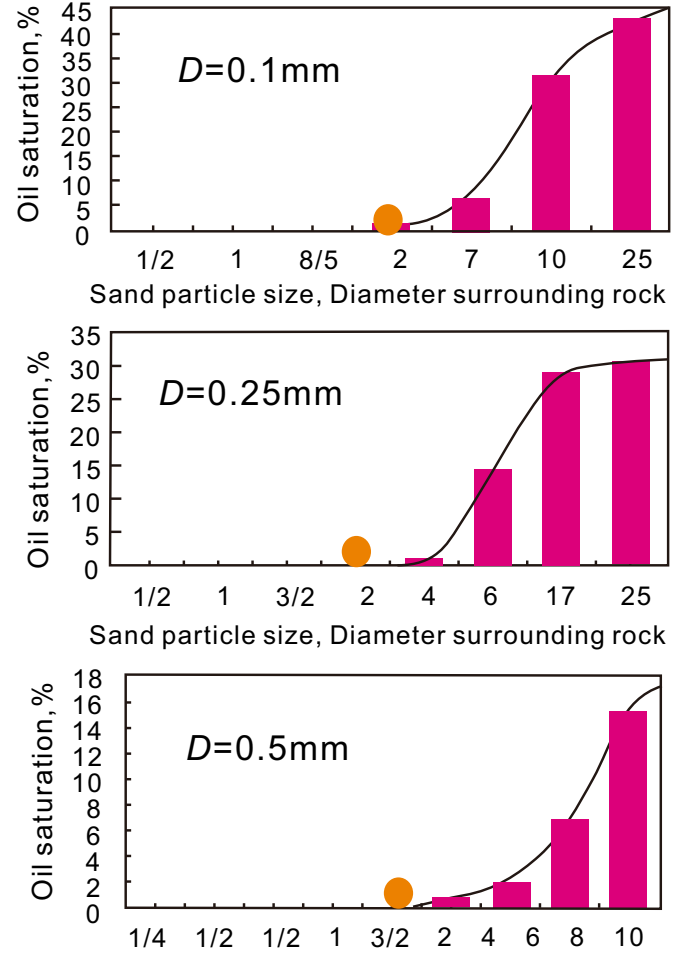

Sand particle size, Diameter surrounding rock

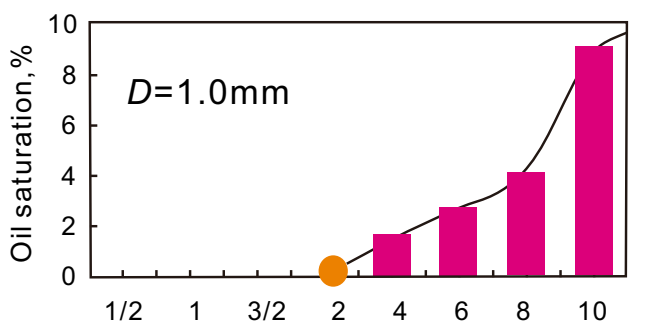

Sand particle size, Diameter surrounding rock

\begin{tabular}{|c|c|c|c|c|c|c|c|}
\hline & \multicolumn{7}{|c|}{$\begin{array}{l}\text { Petroliferous properties of sandstone under } \\
\text { various conditions of wall rock }(D=0.5)\end{array}$} \\
\hline \multirow{8}{*}{ 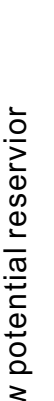 } & No. & Sample No. & $\mathrm{D} / \mathrm{d}$ & Thesamplesize & Extraction of oil & Oil conten & Oil saturation \\
\hline & 1 & 30 mesh-10mesh & $1 / 4$ & 125.1 & 5.3 & 0.0042 & 0.0261 \\
\hline & 2 & 30 mesh-20mesh & $1 / 2$ & 113.8 & 4.7 & 0.0041 & 0.0255 \\
\hline & 3 & 30mesh-30mesh & 1 & 82.4 & 4.9 & 0.0059 & 0.0367 \\
\hline & 4 & 30mesh-60mesh & 2 & 167.6 & 21.2 & 0.0126 & 0.0780 \\
\hline & 5 & 30 mesh-120mesh & 4 & 140.3 & 180.4 & 0.1286 & 0.7929 \\
\hline & 6 & 30 mesh-200mesh & 6 & 152.4 & 452.0 & 0.2966 & 1.8290 \\
\hline & 7 & 30mesh-240mesh & 8 & 142.2 & 1554.0 & 1.0905 & 6.7249 \\
\hline & 8 & 30 mesh-300mesh & 10 & 126.6 & 3143.8 & 2.4833 & 15.3134 \\
\hline
\end{tabular}

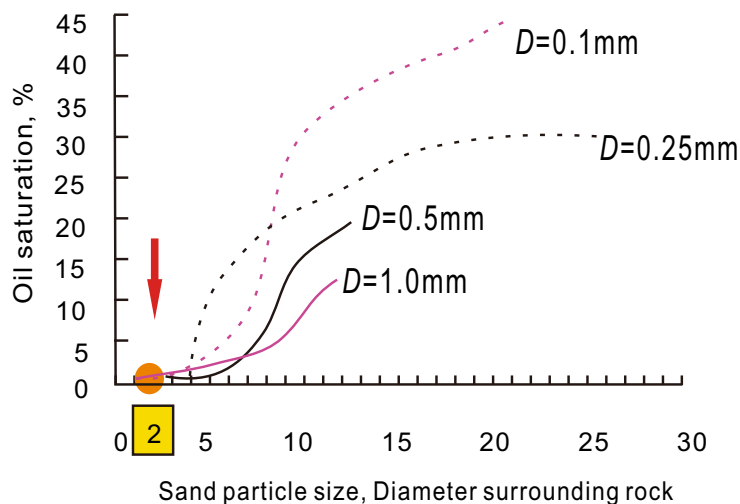

Accumulation=Interfacial energy of wall rock $\geq 2 \quad \times$ Interfacial energy of reservoirs

Fig. 50 Physical experiment results of capillary pressure difference (surface potential) controlling hydrocarbon (Pang et al. 2006) 
$P_{\mathrm{eo}}=\frac{R T}{V-b}-\frac{a}{V^{2}}=\frac{\rho_{\mathrm{o}} R T}{M_{\mathrm{o}}-\rho_{\mathrm{o}} b}-\frac{\rho_{\mathrm{o}}^{2} \times a}{M_{\mathrm{o}}^{2}}$,

where $P_{\text {eg }}$ is the gas reservoir pressure, $\mathrm{MPa} ; z$ is the gas deviation coefficient (compressibility factor), dimensionless; $R$ is the universal gas constant, $0.008314 \mathrm{MPa} \mathrm{m}^{3} /$ $(\mathrm{kmol} \mathrm{K}) ; T$ is the absolute temperature of natural gas, $\mathrm{K}$; $M_{\mathrm{g}}$ is natural gas molar mass, $\mathrm{kg} / \mathrm{kmol} ; \rho_{\mathrm{g}}$ is the natural gas density under strata conditions, $\mathrm{kg} / \mathrm{m}^{3} ; P_{\text {eo }}$ is the oil reservoir pressure, MPa; $\rho_{\mathrm{o}}$ is the oil density under strata conditions, $\mathrm{kg} / \mathrm{m}^{3} ; M_{\mathrm{o}}$ is the molar mass of oil, $\mathrm{kg} / \mathrm{kmol}$; and $a, b$ are van der Waals constants.

The change of any geological parameter in the force equilibrium equations of the buoyancy-controlled threshold will lead to changes of the critical conditions of the buoyancy-controlled threshold. Factors include different driving forces, fluid physical and chemical properties, strata conditions, and the structural environment of basins. Driving forces include hydrocarbon reservoir pressure $\left(P_{\mathrm{e}}\right)$, overlying static water pressure $\left(P_{\mathrm{w}}\right)$, and reservoir media capillary forces $\left(P_{\mathrm{c}}\right)$. The change of any force will lead to change of the buoyancy-driven hydrocarbon accumulation threshold; fluid physical and chemical properties include hydrocarbon-water interface tension, contact angle, density, and temperature; strata media conditions include porosity, permeability, and pore throat radius; the structural environment of basins refers to structural changes of a basin that affect the distribution scope of the buoyancydriven hydrocarbon accumulation threshold.

Under actual geological conditions, the buoyancy-controlled threshold is affected by a combination of the above factors. Research results indicate that the depth of the buoyancy-controlled threshold increases and the corresponding porosity, permeability, or pore throat radius decreases as the sand grain size increases under the circumstances that all the conditions are favorable, and that the corresponding burial depth, porosity, permeability, or pore throat radius of the buoyancy-controlled threshold force equilibrium decreases as the sand grain sorting difficulty increases. According to statistics, generally, the buoyancy-controlled threshold of hydrocarbon basins is as follows: porosity $<12 \%$, permeability $<1 \mathrm{mD}$, and pore throat radius $<2 \mu \mathrm{m}$. Although porosity is often considered a characteristic parameter of buoyancy-controlled threshold, in fact, whether hydrocarbon is controlled by buoyancy in a reservoir or not is mostly decided by the pore throat radius, because it has a direct effect on the capillary force affecting the migration of hydrocarbon. For carbonate reservoirs with smaller porosities, the migration of hydrocarbon is also affected by buoyancy in fissure developed areas. The general relations between porosity, permeability, and pore throat radius are shown in Fig. 53.

Buoyancy-controlled threshold distribution under actual geological conditions can be predicted based on the equilibrium equation (Eqs. (1)-(3)). Figure 54 shows the predicted buoyancy-controlled threshold of tight sandstone reservoirs of the Upper Paleozoic in the Ordos Basin in China based on the force equilibrium equations. The results indicated that they correspond to geological conditions of porosity $<10 \%$ and permeability $<1 \mathrm{mD}$. Below the dynamic boundary, gas is filled in the tight reservoirs of adjacent source rocks; above the boundary, natural gas accumulates only in the upper part of the structure. Figure 55 shows the comparison of predicted buoyancy-driven oil accumulation thresholds with drilling results in the Putaohua reservoir in the Songliao Basin. As shown in Fig. 55, liquid oil also has a buoyancy-controlled threshold, and the force equilibrium boundary corresponds to the burial depth with a porosity between $10 \%$ and $11 \%$. Above this boundary, liquid oil reservoirs have the features
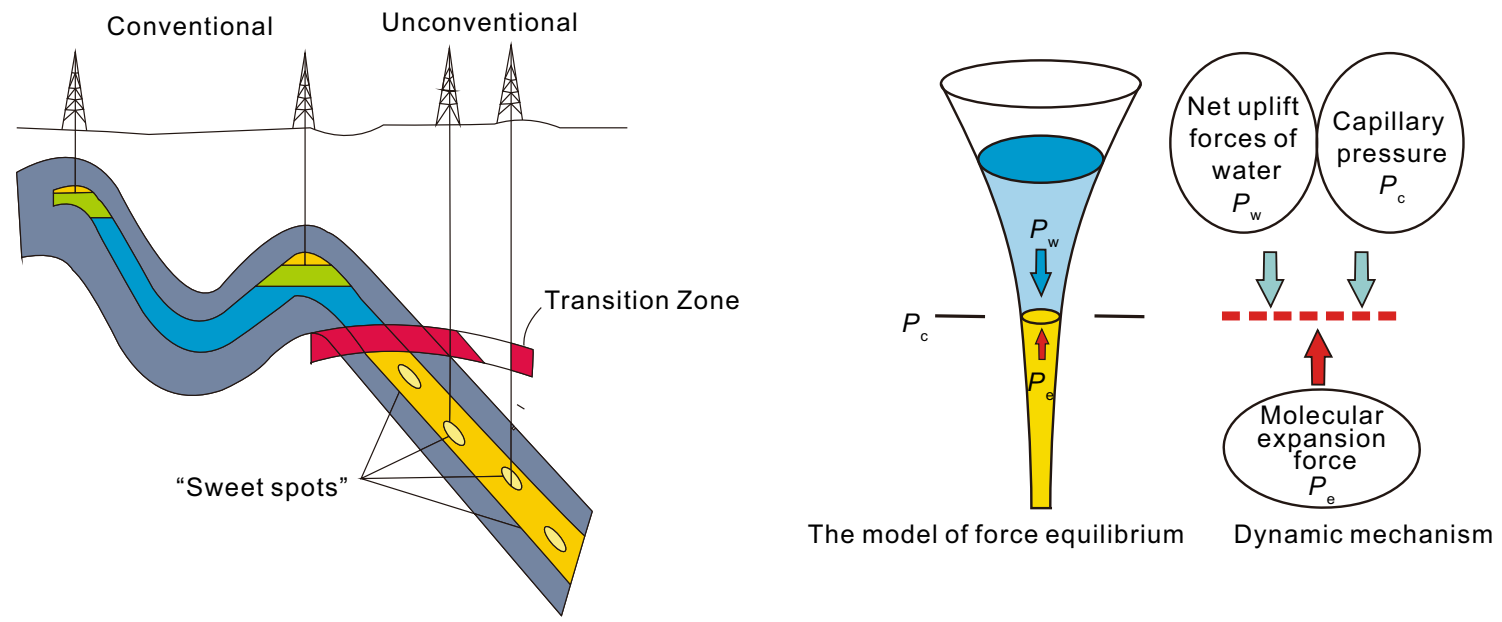

Fig. 51 Conceptual model of buoyancy-controlled thresholds in deep petroliferous basins and controlling the distribution of oil-gas 


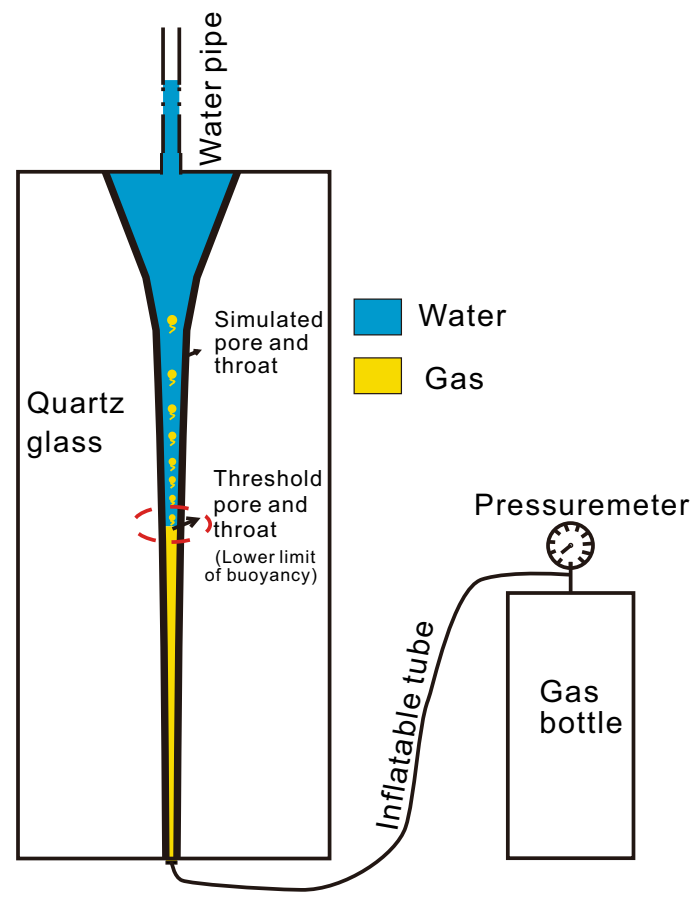

(a) Experiment model and principle

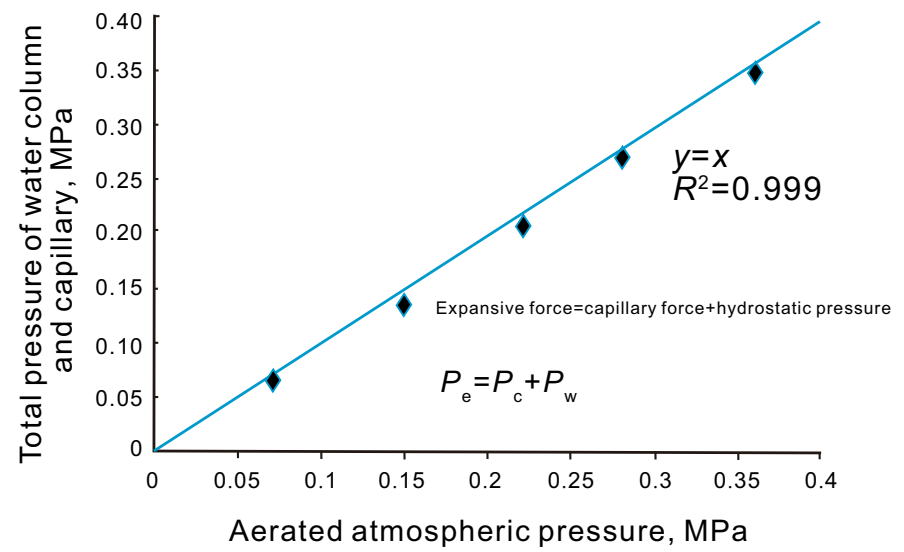

(b) Relevance of balanced data of lower limit for buoyancy action in the test

Fig. 52 Physical simulation of buoyancy-controlled threshold (Pang et al. 2013)

of high-point accumulation, high-porosity enrichment, high-point sealing, and high pressure; below the boundary, liquid oil reservoirs have the features of low-depression accumulation, low-stand inversion, low-porosity enrichment, and low-pressure stability. The consistency of the theoretic prediction results with the actual drilling results reflects the existence of a buoyancy-controlled threshold and the practicality and reliability of the prediction model for both natural gas and liquid oil. Their difference is small (Pang et al. 2013, 2014a).

The second dynamic boundary is the hydrocarbon accumulation limit. It is the maximum depth for hydrocarbon accumulation under geological conditions. The enrichment and accumulation of hydrocarbons require certain temperature and pressure conditions. Theoretically, each hydrocarbon basin may have a hydrocarbon accumulation threshold at a certain depth, below which hydrocarbon accumulations do not exist. The dynamic boundary corresponding to the lower limit of hydrocarbon accumulation is regarded as the hydrocarbon accumulation threshold. According to Pang et al. (2014a), the hydrocarbon accumulation limit is the maximum burial depth or corresponding critical geological condition for hydrocarbon accumulation in hydrocarbon basins, which can be characterized by the porosity, permeability, or pore throat radius of a reservoir (Fig. 56). Pang et al. (2014a) recognized through analysis that the corresponding critical values of the hydrocarbon accumulation limit in clastic petroliferous basins are generally as follows: porosity is less than $2 \%-2.4 \%$, permeability is less than $0.01 \mathrm{mD}$, pore throat radius is less than $0.01 \mu \mathrm{m}$, and burial depth is 5,000-8,000 m.

Many scholars discovered through research using different methods that there is a physical threshold for sedimentary basin oil-gas-bearing reservoirs, below which hydrocarbon does not accumulate or has no exploration significance (Wan et al. 1999; Guo 2004; Shao et al. 2008). Through analysis of actual mass exploration results, four different methods have been used to determine hydrocarbon accumulation limits in the deep part of hydrocarbon basins by Pang et al. (2014a): (1) As the burial depth increases, the bound water saturation in the reservoir will reach $100 \%$, resulting in the termination of hydrocarbon accumulation. When the bound water saturation reaches $100 \%$ in the Fuyang sandstone reservoir in the Songliao Basin, the hydrocarbon accumulation limit porosity is $2.4 \%-4 \%$; when the bound water saturation reaches $100 \%$ in the hydrocarbon-bearing sandstone in the Kuqa Depression in the Tarim Basin, the hydrocarbon accumulation limit porosity is about $2.4 \%$. Figure 56 shows an example of this. (2) The hydrocarbon accumulation limit can be determined when the porosity and permeability as a function of buried depth do not allow the migration of oil and gas normally. As the burial depth increases, the 


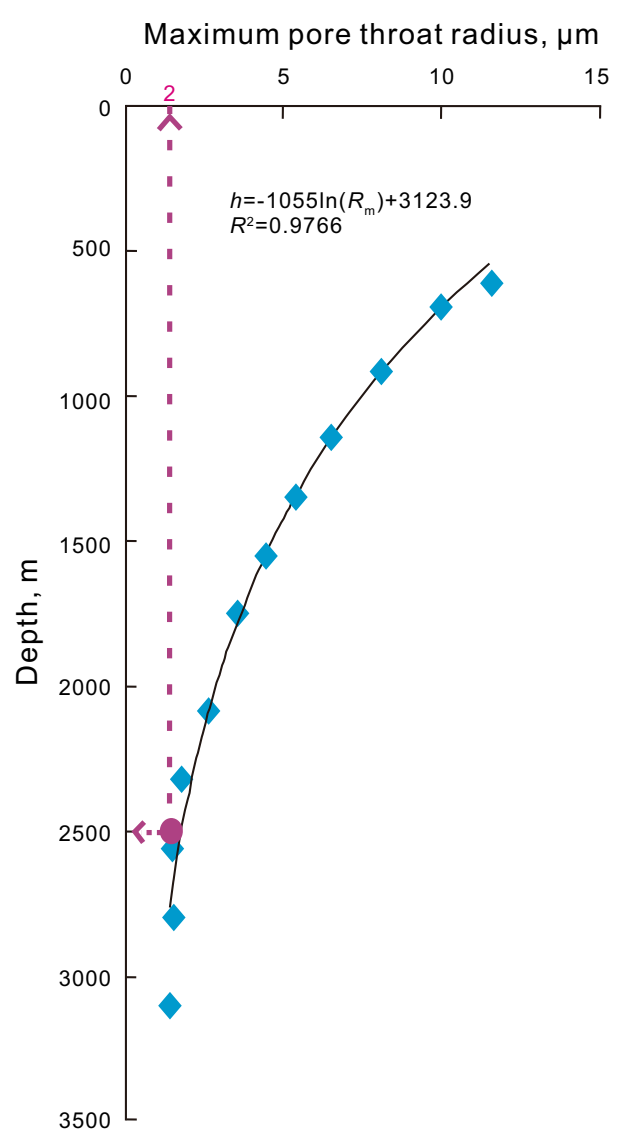

(a) Corresponding maximum pore throat radius of the lower limit of buoyancy reservoir-forming

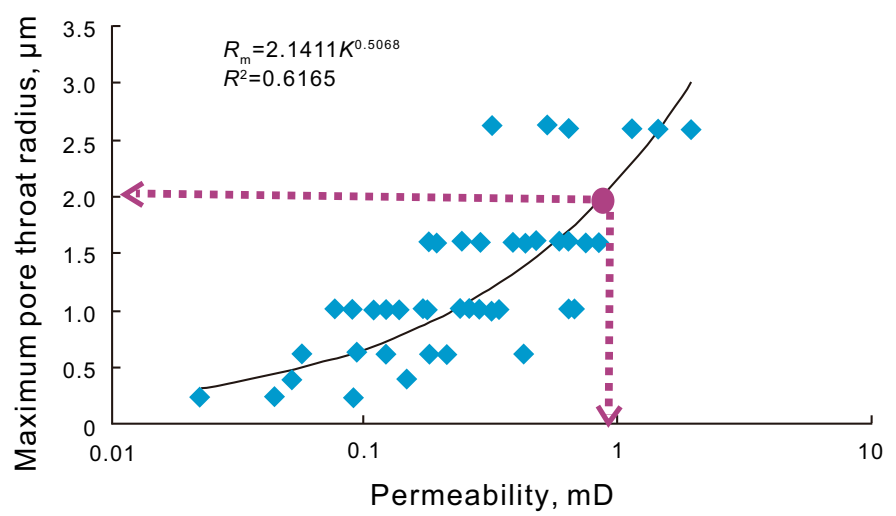

(b) Corresponding maximum permeability of the lower limit of buoyancy reservoir-forming

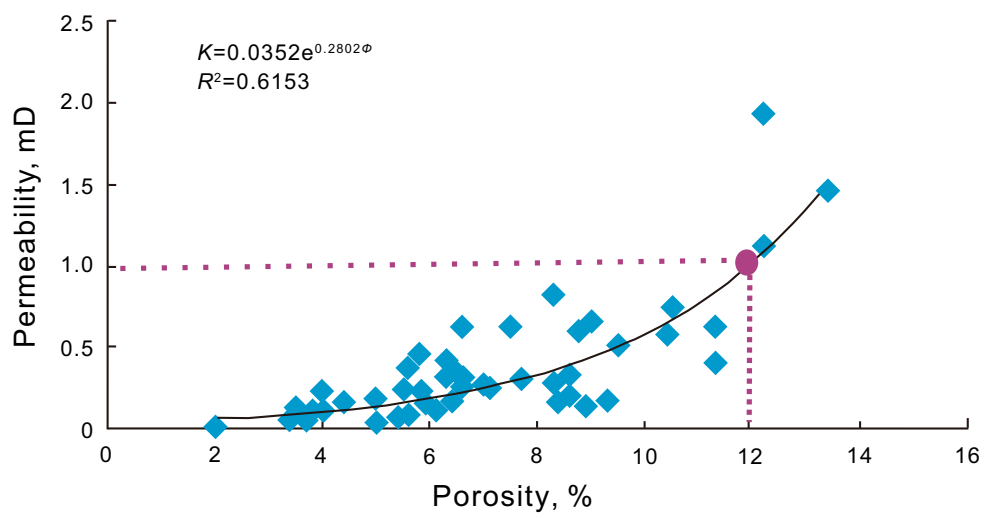

(c) Corresponding maximum porosity of the lower limit of buoyancy reservoir-forming

Fig. 53 Key elements of the equilibrium of forces at buoyancy-controlled threshold and their relations

reservoir permeability under actual geological condition decreases as a result of compaction strengthening. Figure 57 shows an example. (3) The hydrocarbon accumulation limit can be determined when capillary pressure difference between inside and outside the reservoir or the potential difference tends to disappear as a function of buried depth. As the burial depth under actual geological conditions increases, the potential difference between inside and outside the reservoir will disappear, resulting in the termination of hydrocarbon accumulation. Figure 58 shows the hydrocarbon accumulation limits in terms of inner and outer potential difference of major target reservoirs in the Jiyang Depression in the Bohai Bay Basin in eastern China and the Kuqa Depression in the Tarim Basin in western China are at burial depths of 6,000 and 8,500 m, respectively (Fig. 58). (4) The hydrocarbon accumulation limit can be determined based on the exploration well data from a $100 \%$ dry bed. When a $100 \%$ dry bed was met in the exploration well during drilling for the purpose of understanding the hydrocarbon and water distribution in the Central Tarim Basin region, the reservoir porosity was less than $2 \%$, so it is taken as the hydrocarbon accumulation limit (Fig. 59).

We highlight here that the hydrocarbon accumulation limit is not a threshold indicating the existence of hydrocarbon. When hydrocarbon exists in reservoirs below this limit, it was probably accumulated before entering the threshold, below which there may be exploration risks because the strata porosity is low and accumulation has terminated. There may be hydrocarbon (liquid oil) reservoirs of industrial value in strata with a burial depth of $6,000 \mathrm{~m}$, and even with a burial depth exceeding $8,000 \mathrm{~m}$ in some basins in the world. The threshold of deep hydrocarbon accumulation in hydrocarbon basins is in a wide range and changes according to certain rules. As the sand grain size increases or the sand grain sorting difficulty decreases, the hydrocarbon accumulation limit becomes deeper. 


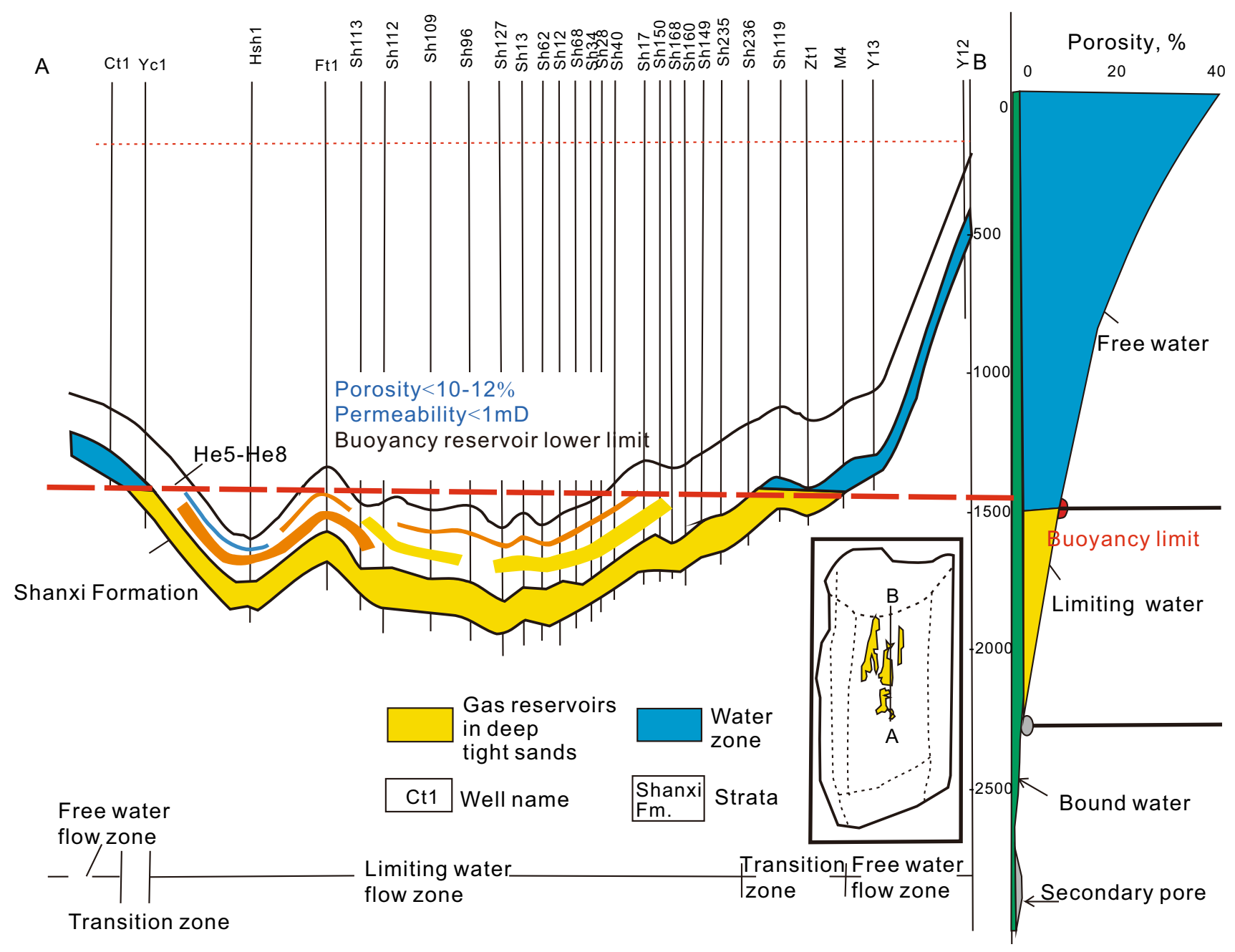

Fig. 54 Comparison of predicted buoyancy-controlled threshold of the Upper Paleozoic with drilling results in the Ordos Basin (Pang et al. 2014a)

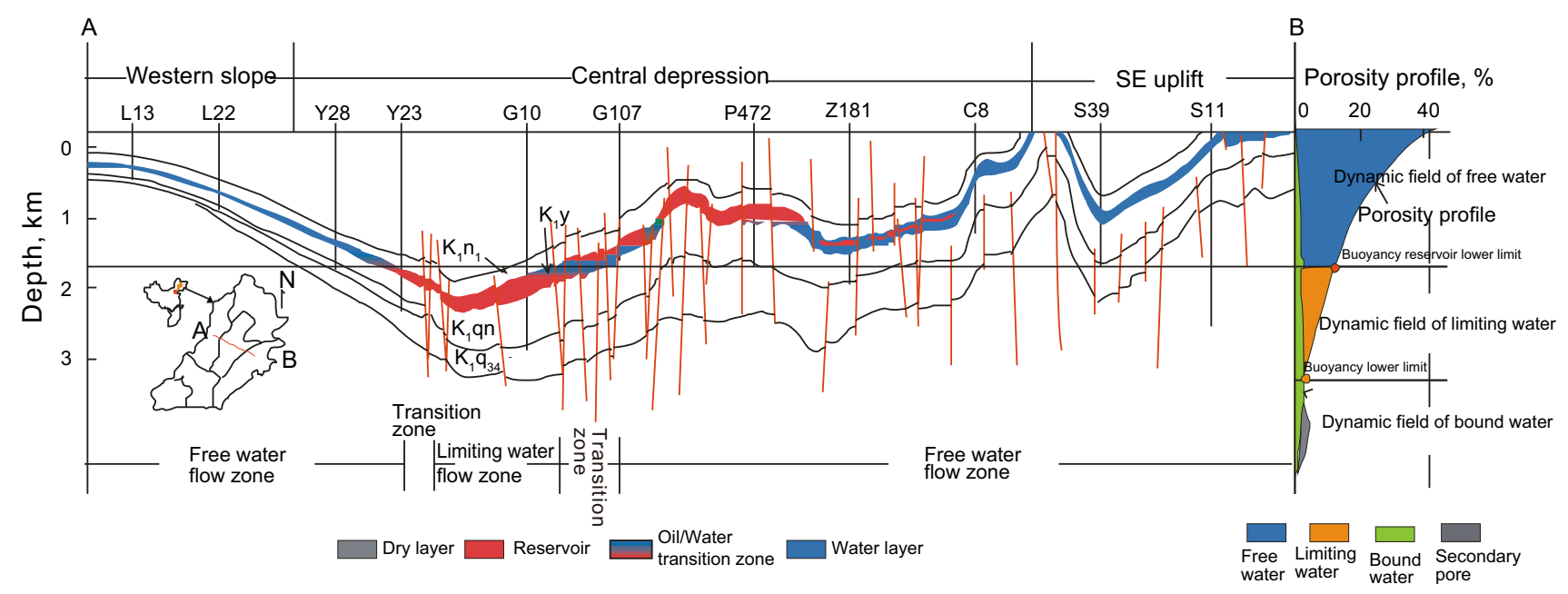

Fig. 55 Comparison of predicted buoyancy-controlled threshold with drilling results in the Putaohua reservoir in the Songliao Basin (Pang et al. 2014a) 


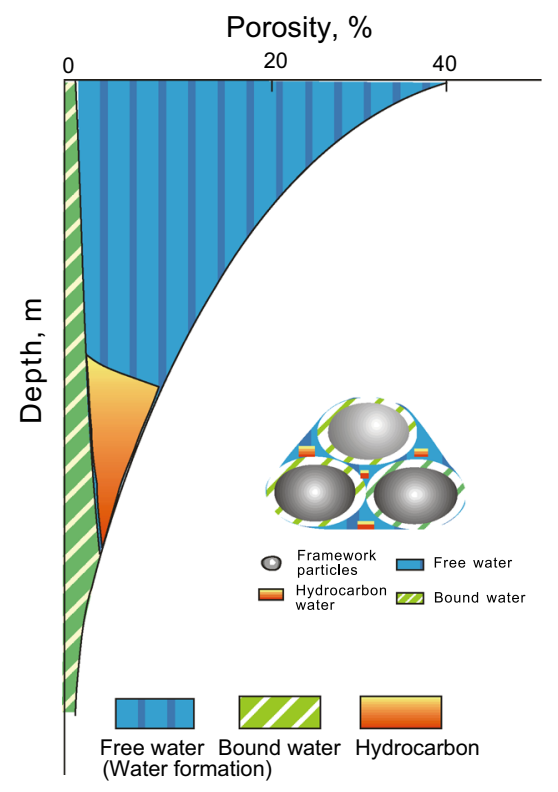

(a) Conceptual model of oil and gas accumulation bottom line

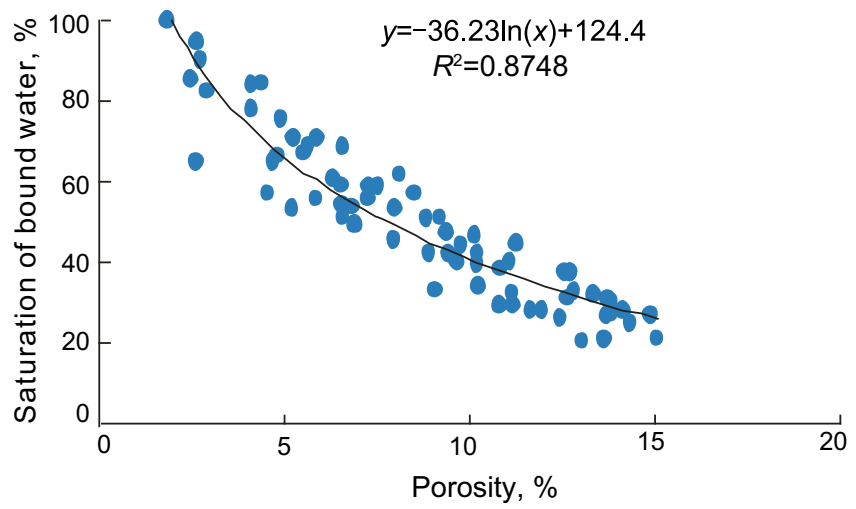

(b) Change of saturation of bound water and the bottom line of oil and gas accumulation of the Kuche Depression

Fig. 56 Bound water saturation in an oil-gas-bearing target reservoir as a function of buried depth and hydrocarbon accumulation limits

The third dynamic boundary is the lower limit of hydrocarbon generation of source rocks. It usually refers to the critical geological condition that hydrocarbon output of organic-rich source rocks is less than $1 \%$ of the total. Methods used to determine the lower limit of hydrocarbon generation mainly include the amount of residual hydrocarbon, organic element variation, hydrocarbon generation potential, and efficiency of hydrocarbon expulsion. The residual hydrocarbon capacity of source rocks is expressed by the amount of residual hydrocarbon in organic carbon ( $S_{1} /$ TOC) or chloroform asphalt ("A"/TOC). The residual hydrocarbon $S_{1} /$ TOC or "A"/TOC of the source rocks increases at first followed by a gradual decrease as the depth or $R_{\mathrm{o}}$ increases, generating a "belly-shaped" curve. When $S_{1} /$ TOC or "A"/TOC reaches a minimal value which is so small that change is hardly visible, it means that hydrocarbon is no longer generated and expelled from the organic matter, and the $R_{\mathrm{o}}$ value at such minimal value is the lower limit of hydrocarbon generation (Fig. 60a). The organic element variation method is described as follows: When $\mathrm{H} / \mathrm{C}$ and $\mathrm{O} / \mathrm{C}$ in the source bed reaches a minimal value which is so small that change is hardly visible, the source rock will no longer yield hydrogen-rich hydrocarbons. That is the lower limit of hydrocarbon generation. Theoretically, when hydrocarbon generation terminates, $\mathrm{H} / \mathrm{C}$ will no longer change when reaching a minimal value. Huo et al. (2014b) determined the lower limit of hydrocarbon generation of carbonate rocks in the basin-platform region of the Tarim Basin, by supposing that the minimal value
$\mathrm{H} / \mathrm{C}=0.1$ and the $\mathrm{H} / \mathrm{C}$ value at $R_{\mathrm{o}}=0.5 \%$ as the maximum value (Fig. 60b). In the diagram of hydrocarbon generation potential changes of source rocks, $\left(S_{1}+S_{2}\right) / \mathrm{TOC}$ is the current hydrocarbon generation potential index of the source rocks. Due to hydrocarbon generation and expulsion from the source rocks, $\left(S_{1}+S_{2}\right) /$ TOC increases first followed by a gradual decrease as the depth or $R_{\mathrm{o}}$ increases, generating a "belly-shaped" curve. When the hydrocarbon generation potential reaches a certain minimal value, the hydrocarbon generation potential stops changing. This means that the source rock stops generating hydrocarbon and the lower limit of hydrocarbon generation of the source rock is reached (Fig. 60c). The amount of hydrocarbon expelled from source rock increases at first followed by a gradual decrease as the depth or $R_{\mathrm{O}}$ increases. When the amount of expelled hydrocarbon drops to zero or a minimal value, it means that hydrocarbon expulsion stops, and hydrocarbon generation may also have stopped. The $R_{\mathrm{o}}$ value when the amount of expelled hydrocarbon is zero or reaches a minimal value is the lower limit of hydrocarbon generation. When the amount of expelled hydrocarbon is zero, the hydrocarbon expulsion rate is also zero, but the hydrocarbon expulsion efficiency increases to the maximum of nearly $100 \%$. The lower limit of hydrocarbon generation can be determined according to the hydrocarbon expulsion rate and efficiency instead of the amount of expelled hydrocarbon. According to the lower limit of hydrocarbon generation concept, the $R_{\mathrm{o}}$ value when $F_{\mathrm{e}}=99 \%$ is the lower limit of hydrocarbon generation (Fig. 60d). 
Fig. 57 Porosity and permeability changes and hydrocarbon accumulation limits in the burial process of a hydrocarbon-bearing target layer

Porosity, \%

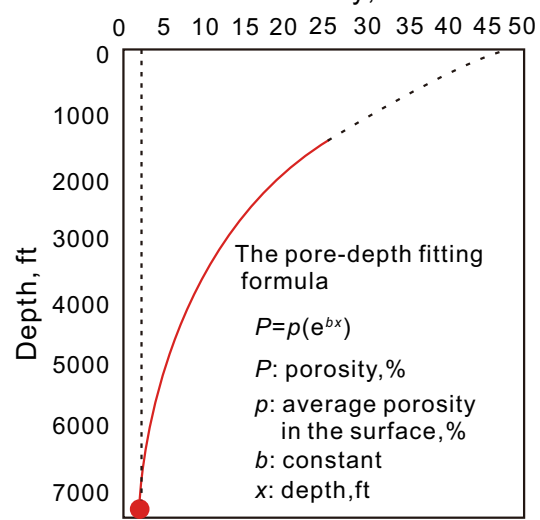

(a) Relationship between porosity and depth

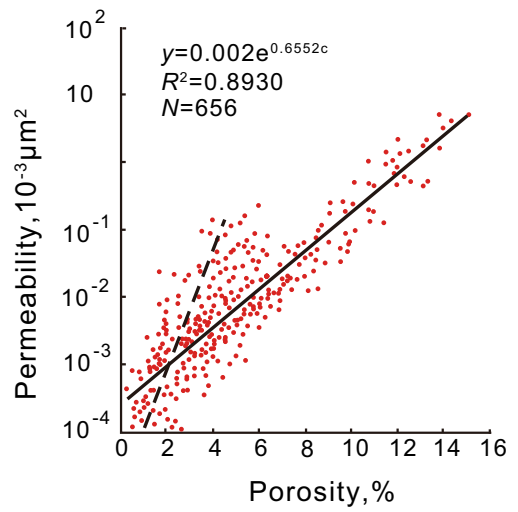

(b) Relationship between permeability and effective porosity in Xu6, Chuanxi section

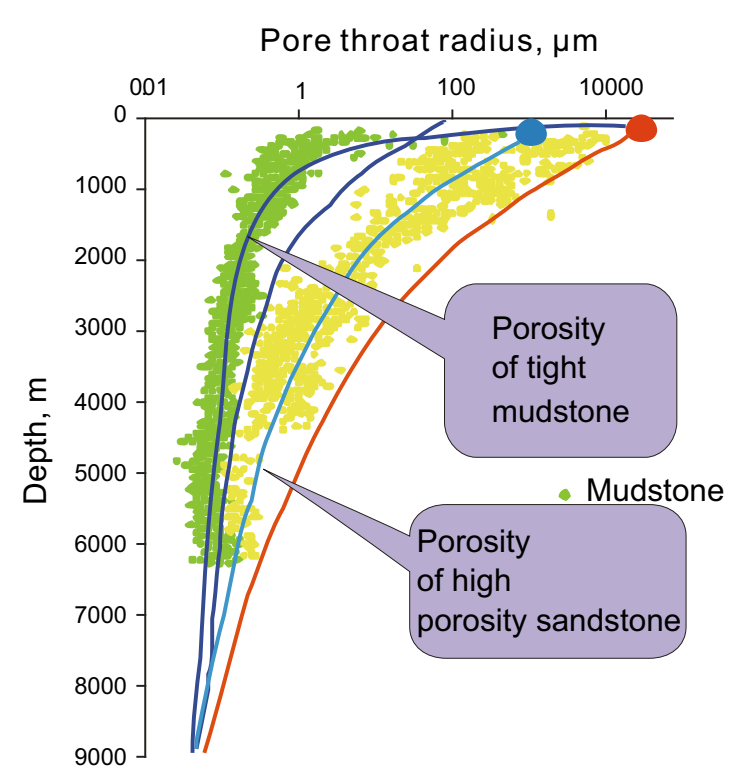

(a) Yeyun2 well pore throat radius changes with depth
Mudstone interface potential energy/ Sandstone interface potential energy

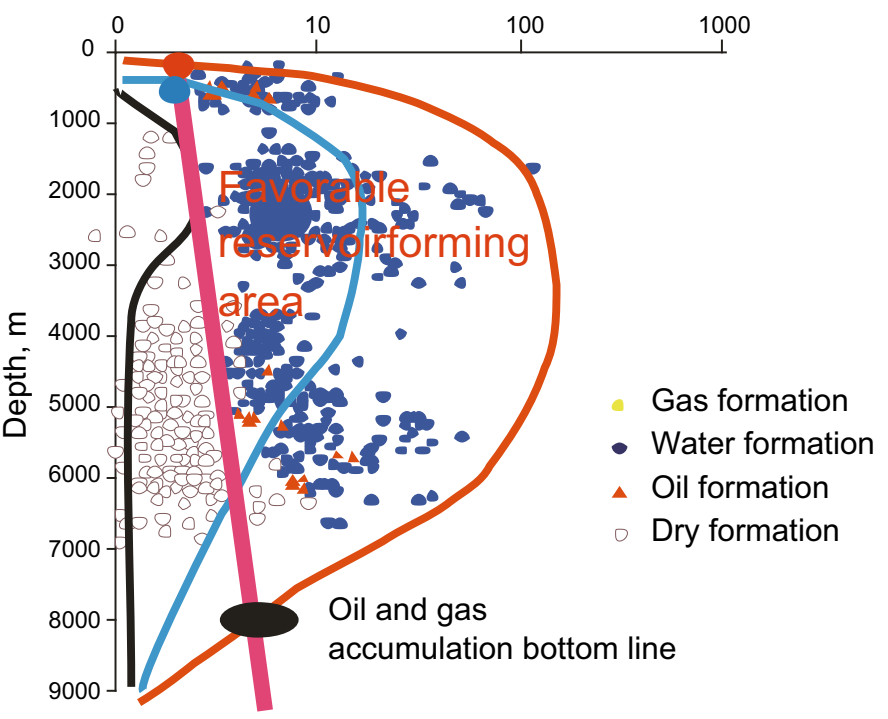

(b) Changes of potential difference of inner-outer interface in Kuqa Depression, Tarim as a function of depth

Fig. 58 Changes of inner-outer surface potential and capillary pressure difference and hydrocarbon accumulation limits

5.5 The formation and distribution of deep

hydrocarbon reservoirs are controlled by three fluid dynamic fields

Research on fluid dynamic fields originated from fluid dynamics research in the domain of geodynamics. In 1953, Hubbert (1953) proposed the fluid potential concept in order to describe energy changes and migration rules of underground fluids. Ye et al. (1999) made a detailed description of the concept, pointing out that a fluid dynamic field is an integration of temperature, pressure, fluid potential, and structural stress fields in a sedimentary basin and their relations. Based on the above analysis that there is a buoyancy-controlled threshold and a hydrocarbon accumulation limit in the deep part of each hydrocarbon basin, Pang et al. (2014a) suggested that a hydrocarbon basin may be divided into three dynamic fields according to buoyancy-controlled threshold and hydrocarbon 


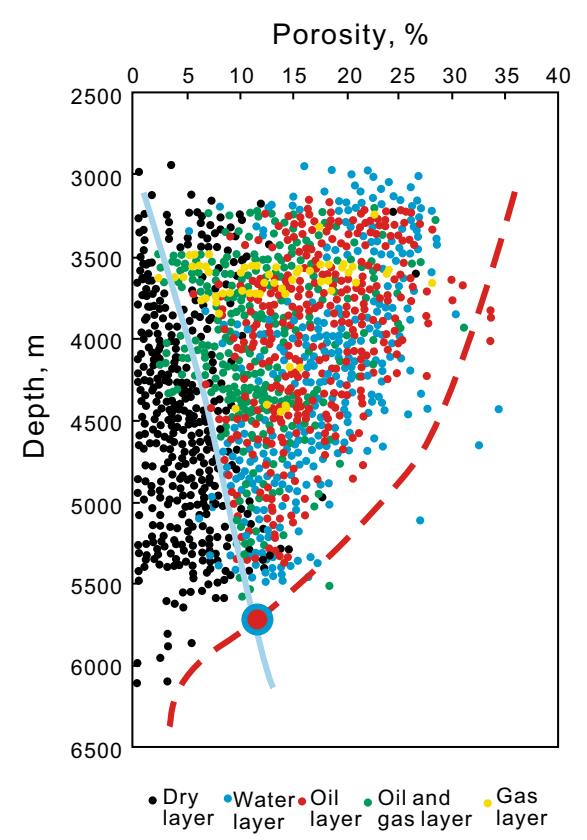

(a) Diagram showing the fluid porosity of the Tarim reservoirs

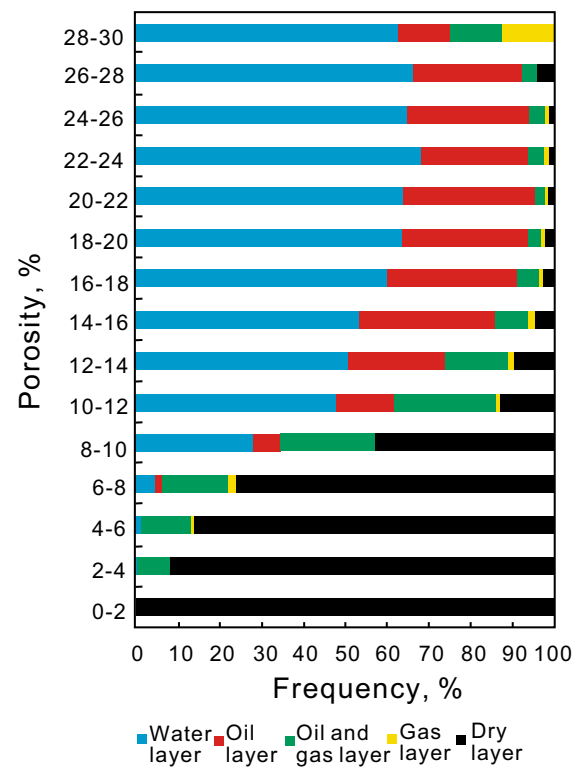

(b) Frequency histogram of changes of fluid in the Tazhong reservoirs as a function of porosity

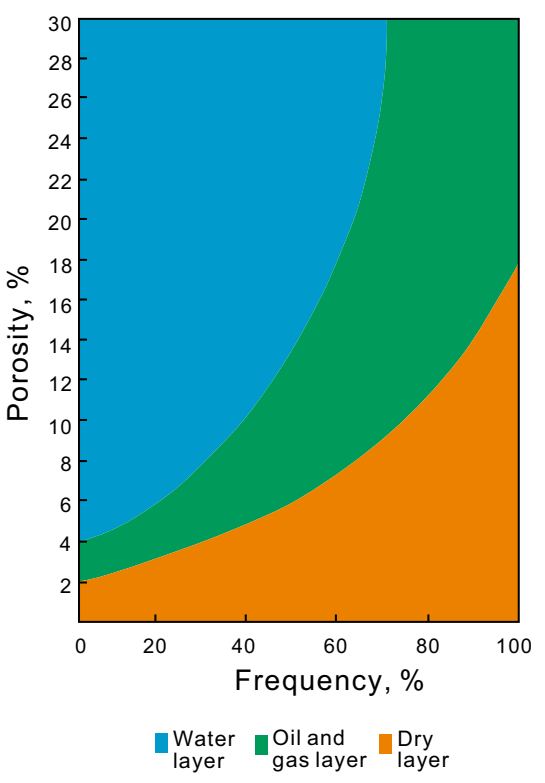

(c) Change model of fluid in the Tazhong reservoirs as a function of porosity

Fig. 59 Distribution of oil-gas, water bearing, and dry layers in the Central Tarim Basin region and accumulation thresholds

accumulation limit. Strata above the buoyancy-controlled threshold are called the free fluid dynamic field; strata between the buoyancy-controlled threshold and hydrocarbon accumulation limit are in the limited fluid dynamic field; and strata below the hydrocarbon accumulation limit are in the bound fluid dynamic field (Fig. 61). The fluid dynamic field is referred to the strata field where the hydrocarbon has identical or similar media, migrationaccumulation force and reservoir-forming rule.

The research conducted by Pang et al. (2014a) shows that deep hydrocarbon reservoirs are controlled by free and limited fluid dynamic fields. The free fluid dynamic field is where conventional hydrocarbon reservoirs develop, and where buoyancy has a dominant effect on the migration and accumulation of hydrocarbons, with the hydrocarbon distribution features of high-point sealing and accumulation, high-porosity enrichment, and high-pressure stability. The limited fluid dynamic field is where tight hydrocarbon reservoirs develop, and where buoyancy has less effect on the migration and accumulation of hydrocarbons. The sandstone porosity in this field is generally $2.4 \%-12 \%$, permeability is $0.01-1 \mathrm{mD}$, and pore throat radius is $0.01-2 \mu \mathrm{m}$. In this formation area, three major tight hydrocarbon reservoirs are formed. (1) the conventional tight hydrocarbon reservoirs are developed from preexisting conventional reservoirs under compaction, i.e., first forming reservoirs and then being compacted, such reservoirs are characterized by the features of high-point accumulation, high-stand sealing, and high-pressure stability; (2) the tight deep basin gas reservoirs underwent the process of first compaction and then reservoir forming. They show the features of low-depression accumulation, low-stand inversion, low-porosity enrichment, and lowpressure stability. They are mainly formed by the expansion of the petroleum area caused by the volume expansion of hydrocarbon when migrating into the tight reservoirs; (3) the tight superimposed hydrocarbon reservoirs are formed by the combination of the two hydrocarbon reservoir types mentioned above, which are formed by compaction and molecule volume expansion. They underwent three stages, i.e., reservoir forming-compaction-reservoir forming. They generally show the features as follows: the coexistence of oil and gas of high and low points; the coexistence of oil and gas of high and low porosity; the coexistence of oil-gas-bearing zone of high and low pressure; the coexistence of oil-gas reservoirs of high and low production. A superimposed continuous hydrocarbon reservoir is formed by the superimposition of the tight hydrocarbon reservoirs mentioned above (Pang et al. 2014a). The bound fluid dynamic field is at the bottom of the basin, and the oil and gas in it were accumulated at an early stage and retained from that earlier time. The risk of exploration and development is huge in this field, as the target formation is characterized by deep-buried depth, low 


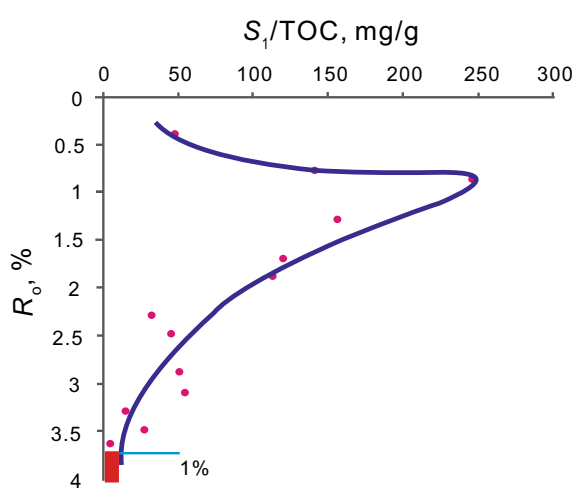

(a) The characteristic of changes of $S_{1} / \mathrm{TOC}$

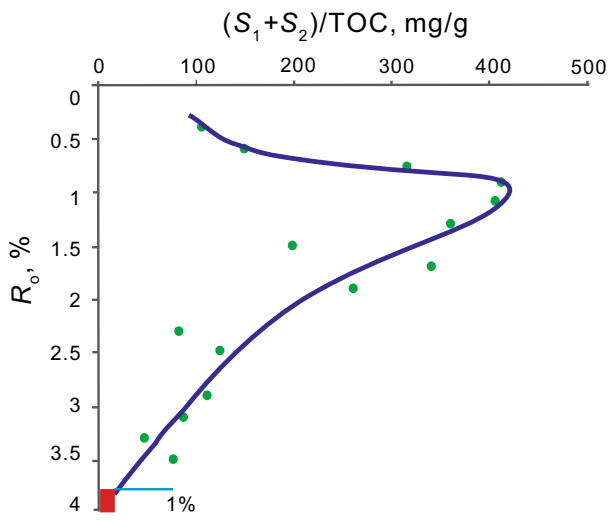

(c) The characteristic of the changes of $\left(S_{1}+S_{2}\right) /$ TOC

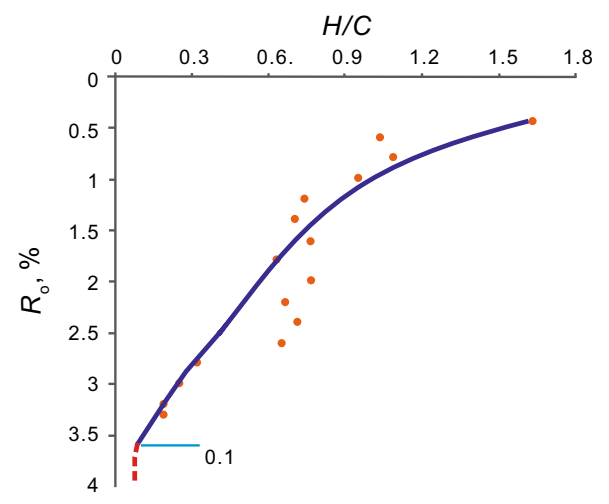

(b) The characteristic of $H / C$ changes with $R_{\text {。 }}$

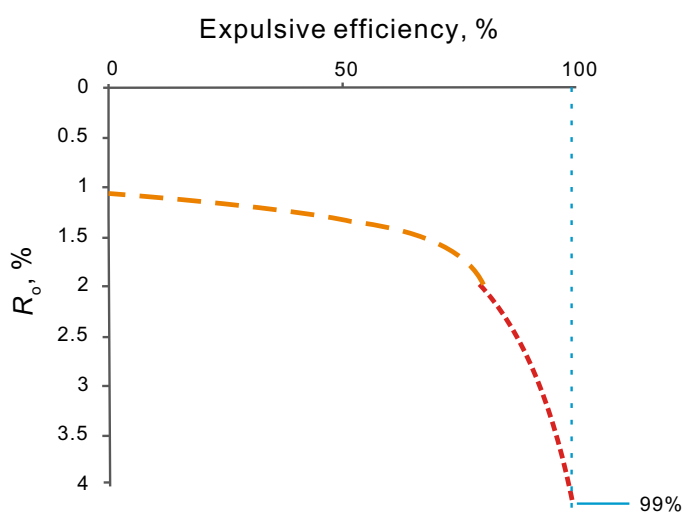

(d) The characteristic of changes of expulsive efficiency

Fig. 60 Changes of hydrocarbon generation and expulsion in the source rocks as a function of buried depth and the lower limit of hydrocarbon accumulation (blue line) (Huo et al. 2014b)

porosity and permeability, and lack of formation energy (Fig. 62). Later tectonism may damage and reconstruct the hydrocarbon reservoirs and develop fracture type, cavetype, or fracture-cave complex-type hydrocarbon reservoirs. They are tight reservoirs, but the porosity and permeability may be good in some parts of the area, which then show the geological features of conventional hydrocarbon reservoirs.

The distribution of fluid dynamic fields varies in different basins. It is affected by the following three factors in the deep strata of hydrocarbon basins: (1) The changing rate of porosity and permeability with the burial depth. The depth of a fluid dynamic field decreases as the changing rate increases, and vice versa; (2) The uplifting of deep strata as a result of erosion of overlying strata leads to the uplifting of tight strata as a whole and the limited and bound fluid dynamic fields in the basins uplift to a shallow formation or even to the surface; (3) Faults caused by structural changes may damage the fluid dynamic field boundary in hydrocarbon basins. Faults may change a limited fluid dynamic field into a free fluid dynamic field near the faults and damage some reservoirs. Overall faulting may change the deep part into a free fluid dynamic field to form conventional hydrocarbon reservoirs under the effect of buoyancy.

5.6 Tight hydrocarbon resources in limited deep fluid dynamic fields and exploration prospects

Tight hydrocarbon reservoirs in limited deep fluid dynamic fields can be divided into three types by the development mode: conventional reservoirs, deep basin reservoirs, and composite reservoirs, and each has its own unique formation process. Conventional tight reservoirs were deep-buried conventional reservoirs formed under the action of buoyancy after long years of compaction and diagenesis, characterized by an "accumulation followed by tightening" process; deep basin tight reservoirs were formed by hydrocarbons expelled from source rocks and accumulated in adjacent tight rocks without being controlled by buoyancy forces. These reservoirs are characterized by a "tightening followed by accumulation" process; composite tight reservoirs are a combination of conventional tight reservoirs and deep basin tight reservoirs, characterized by 
Fig. 61 Diagram showing the division of dynamic field boundary and fluid dynamic field of hydrocarbon migration and accumulation in deep petroliferous basins

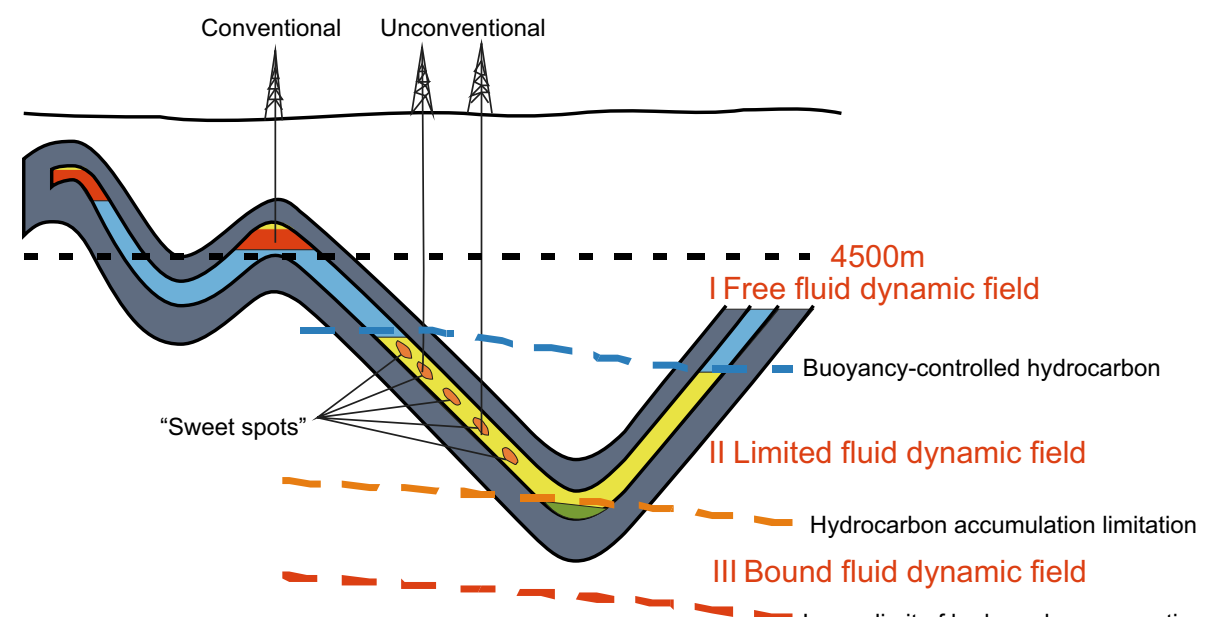

an "accumulation-tightening-accumulation" process. Figure 63 shows the migration-accumulation force, sourcereservoir matching, major controlling factors, and reservoir forming modes in the three tight hydrocarbon reservoirs.

Deep reservoirs in hydrocarbon basins have better forming and preserving conditions than shallow ones in the following aspects: (1) Reservoir tightness. Buoyancy has less effect on the migration and accumulation of hydrocarbons. This means that all hydrocarbons from source rocks during this period are not easily dispersed, and the preservation conditions are much better than those in the free fluid dynamic field. (2) Thermal maturity of source rocks. The geotemperature is high, between 100 and $200{ }^{\circ} \mathrm{C}$, and $R_{\mathrm{O}}$ is $1.2 \%-2.5 \%$. The hydrocarbon yield of per unit weight of parent matter is 1.0-2.2 t/tc, and hydrocarbon expulsion efficiency is $25 \%-99 \%$, equivalent to 2 and 5 times those in the free fluid dynamic field, respectively. (3) Hydrocarbon migration and accumulation efficiency. Hydrocarbons from source rocks accumulate in adjacent rocks to form reservoir resources. The migration and accumulation efficiency is 3-10 times that in the free fluid dynamic field. (4) The hydrocarbon targets in limited deep fluid dynamic fields have experienced the evolution period of free fluid dynamic fields, and the conventional reservoirs formed in early periods accumulated in limited fluid dynamic fields, where they were compacted and changed into conventional tight reservoirs as part of the hydrocarbon resources of limited fluid dynamic fields. The oil and gas resource evaluating results of limited fluid dynamic fields in several China major basins evaluated by Pang et al. (2014a) indicate the oil and gas resource accumulated in the field accounts for more than $84 \%$ of the total basin resource.

The hydrocarbon resource potential is different in different types of tight reservoirs in deep petroliferous basins. Deep hydrocarbon reservoir distribution patterns are
Fig. 62 Distribution of deep fluid dynamic field-controlled hydrocarbons in hydrocarbon basins (Pang et al. 2014a)

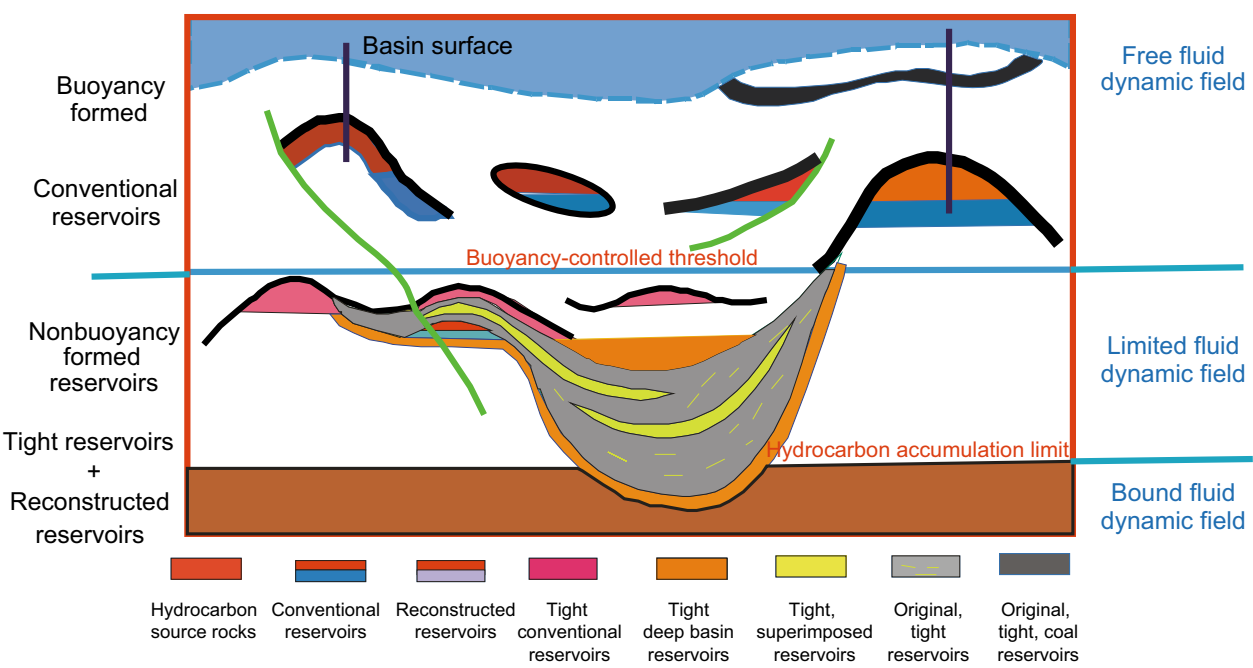


affected and controlled by single factor (Fig. 64). (1) under the control of terrestrial heat flow or geothermal gradient in the basin, "cold basins" characterized by low geothermal gradient and terrestrial heat flow values are favorable for deep oil and gas exploration. They can develop both free fluid dynamic fields and limited or bound fluid dynamic fields below a depth of 4,500 $\mathrm{m}$ with an extensive formation area for favorable exploration. Their resource potential is huge and a variety of hydrocarbon reservoir types are found in the basins with promising exploration prospects. "Hot basins" characterized by a high geothermal gradient and terrestrial heat flow values are unfavorable for deep oil and gas exploration, only developing a limited fluid dynamic field below the depth of $4,500 \mathrm{~m}$ with limited formation area favorable for exploration. Their resource potential and reservoir types are limited, with huge exploration risk. "Warm basins" whose geothermal gradient and terrestrial heat flow values are between "cold basins" and "hot basins" have an extensive formation area favorable for exploration and the resource potential and exploration prospects are between the two extremes. (2) When hydrocarbon source rocks are widely developed and hydrocarbon generation and expulsion amounts are large, the exploration potential is favorable. When a source-reservoir-cap rock combination is completed and the cap rock condition is good, the exploration potential is also favorable. (3) When intense tectonic movements occurred with fractures dominating, deep oil and gas reservoirs are susceptible to damage leading to low exploration potential. When a deep fluid dynamic field is uplifted to middleshallow formation due to the denudation of overlying strata, the oil and gas exploration potential is weakened below a depth of $4,500 \mathrm{~m}$. For example, the limited fluid dynamic field is currently above a depth of $4,500 \mathrm{~m}$ in the Chu-Saleisu Basin, Kazakhstan, resulting from the overall uplifting caused by the denudation of overlying strata. So the bound fluid dynamic field, which is unfavorable for oil and gas exploration, is currently developed below a depth of $4,500 \mathrm{~m}$.

\section{Geological research directions for hydrocarbons in deep petroliferous basins}

\subsection{Identification of deep hydrocarbon sources and relative contribution evaluation}

The sources of deep hydrocarbons are complex. Some have single source and some have mixed sources. The hydrocarbon can originate from degradation of organic matter, from thermal cracking of asphalt sand or dispersed organic matter, or from the catalytic action of deep hydrothermal activity so it is very important to understand the origin of deep hydrocarbon and evaluate relative contributions. This will play a leading role in determining the hydrocarbon resource potential and favorable exploration directions. Scholars have done a lot of research into the identification of hydrocarbon sources and quantitative evaluation of hydrocarbon contributions using a variety of methods, laying a solid foundation for further work.

Methods for hydrocarbon source identification mainly include total hydrocarbon gas chromatographic

\begin{tabular}{|c|c|c|c|c|c|c|c|}
\hline \multicolumn{2}{|c|}{ Classification } & \multicolumn{2}{|c|}{ Mechanism of accumulation } & \multicolumn{3}{|l|}{ Mode of accumulation } & \multirow{2}{*}{$\begin{array}{c}\text { Example } \\
\begin{array}{c}\text { At home and } \\
\text { abroad }\end{array}\end{array}$} \\
\hline Categories & $\begin{array}{l}\text { Sub- } \\
\text { categories }\end{array}$ & $\begin{array}{l}\text { Power for } \\
\text { migration }\end{array}$ & $\begin{array}{c}\text { Matching of } \\
\text { source rock and } \\
\text { reservoir rock }\end{array}$ & Conceptual model & $\begin{array}{c}\text { Factor } \\
\text { combination }\end{array}$ & $\begin{array}{c}\text { Regularities } \\
\text { of } \\
\text { distribution }\end{array}$ & \\
\hline 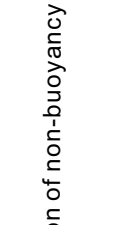 & $\begin{array}{c}\text { Conventional } \\
\text { tight oil } \\
\text { and gas oil } \\
\text { reservoir }\end{array}$ & $\begin{array}{c}\text { Static formation } \\
\text { pressure }\end{array}$ & $\begin{array}{l}\text { Accumulating } \\
\text { first, and then } \\
\text { becoming } \\
\text { tight reservoir }\end{array}$ & $\begin{array}{cl}\text { C Cap protection } \\
\text { D Tight reservoir } \\
\text { P Buoyancy action } \\
\text { (accumulated } \\
\text { Sccumutightened }\end{array}$ & T-CDPS & \multirow{3}{*}{ 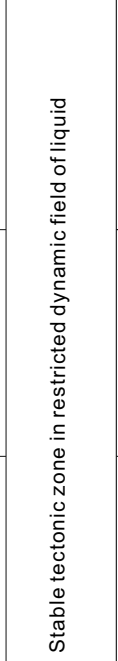 } & $\begin{array}{c}\text { Dina } 2 \text { and tight } \\
\text { conventional oil } \\
\text { and gas reservoirs } \\
\text { currently } \\
\text { discovered } \\
\text { below } 4500 \mathrm{~m}\end{array}$ \\
\hline 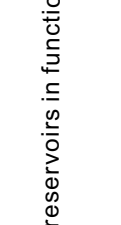 & $\begin{array}{l}\text { Deep-basin } \\
\text { tight oil and } \\
\text { gas reservoir }\end{array}$ & $\begin{array}{l}\text { Expansion stress } \\
\text { of hydrocarbon; } \\
\text { the differences of } \\
\text { capillary force } \\
\text { and concentration } \\
\text { of hydrocarbon } \\
\text { petween the source } \\
\text { rock and } \\
\text { reservoir rock }\end{array}$ & $\begin{array}{l}\text { Becoming tight } \\
\text { reservoir first, } \\
\text { and then } \\
\text { accumulating }\end{array}$ & 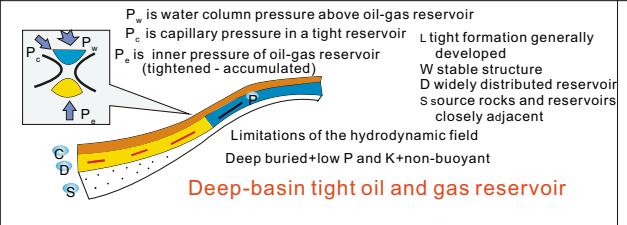 & T-LWDS & & $\begin{array}{l}\text { Yinan } 2 \text { and } \\
\text { deep-basin } \\
\text { reservoirs in } \\
\text { the Alberta Basin }\end{array}$ \\
\hline 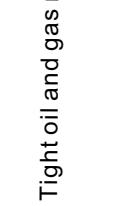 & $\begin{array}{l}\text { Compound } \\
\text { tight oil } \\
\text { and gas } \\
\text { reservoir }\end{array}$ & \begin{tabular}{|l|} 
Static formation \\
pressure; \\
expansion stress of \\
hydrocarbon; \\
the difference \\
between \\
inner and outer
\end{tabular} & $\begin{array}{c}\text { Accumulating } \\
\text { first, becoming } \\
\text { tight reservoir } \\
\text { later, } \\
\text { accumulating } \\
\text { again }\end{array}$ & $\begin{array}{l}\text { C cap protection } \\
\text { The pillar is pressure dense } \\
\text { P1 tight recrock pillar } \\
\text { P2 volume of hydrocarbon } \\
\text { and pressure increase } \\
\text { P pressure from water column } \\
\text { (accumulated-tightened-accumulateo } \\
\text { S source of oil and gas }\end{array}$ & $\begin{array}{l}\text { T-CDPS } \\
+\stackrel{+}{\text { T-LWDS }}\end{array}$ & & $\begin{array}{l}\text { Dibei Oil field } \\
\text { structural high } \\
\text { gas reservoir in } \\
\text { Paleozoic tight } \\
\text { gas reservoir of } \\
\text { the Erdos Basin }\end{array}$ \\
\hline
\end{tabular}

Fig. 63 Three unconventional non-buoyancy tight hydrocarbon reservoirs in limited fluid dynamic field and basic modes 
Fig. 64 Relations between the distribution of limited fluid dynamic fields and geothermal gradients in a deep petroliferous basin

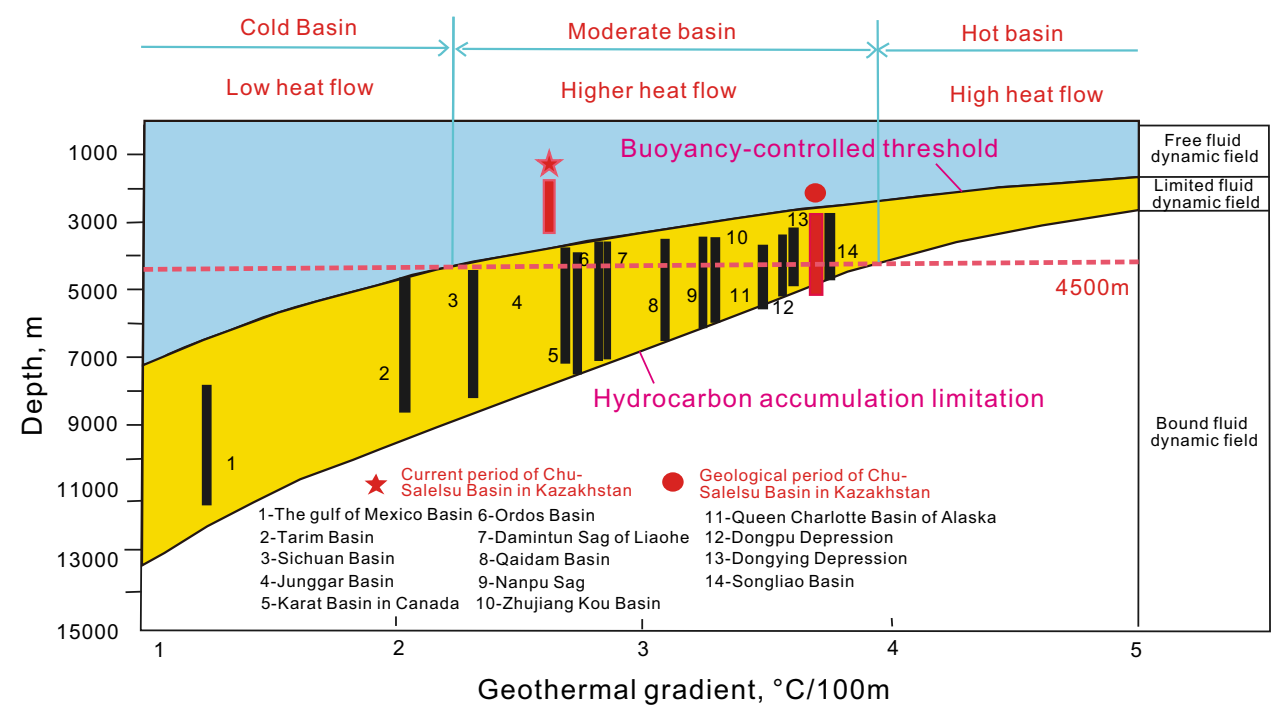

fingerprints, $n$ - and iso-alkane hydrocarbon ratios, steroids/ terpenoids, aromatics, non-aromatics, as well as family composition and carbon isotope studies (Gormly et al. 1994; Telnæs and Cooper 1991; Stahl 1978; Seifert 1978; Hirner et al. 1981); index comparison using aromatics and thiophene compounds (Michael et al. 1989; Mukhopadhyay et al. 1995; Jing 2005) and comprehensive crude oil light hydrocarbon analysis for multi-period and multisource reservoirs (Chen et al. 2006; Philippi 1981; Odden et al. 1998; Chen et al. 2003).

Methods for quantitative evaluation of the relative contribution of mixed hydrocarbon sources mainly include special compound absolute concentration quantification (Zhang et al. 2005a), biomarker parameters (Li et al. 2002), carbon isotope ratios (Song et al. 2004), and chart matching (Wang et al. 1999, 2004).

In deep strata, there are multiple sets and multiple varieties of hydrocarbon sources (including shale, carbonate, paleo-reservoir asphalt, and inorganic hydrocarbons) and multiple hydrocarbon-generating points, which experienced a number of periods of hydrocarbon generation and expulsion and multiple hydrocarbon migration pathways (faults, unconformities, carrier systems, and combinations). For source rocks that experienced many periods of evolution, the results of comparison using a single biomarker will be seriously affected by the degree of maturity. For multiple sets of source rocks, the results of analysis using the carbon isotope method will be affected by the sedimentary environment and climate conditions. Therefore, integrated analysis is required for the determination of deep hydrocarbon sources, including geological (altitude, log response, color, and mud content) and geochemical (biomarker, carbon isotope) analysis. The determination of deep hydrocarbon sources and evaluation of relative contributions are important to the evaluation of deep hydrocarbon resources and determination of hydrocarbon exploration fields.

\subsection{Genetic mechanisms and preservation conditions} of deep-buried high-quality reservoirs

Deep reservoirs include clastic, carbonate, volcanic, and metamorphic reservoirs. Research on the genesis and preservation of high-quality, high-porosity, and high-permeability reservoirs has drawn the attention of many geologists, but there is hardly any research done on the physical thresholds of deep-buried reservoirs. Although the limited fluid dynamic field mainly forms tight hydrocarbon and unconventional reservoirs, what concerns people is still "sweet point" formation in high-porosity and high-permeability reservoirs. The most important part of deep oil and gas exploration is to find these reservoirs under current conditions.

The genesis of deep-buried high-quality reservoirs mainly includes dissolution by organic acids (Surdam et al. 1984), effects of hydrocarbon charging and deep thermal fluids (Navon et al. 1988), clay mineral membranes (Ehrenberg 1993; Dolbier 2001), temperature and depth (Ezat 1997), faulting (Moretti et al. 2002), abnormal pressure (Wilkinson et al. 1997; Osborne and Swarbrick 1999), effects of fractures (Harris and Bustin 2002), sedimentary environment (Amthor and Okkerman 1998; Khidir and Catuneanu 2003; Pape et al. 2005; Rossi et al. 2001), and tectonics (Watkinson and Ward 2006). Preservation mechanisms mainly include early hydrocarbon charging (Gluyas et al. 1990; Robinson and Gluyas 1992; Rothwell et al. 1993), grain coating (Heald and Larese 1974; Ramm et al. 1997), and overpressure (Ramm et al. 1997; Osborne and Swarbrick 1999). 
There is little research on physical thresholds of deep reservoirs. Deep clastic reservoirs are extensively distributed, ranging from 3,000 to $6,000 \mathrm{~m}$, but most are distributed between 3,500 and 4,000 m (Wood and Hewett 1984; Surdam et al. 1984; Gaupp et al. 1993; Ehrenberg 1993; Gu 1996; Gu et al. 1998, 2001; Aase et al. 1996; Wilkinson et al. 1997). Deep carbonate reservoirs have developed secondary pores (such as leaching pores and dissolution pores), cracks, and fissures, which greatly improve the physical properties of the reservoirs even at considerable depths (Shi et al. 2005; Xie et al. 2009). Deep volcanic reservoirs are buried deep, with complicated geological conditions, which add to the particularity and uncertainty of the reservoirs (Zhang and Wu 1994; Liu et al. 2010a). The physical properties of deep metamorphic reservoirs are decided by the development of fractures and are affected by structural movements and faulting activities (Nelson 1985; Waples 1990; Walker and James 1992; Nelson 2000).

Due to the burial depth, long evolutional history, multiple formation mechanisms, and complicated distribution, geological and geophysical exploration for deep reservoirs is difficult, and limited by technical conditions. The accuracy of geophysical data is low, the number of deep wells and ultra-deep wells are limited, and the availability of original data cannot be guaranteed. Besides, there are intense diagenesis and structural volcanic activities and abnormal pressures. All of these add to the difficulty in understanding the genesis of deep-buried high-porosity and high-permeability reservoirs. Traditional petroleum and geological theories can neither explain why there are porosities of $20 \%$ or more at such depths nor guide the exploration and development of deep reservoirs. Therefore, understanding the genesis and preservation mechanisms of deep-buried high-quality reservoirs and studying the physical thresholds of different reservoirs are of great significance to improving the success rate of deep effective reservoir exploration and reducing exploration risks.

\subsection{Phase behavior and conversion mechanisms of deep hydrocarbon and its distribution prediction}

Deep hydrocarbons are subject to complicated temperature and pressure conditions and are affected by multiple fluid compositions. Understanding the phase behavior of oil and gas accumulation in deep basins plays a leading role in revealing its genetic mechanism and distribution regularity.

The temperature and pressure environment of deep hydrocarbon reservoirs mainly include high temperature + high pressure, high temperature + low pressure, low temperature + high pressure, and low temperature + low pressure (Miao et al. 2000; Gu et al. 2001; Jiao et al. 2002; Ma et al. 2005; Meng et al. 2006; Zhang et al.
2008). Deep hydrocarbon reservoirs are primarily composed of gaseous hydrocarbons, oil gas mixtures, oil, water vapor, and water (Zhang 2006). Due to the unique temperature and pressure environment, deep hydrocarbons exist in three forms: free, dissolved, and adsorbed, and three phases: oil, gas, and mixed (Tuo 2002; Shi et al. 2005; Wu and Xian 2006; Huang et al. 2007).

The migration of deep hydrocarbons is affected by a variety of forces, such as buoyancy, (oil) gas molecular expansive force, capillary force, molecular adsorption, and binding forces, which jointly act on the accumulation and entrapment of hydrocarbons (Pang et al. 2007b). For deep conventional reservoirs, buoyancy is the main force on the migration of hydrocarbons; for deep unconventional reservoirs, gas molecular expansion is the main force (Gies 1984; Pang et al. 2003; Xiao et al. 2008; Ma et al. 2009; Jiang et al. 2010; Zhu et al. 2010).

Affected by the widely different temperature and pressure conditions and complicated fluid compositions, deep hydrocarbon reservoirs occur in different forms, which are difficult to predict. Besides, due to the unique porosity and permeability conditions, the fluid moving forces are so complicated that it is impossible to characterize the dynamic mechanism that controls the hydrocarbons. In addition, the hydrocarbon driving forces are related to the conditions in a complicated manner. Different hydrocarbon phases have different forces, and the forces are affected by the hydrocarbon phases. Therefore, the formation of deep hydrocarbon reservoirs is not only related to fluid composition and occurrence conditions, but also is jointly controlled by a range of forces including buoyancy. Prediction of the occurrence conditions of deep fluids and characterization of their dynamic mechanism are important to the scientific prediction of deep hydrocarbon resources and the determination of favorable exploration directions.

\subsection{Economic feasibility evaluation for deep-buried tight hydrocarbon exploration and development}

The exploration and development of deep hydrocarbons is difficult, and the investment return is low. It not only relies on the further understanding of related theories, but also is affected by technical (well drilling and completion techniques) and economic feasibilities.

Economic feasibility is a key to the development of deep hydrocarbon exploration and can decide the exploration direction. It is related to development costs and profits. Profits are affected by the international oil price. Oil exploration is a system, in which drilling costs account for about $50 \%-70 \%$ of the total production costs and drilling costs increase considerably as the drilling depth increases (Du and Yao 2001). According to research by some scholars, drilling costs increase exponentially, instead of 
linearly, as the depth increases (Guan et al. 2012). Profits are mainly affected by oil price and output. The higher the oil price is, the more output there will be, and the more profit it will bring. Output is controlled by the market as well as geological and engineering factors. The higher the international oil price is, the more output there will be. Rapid increase of output will in turn restrain the price rise.

According to the 2014 International Energy Agency, the United States will close $2 \%$ of its shale wells if the international oil price drops below $\$ 80 / \mathrm{bbl}$; it will close $18 \%$ of its shale wells if the international oil price drops below $\$ 60 / \mathrm{bbl}$. This suggests that production profits are the motive force of hydrocarbon exploration. Cost and breakeven analysis and economic feasibility research are important factors for the prediction of deep hydrocarbon exploration prospects.

Acknowledgments The paper is completed based on the National Basic Research Program of China (973 Program, 2011CB201100) "Complex hydrocarbon accumulation mechanism and enrichment regularities of deep superimposed basins in Western China" and National Natural Science Foundation of China (U1262205) under the guidance of related department heads and experts. Here, the authors express gratitude and appreciation for their contributions. In addition, we thank the postgraduates including Li-Ming Zhou, Hua Bai, Jing Bai, Lu-Ya Wu, Qian-Wen Li, and Rui Yu for their help in data gathering and sorting.

Open Access This article is distributed under the terms of the Creative Commons Attribution License which permits any use, distribution, and reproduction in any medium, provided the original author(s) and the source are credited.

\section{References}

Aase NE, Bjprkum PA, Nadeau PH. The effect of grain coating micro quartz on preservation of reservoir porosity. AAPG Bull. 1996;80(10):1654-73.

Amthor JE, Okkerman J. Influence of early diagenesis on reservoir quality of Rotliegende sandstones, northern Netherlands. AAPG Bull. 1998;82(12):2246-65.

Bai GP, Cao BF. Characteristic and distribution patterns of deep petroleum accumulations in the world. Oil Gas Geol. 2014;01:7-19 (in Chinese).

Barker C, Takach NE. Prediction of natural gas composition in ultradeep sandstone reservoirs. AAPG Bull. 1992;76(12):1859-73.

Barker C. Calculated volume and pressure changes during the thermal cracking of oil to gas in reservoirs. AAPG Bull. 1990;74:1254-61.

Barker C. Primary migration: The importance of water organic mineral matter interaction in the source rock. Tulsa: AAPG Studies in Geology; 1980.

Baskin DK. Atomic ratio H/C of kerogen as an estimate of thermal maturity and organic matter conversion. AAPG Bull. 1997;81(9):1437-50.

Berkenpas PG. The Milk River shallow gas pool: role of the up dip water trap and connate water in gas production from the pool. SPE. 1991;229(22):371-80.

Bluokeny TB. Translated by Shi D. Development properties under deep abnormally high pressure. Nat Gas Geosci. 2001;12(4-5):61-4 (in Chinese).
Burruss RC. Stability and flux of methane in the deep crust a review. In: The future of energy gases. US Geological Survey Professional Paper; 1993. p. 21-29.

Cant DJ. Diagenetic traps in sandstones. AAPG Bull. 1986;70(2):155-60.

Chen DX, Pang XQ, Qiu NS, et al. Accumulation and filling mechanism of lenticular sand body reservoirs. Earth Sci. 2004;29(4):483-8 (in Chinese).

Chen JP, Liang DG, Wang XL, et al. Mixed oils derived from multiple source rocks in the Cainan oilfield, Junggar Basin, Northwest China. Part II: artificial mixing experiments on typical crude oils and quantitative oil-source correlation. Org Geochem. 2003;34(7):911-30.

Chen SJ, Zhang Y, Lu JG, et al. Limitation of biomarkers in the oilsource correlation. J Southwest Petrol Instit. 2006;28(5):11-4 (in Chinese).

Cheng KM, Wang ZY, Zhong NN, et al. Carbonate hydrocarbon generation theory and practice. Beijing: Petroleum Industry Press; 1996. p. 290-303 (in Chinese).

Cluff RM, Cluff SG. The origin of Jonah field, Northern Green River Basin, Wyoming. In: Robinson JW and Shanley KW (eds.) Jonah field: case study of a tight-gas fluvial reservoir. AAPG Stud Geol. 2004;52:215-41.

Dai JX, Qin SF, Tao SZ, et al. Developing trends of natural gas industry and the significant progress on natural gas geological theories in China. Nat Gas Geosci. 2005;16(2):127-42 (in Chinese).

Dai JX. Characteristic of abiogenic gas resource and resource perspective. Nat Gas Geosci. 2006;17(1):1-6 (in Chinese).

Dai JX. Enhance the studies on natural gas geology and find more large gas field in China. Nat Gas Geosci. 2003;14(1):3-14 (in Chinese).

Darouich T, Behar F, Largeau C. Thermal cracking of the light aromatic fraction of Safaniya crude oil-experimental study and compositional modelling of molecular classes. Org Geochem. 2006;37:1130-54.

Davies GR, Smith LB. Structurally controlled hydrothermal dolomite reservoir facies: an overview. AAPG Bull. 2006;90(11):1641-90.

Dickey PA. Possible primary migration of oil from source rock in oil phase. AAPG Bull. 1975;59(2):337-45.

Dolbier RA. Origin, distribution, and diagenesis of clay minerals in the Albian Pinda Formation, offshore Cabinda, Angola. Reno: University of Nevada; 2001.

Dominé F, Dessort D, Brevart O. Towards a new method of geochemical kinetic modelling: implications for the stability of crude oils. Org Geochem. 1998;28:576-612.

Du CG, Hao F, Zou HY, et al. Process and mechanism for oil and gas accumulation, adjustment and reconstruction in Puguang gas field, Northeast Sichuan Basin, China. Sci China. 2009;52(12):1721-31 (in Chinese).

Du JH, Wang ZM, Li QM, et al. Oil and gas exploration of cambrianordovician carbonate in Tarim Basin. Beijing: Petroleum Industry Press; 2010. p. 1-4 (in Chinese).

$\mathrm{Du} \mathrm{XD}$, Yao C. The necessary need of deep oil and gas exploration. Mar Oil and Gas Geol. 2001;6(1):1-5 (in Chinese).

Durand B. Understanding of $\mathrm{HC}$ migration in sedimentary basins (present state of knowledge). Org Geochem. 1988;13(1-3):445-59.

Dyman TS, Cook TA. Summary of deep oil and gas wells in the United States through 1998, Chapter B. In: Dyman TS, Kuuskraa BN, editors. Geologic Studies of Deep Natural Gas Resources. U.S. Geological Survey Digital Data Series DDS-67, Version 1.00; 2001. p. B1-B9.

Dyman TS, Crovelli RA, Bartberger CE, et al. Worldwide estimates of deep natural gas resources based on the US Geological Survey 
World Petroleum Assessment 2000. Nat Resour Res. 2002;11(6):207-18.

Dyman TS, Litinsky VA, Ulmishek GF. Geology and natural gas potential of deep sedimentary basins in the Former Soviet Union, Chapter C. In: Dyman TS, Kuuskraa VA, editors. U. S. Geological Survey studies of deep natural gas resources. U. S. Geological Survey Digital Data Series DDS-67, Version 1.00; 2001. p. C1-C29.

Dyman TS, Spencer CW, Baird JK, et al. Geologic and production characteristics of deep natural gas resources based on data from significant fields and reservoirs, Chapter C. In: Dyman TS, Rice DD, Westcott WA, editors. Geologic controls of deep natural gas resources in the United States. U.S. Geological Survey Bulletin 2146-C; 1997. p. 19-38.

Ehrenberg SN. Preservation of anomalously high porosity in deeply buried sandstones by grain-coating chlorite: examples from the Norwegian Continental Shelf. AAPG Bull. 1993;77(7):1260-86.

Ezat $\mathrm{H}$. The role of burial diagenesis in hydrocarbon destruction and $\mathrm{H}_{2} \mathrm{~S}$ accumulation, Upper Jurassic Smackover Formation, Black Creek Field, Mississippi. AAPG Bull. 1997;81(1):26-45.

Fan JS. Characteristics of carbonate reservoirs for oil and gas field in the world and essential controlling factors for their formation. Earth Sci Front. 2005;13(3):23-30 (in Chinese).

Fan SF, Zhou ZY, Jie QD. Characteristics and simulation experimental study of generation and conservation of deep carbonate oils and gases. Acta Sedimentol Sin. 1997;2:114-7 (in Chinese).

Feng ZQ. Exploration of large Qingshen gas field in the Songliao Basin. Nat Gas Ind. 2006;26(6):1-5 (in Chinese).

Fisher JB, Boles JR. Water rock interaction in tertiary sandstones, San Joaquin Basin, California, USA: diagenetic controls on water composition. Chem Geol. 1990;82:83-101.

Gaupp R, Matter A, Platt J, et al. Diagenesis and fluid evolution of deeply buried Permian (Rotliegende) gas reservoir, Northwest Germany. AAPG Bull. 1993;77(7):1111-28.

Gies RM. Case history for a major Alberta deep basin gas trap: the Cadomin Formation. AAPG Mem. 1984;38:115-40.

Gluyas JG, Leonard AJ, Oxtoby NH. Diagenesis and oil emplacement: the race for space Ultra Trend, North Sea. In: 13th International sedimentological congress. International Association of Sedimentologists; 1990. p. 193.

Gong S, Peng PA, Lu YH, et al. The model experiments for secondary pyrolysis of biodegraded bituminous sandstone. Chin Sci Bull. 2004;49:39-47 (in Chinese).

Gormly JR, Buck SP, Chung HM. Oil-source rock correlation in the North Viking Graben. Org Geochem. 1994;22(3-5):403-13.

$\mathrm{Gu}$ JY. Sedimentary environment and reservoir characters of the Carboniferous Donghe sandstone in the Tarim Basin. Acta Geol Sinica. 1996;70(2):153-61 (in Chinese).

Gu JY, Ning CQ, Jia JH. High-quality reservoir features and generate analysis of clastic rocks in the Tarim Basin. Geol Rev. 1998;44(1):83-9 (in Chinese).

Gu JY, Zhou XX, Liu WL. Buried-hill Karst and the distribution of hydrocarbon in Lunnan Area, Tarim Basin. Beijing: Petroleum Industry Press; 2001 (in Chinese).

Guan DS, Niu JY. Unconventional oil and gas geology in China. Beijing: Petroleum Industry Press; 1995. p. 60-5 (in Chinese).

Guan D, Luo Y, Zhang XD, et al. Research on prediction methods and analysis of cost influential factors for offshore drilling. Drill Prod Technol. 2012;35(4):41-9 (in Chinese).

Guo R. Supplement to determining method of cut-off value of net play. Petrol Explor Dev. 2004;31(5):140-4 (in Chinese).

Hao F, Zou HY, Huang BJ. Gas generation model and geo-fluid response, Yinggehai Basin. Science China Ser D. 2002;32(11):889-96 (in Chinese).

Hao SS, Gao G, Wang FY. Highly-over mature marine source rocks. Beijing: Petroleum Industry Press; 1996. p. 98-109 (in Chinese).
Hao SS, Liu GD, Huang ZL, et al. Dynamic equilibrium model of migration and accumulation for natural gas resource evaluation. Petrol Explor Dev. 1993;20(3):16-21 (in Chinese).

Harris RG, Bustin RM. Diagenesis, reservoir quality, and production trends of Doig Formation sand bodies in the Peace River area of Western Canada. Bull Can Pet Geol. 2002;48(4):339-59.

He DF, Jia CZ, Zhou XY, et al. Control principles of structures and tectonics over hydrocarbon accumulation in multi-stage super imposed basins. Acta Petrol Sin. 2005;26(3):1-9 (in Chinese).

He ZL, Wei XC, Qian YX, et al. Forming mechanism and distribution prediction of quality marine carbonate reservoirs. Oil Gas Geol. 2011;32(4):489-98 (in Chinese).

Heald MT, Larese RE. Influence of coating on quartz cementation. J Sediment Petrol. 1974;44(4):1269-74.

Hirner A, Graf W, Hahn-Weinheimer P. A contribution to geochemical correlation between crude oils and potential source rocks in the eastern Molasse Basin (Southern Germany). J Geochem Explor. 1981;15(1-3):663-70.

Hu GY, Xiao ZY, Luo X, et al. Light hydrocarbon composition difference between two kinds of cracked gases and its application. Nat Gas Ind. 2005;25(9):23-5 (in Chinese).

Huang JW, Gu Y, Chen QL, et al. Thermal simulation of Silurian bituminous sandstone of hydrocarbon supply in northern Tarim Basin. Petrol Geol Exp. 2012;34(4):445-50 (in Chinese).

Huang J, Zhu RK, Hou DJ, et al. The new advances of secondary porosity genesis mechanism in deep clastic reservoir. Geol Sci Technol Inf. 2007;26(6):76-82 (in Chinese).

Hubbert MK. Entrapment of petroleum under hydrodynamic conditions. AAPG Bull. 1953;37(8):1954-2026.

Hunt JM. Petroleum geochemistry and geology. 1st ed. New York: Freeman; 1979. p. 261-73.

Huo ZP, Pang XQ, Fan K, et al. Application of facies-potential coupling reservoir-controlling effect in typical lithologic reservoirs in Jiyang depression. Petrol Geol Exp. 2014a;36(5):574-83 (in Chinese).

Huo ZP, Pang XQ, Ouyang XC, et al. Upper limit of maturity for hydrocarbon generation in carbonate source rocks in the Tarim Basin, China. Arab J Geosci. 2014b;. doi:10.1007/s12517-014-1408-9.

Ingersoll RV. Tectonics of sedimentary basins with revise nomenclature. In: Busby CJ, Perez AA, editors. Tectonics of sedimentary basins: recent advances. Cambridge, MA: Blackwell Science; 1995. p. 1-151.

Jemison RM. Geology and development of Mills Ranch complexworld's deepest field. AAPG Bulletin. 1979;63(5):804-9.

Jia CZ, Zhou XY, Wang ZM, et al. Petroleum geological features of Kela-2 gas field. Chin Sci Bull. 2002;47(S1):90-6 (in Chinese).

Jiang FJ, Pang XQ, Wu L. Geologic thresholds and its gas controlling function during forming process of tight sandstone gas reservoir. Acta Petrol Sin. 2010;31(1):49-54 (in Chinese).

Jiao HS, Fang CL, Niu JY, et al. Deep petroleum geology of Eastern China. Beijing: Petroleum Industry Press; 2002. p. 24-162 (in Chinese).

Jin ZJ, Zhang LP, Yang L, et al. Primary study of geochemical features of deep fluids and their effectiveness on oil-gas reservoir formation in sedimentary basins. Earth Sci. 2002;27(6):659-65 (in Chinese).

Jing GL. Aromatic compounds in crude oils and source rocks and their application to oil-source rock correlations in the Tarim Basin, NW China. J Asian Earth Sci. 2005;25(2):251-68.

Jones RW, Edison TA. Microscopic observations of kerogen related to geochemical parameters with emphasis on thermal maturation. In: Oltz DF, editor. Low temperature metamorphism of kerogen and clay minerals. Los Angeles: Pacific Section, SEPM; 1978. p. 1-12.

Kang YZ. Geological conditions of the formation of the large Tahe oilfield in the Tarim Basin and its prospects. Geol China. 2003;30(3):315-9 (in Chinese). 
Khidir A, Catuneanu O. Sedimentology and diagenesis of the Scollard sandstones in the Red Deer Valley area, central Alberta. Bull Can Pet Geol. 2003;51(1):45-69.

Kutcherov V, Lundin A, Ross RG, et al. Theory of abyssal abiotic petroleum origin: challenge for petroleum industry. AAPG Eur Reg Newslett. 2008;3:2-4.

Land LS, MacPherson GL. Origin of saline formation waters, Cenozoic section, Gulf of Mexico sedimentary basin. AAPG Bull. 1992;76(9):1344-62.

Li GY, Lü MG. Atlas of petroliferous basins in China. Beijing: Petroleum Industry Press; 2002 (in Chinese).

Li GY. Atlas of world petroliferous basins. Beijing: Petroleum Industry Press; 2009 (in Chinese).

Li HX, Ren JH, Ma JY, et al. Abnormal high pore fluid pressure and clastic rock deep reservoir. Petrol Explor Dev. 2001;28(6):5-8 (in Chinese).

Li L, Ren ZW, Sun HB. An integrated evaluation on petroleum geology of the deep reservoirs in the west depression, Liaohe Basin, China. Acta Petrol Sin. 1999;20(6):9-15 (in Chinese).

$\mathrm{Li} \mathrm{MC}$, Shan XQ, Ma CH, et al. Dynamics of sand lens reservoir. Oil Gas Geol. 2007;28(2):209-15 (in Chinese).

Li SM, Pang XQ, Jin ZJ, et al. Geochemical characteristics of the mixed oil in Jinhu Sag of Subei Basin. J China Univ Petrol. 2002;26(1):11-5 (in Chinese).

Li Z, Li HS. An approach to genesis and evolution of secondary porosity in deeply buried sandstone reservoirs, Dongpu depression. Sci Geol Sin. 1994;29(3):267-75 (in Chinese).

Li Z, Chen JS, Guan P. Scientific problems and frontiers of sedimentary diagenesis research in oil-gas-bearing basins. Acta Petrol Sin. 2006;22(8):2113-22 (in Chinese).

Li Z, Huang SJ, Liu JQ, et al. Buried diagenesis, structurally controlled thermal-fluid process and their effect on Ordovician carbonate reservoirs in Tahe, Tarim Basin. Acta Sedimentol Sin. 2010;28(5):969-74 (in Chinese).

Lin CS, Li H, Liu JY. Major unconformities, tectonostratigraphic framework, and evolution of the superimposed Tarim Basin, northwest China. J Earth Sci. 2012;23(4):395-407.

Liu JQ, Meng FC, Cui Y, et al. Discussion on the formation mechanism of volcanic oil and gas reservoirs. Acta Petrol Sin. 2010a;26(1):1-13 (in Chinese).

Liu QY, Jin ZJ, Gao B, et al. Characterization of gas pyrolysates from different types of Permian source rocks in Sichuan Basin. Nat Gas Geosci. 2010b;21(5):700-4 (in Chinese).

Liu WH, Chen MJ, Guan P, et al. Ternary geochemical-tracing system in natural gas accumulation. Sci China Ser D. 2007a;37(7):908-15 (in Chinese).

Liu WH, Zhang JY, Fan M, et al. Gas generation character of dissipated soluble organic matter. Petrol Geol Exp. 2007b;29(1):1-6 (in Chinese).

Liu Z, Zhu WQ, Sun Q, et al. Characteristics of geotemperaturegeopressure systems in petroliferous basins of China. Acta Petrol Sin. 2012;33(1):1-17 (in Chinese).

Luo P, Qiu YN, Jia AL, et al. The present challenges of Chinese petroleum reservoir geology and research direction. Acta Sedimentol Sin. 2003;21(1):142-7 (in Chinese).

Luo XR, Yu J, Zhang FQ, et al. Numerical migration model designing and its application in migration studies in the 8th segment in the Longdong area of Ordos Basin, China. Sci China Ser D. 2007;37(S1):73-82 (in Chinese).

Luo XR. Review of hydrocarbon migration and accumulation dynamics. Nat Gas Geosci. 2003;14(5):337-46 (in Chinese).

Ma WM, Wang XL, Ren LY, et al. Over-pressures and secondary pores in Dongpu Depression. J Northwest Univ. 2005;35(3):325-30 (in Chinese).
Ma XZ, Pang XQ, Meng QY, et al. Hydrocarbon expulsion characteristics and resource potential of deep source rocks in the Liaodong Bay. Oil Gas Geol. 2011;32(2):251-9 (in Chinese).

Ma YS, Chu ZH. Building-up process of carbonate platform and highresolution sequence stratigraphy of reservoirs of reef and oolitic shoal facies in Puguang gas field. Oil Gas Geol. 2008;29(5):548-56 (in Chinese).

Ma YS, Guo TL, Zhao XF, et al. Formation mechanism of high porosity and permeability dolomites deeply buried in Puguang gas field. Sci China Ser D. 2007;37:43-52 (in Chinese).

Ma YS, Zhang SC, Guo TL, et al. Petroleum geology of the Puguang sour gas field in the Sichuan Basin, SW China. Mar Petrol Geol. 2008;25(4-5):357-70.

Ma ZZ, Wu HY, Dai GW. Progress of study on reservoir forming mechanism of deep basin gas. Petrol Geol Oilfield Dev Daqing. 2009;28(6):57-61 (in Chinese).

Magara K. Compaction and fluid migration: practical petroleum geology. London: Elsevier; 1978. p. 319.

Mango FD. The stability of hydrocarbon under the time/temperature conditions of petroleum genesis. Nature. 1991;352:146-8.

Manhadieph NR. Translated by Shi D. Geothermal conditions of deep hydrocarbon-bearing layers. Nat Gas Geosci. 2001;12(2):56-60 (in Chinese).

Masters JA. Deep basin gas trap, Western Canada. AAPG Bull. 1979;63(z2):152-81.

Melienvski BN. Translated by Shi D. Discussion on the deep zonation of the oil-gas formation. Nat Gas Geosci. 2001;12(4-5):52-5 (in Chinese).

Meng YL, Gao JJ, Liu DL, et al. Diagenetic facies analysis and anomalously high porosity zone prediction of the Yuanyanggou area in the Liaohe depression. J Jilin Univ. 2006;36(2):227-33 (in Chinese).

Miao JY, Zhu ZQ, Liu WR, et al. Relationship between temperature, pressure and secondary pores of deep reservoirs in eogene in the Jiyang depression. Acta Petrolei Sinica. 2000;21(3):36-40 (in Chinese).

Michael GE, Lin LH, Philp RP, et al. Biodegradation of tar-sand bitumens from the Ardmore/Anadarko Basins, Oklahoma-II correlation of oils, tar sands and source rocks. Org Geochem. 1989;14(6):619-33.

Ministry of Land and Resources. Resource evaluation of the new round national oil and gas resources. Beijing: China Land Press; 2005 (in Chinese).

Moretti I, Labaume P, Sheppard SMF, et al. Compartmentalization of fluid migration pathways in the sub-Andean zone, Bolivia. Tectonophysics. 2002;348(1-3):5-24.

Mukhopadhyay PK, Wade JA, Kruge MA. Organic facies and maturation of Jurassic/Cretaceous rocks, and possible oil-source rock correlation based on pyrolysis of asphaltenes, Scotian Basin, Canada. Org Geochem. 1995;22(1):85-104.

Navon O, Hutcheon ID, Rossman GR, et al. Mantle-derived fluids in diamond micro-inclusions. Nature. 1988;335:784-9.

Nelson RA. Production characteristics of the fractured reservoirs of the La Paz field, Maracaibo Basin, Venezuela. AAPG Bull. 2000;84(11):1791-809.

Nelson RA. Geologic analysis of naturally fractured reservoirs. Houston: Gulf Publishing Company; 1985. p. 304-51.

Odden W, Patience RL, Van Graas GW. Application of light hydrocarbons $\left(\mathrm{C}_{4}-\mathrm{C}_{13}\right)$ to oil/source rock correlations: a study of the light hydrocarbon compositions of source rocks and test fluids from offshore Mid-Norway. Org Geochem. 1998;28(12):823-47.

Osborne MJ, Swarbrick RE. Diagenesis in North Sea HPHT clastic reservoirs- consequences for porosity and overpressure prediction. Mar Pet Geol. 1999;16:337-53. 
Pan WQ, Liu YF, Dickson J, et al. The geological model of hydrothermal activity in outcrop and the characteristics of carbonate hydrothermal karst of Lower Paleozoic in Tarim Basin. Acta Sedimentol Sin. 2009;27(5):983-94 (in Chinese).

Pang XQ. Key challenges and research methods of petroleum exploration in the deep of superimposed basins in western China. Oil Gas Geol. 2010;31(5):517-41 (in Chinese).

Pang XQ, Chen DX, Zhang J, et al. Concept and categorize of subtle reservoir and problems in its application. Lithol Reserv. 2007a;19(1):1-8 (in Chinese).

Pang XQ, Chen DX, Zhang J, et al. Physical simulation experimental study on mechanism for hydrocarbon accumulation controlled by facies-potential-source coupling. Journal of Palaeogeography. 2013;5:575-92 (in Chinese).

Pang XQ, Gao JB, Meng QY. A discussion on the relationship between tectonization and hydrocarbon accumulation and dissipation in the platform-basin transitional area of Tarim Basin. Oil Gas Geol. 2006;27(5):594-603 (in Chinese).

Pang XQ, Gao JB, Lü XX, et al. Reservoir accumulation pattern of multi-factor recombination and procession superimposition and its application in Tarim Basin. Acta Petrol Sin. 2008;29(2):159-66 (in Chinese).

Pang XQ, Jiang ZX, Huang HD, et al. Genetic mechanism, development mode and distribution forecast of overlapping continuous oil and gas reservoir. Acta Petrol Sin. 2014a;35(5):1-34 (in Chinese).

Pang XQ, Jin ZJ, Zuo SJ. Dynamics models and classification of hydrocarbon accumulations. Earth Sci Front. 2000;7(4):507-14 (in Chinese).

Pang XQ, Jin ZJ, Jiang ZX, et al. Critical condition for gas accumulation in the deep basin trap and physical modeling. Nat Gas Geosci. 2003;14(2):207-14 (in Chinese).

Pang XQ, Li QW, Chen JF, et al. Recovery method of original TOC and its application in source rocks at high mature-over mature stage in deep petroliferous basin. J Palaeogeogr. 2014b;16(6):769-88 (in Chinese).

Pang XQ, Li SM, Jin ZJ, et al. Geochemical evidence of hydrocarbon expulsion threshold and its application. Earth Sci. 2004;29(4):384-9 (in Chinese).

Pang XQ, Luo XR, Jiang ZX, et al. Advancements and problems on hydrocarbon accumulation research of complicated superimposed basins in Western China. Adv Earth Sci. 2007b;22(9):879-87 (in Chinese).

Pape $\mathrm{H}$, Clauser $\mathrm{C}$, Iffland $\mathrm{J}$, et al. Anhydrite cementation and compaction in geothermal reservoirs: interaction of pore-space structure with flow, transport, P-T conditions, and chemical reactions. Int J Rock Mech Min Sci. 2005;42(7-8):1056-69.

Perry W Jr. Structural settings of deep natural gas accumulations in the conterminous United States. In: Dyman TS, Rice DD and Westcott PA (eds.), geologic controls of deep natural gas resources in the United States. USGS Bull. 1981;2146-D:41-6.

Philippi GT. Correlation of crude oils with their oil source formation, using high resolution GLC $\mathrm{C}_{6}-\mathrm{C}_{7}$ component analyses. Geochim Cosmochim Acta. 1981;45(9):1495-513.

Qiao HS, Zhao CL, Tian KQ, et al. Petroleum geology of deep reservoirs in the eastern China. Beijing: Petroleum Industry Press; 2002. p. 254-8 (in Chinese).

Qin JZ, Jin JC, Liu BQ. Thermal evolution pattern of organic matter abundance in various marine source rocks. Oil Gas Geol. 2005;26(2):177-84 (in Chinese).

Ramm M, Forsberg AW, Jahren J S. Porosity-depth trends in deeply buried Upper Jurassic reservoirs in the Norwegian Central Graben: an example of porosity preservation beneath the normal economic basement by grain-coating microquartz. In: AAPG Memoir 69: reservoir quality prediction in sandstones and carbonates; 1997. p. 177-199.
Robinson A, Gluyas J. Duration of quartz cementation in sandstones, North Sea and Haltenbanken Basins. Mar Pet Geol. 1992;9:324-7.

Rodrenvskaya МИ. Translated by Shi D. Hydrocarbon potential in deep layers. Nat Gas Geosci. 2001;12(4-5):49-51 (in Chinese).

Rossi C, Marfil R, Ramseyer KR, et al. Facies related diagenesis and multiphase siderite cementation and dissolution in the reservoir sandstones of the Khatatba Formation, Egypt's Western Desert. J Sediment Res. 2001;71(3):459-72.

Rothwell NR, Sorensen A, Peak JL, et al. Gyda: recovery of difficult reserves by flexible development and conventional reservoir management. In: SPE26778, Proceedings of the offshore Europe conference; 1993. p. 271-280.

Samvelov PГ. Translated by Guan F X Deep oil-gas reservoir forming characteristics and distribution. Northwest Oil Gas Explor. 1997;9(1):52-7 (in Chinese).

Seifert WK. Steranes and terpanes in kerogen pyrolysis for correlation of oils and source rocks. Geochim Cosmochim Acta. 1978;42(5):473-84.

Shao CX, Wang YZ, Cao YZ. Determine the effective reservoir lower limit-two new methods and application to Paleogene deep clastic reservoirs in Dongying Sag as an example. J Oil Gas Technol. 2008;30(2):414-6 (in Chinese).

Shi JA, Wang Q. A discussion on main controlling factors on the properties of clastic gas reservoirs. Acta Sedimentol Sin. 1995;13(2):128-39 (in Chinese).

Shi X, Dai JX, Zhao WZ. Analysis of deep oil and gas reservoir exploration prospect. China Petrol Explor. 2005;10(1):1-10 (in Chinese).

Simmons MR. The world's giant oilfields. Hubbert Center Newslett. 2002;1:1-62.

Song CC, Peng YM, Qiao YL, et al. Direction for future oil \& gas exploration in SINOPEC's exploration area in the Junggar Basin. Oil Gas Geol. 2008;29(4):453-9 (in Chinese).

Song FQ, Zhang DJ, Wang PR, et al. A contribution evaluation method for biodegraded mixed oils. Petrol Explor Dev. 2004;31(2):67-70 (in Chinese).

Spencer CW. Review of characteristics of low-permeability gas reservoirs in western United States. AAPG Bull. 1989;73(5):613-29.

Stahl WJ. Source rock-crude oil correlation by isotopic type-curves. Geochim Cosmochim Acta. 1978;42(10):1573-7.

Sugisaki R. Deep-seated gas emission induced by the earth tide: a basic observation for geochemical earthquake prediction. Science. 1981;212(4500):1264-6.

Sun LD, Fang CL, Li F, et al. Petroleum exploration and development practices of sedimentary basins in China and research progress of sedimentology. Petrol Explor Dev. 2010;37(4):385-96 (in Chinese).

Sun LD, Zou CN, Zhu RK, et al. Formation, distribution and potential of deep hydrocarbon resources in China. Petrol Explor Dev. 2013;40(6):641-9 (in Chinese).

Surdam RC, Boese SW, Crossey LJ. The chemistry of secondary porosity. AAPG Mem. 1984;37:127-49.

Surdam RC, Crossey LJ, Hagen ES, et al. Organic-inorganic and sandstone diagenesis. AAPG Bull. 1989;73(1):1-23.

Svetlakova EA. Model of formation regularities of distribution of hydrocarbon pools in the North Caspian Basin. In: Krylov NA, Nekhrikova NA, editors. Petroleum potential of the North Caspian Basin and Adjacent Areas (Neftegazonosnost Prikaspiyskoy vpadinyi sopredelnykh rayonov). Moscow: Nauka; 1987. p. 151-4.

Telnæs N, Cooper BS. Oil-source rock correlation using biological markers, Norwegian continental shelf. Mar Pet Geol. 1991;8(3):302-10.

Tissot BP, Welte DH. Petroleum formation and occurrence: a new approach to oil and gas exploration. Berlin: Springer; 1978. 
Tissot B, Durand B, Espitalé J, et al. Influence of the nature and diagenesis of organic matter in the formation of petroleum. AAPG Bull. 1974;58:499-506.

Tuo JC. Research status and advances in deep oil and gas exploration. Adv Earth Sci. 2002;17(4):565-71 (in Chinese).

Tuo JC. Secondary hydrocarbon generation in carbonate rocks. Nat Gas Geosci. 1994;3:9-13 (in Chinese).

Tuo JC, Huang XZ, Ma WY. The lagging phenomenon of the petroleum generation in carbonate rocks. Petrol Explor Dev. 1994;21(6):1-5 (in Chinese).

Tuo JC, Wang XB, Zhou SX. Prospect of oil-gas resources in the Bohai Bay Basin. Nat Gas Geosci. 1999a;06:27-31 (in Chinese).

Tuo JC, Wang XB, Zhou SX, et al. Exploration situation and research development of deep hydrocarbon. Nat Gas Geosci. 1999b;06:1-8 (in Chinese).

Walker RG, James NP. Facies models: response to sea level change. Geol Assoc Can. 1992;4(5):153-70.

Wan L, Sun Y, Wei GQ. A new method used to determine the lower limit of the petrophysical parameters for reservoir and its application: a case study on Zhongbu Gas Field in Ordos Basin. Acta Sedimentol Sin. 1999;17(3):454-7 (in Chinese).

Wang GQ, Chen YD, Zhou YH. Difficulty analysis and solution discussion for deep and ultra-deep exploration well. Oil Drill Prod Technol. 1998;20(1):1-17 (in Chinese).

Wang Q, Song YJ, Zhang SM. The study on the methods used to delineate the deep tight gas bearing sands in Daqing oil field. J Daqing Petrol Inst. 1994;18(2):22-6 (in Chinese).

Wang TG, Wang CJ, He FQ, et al. Determination of double filling ratio of mixed crude oils in the Ordovician oil reservoir, Tahe Oilfield. Petrol Geol Exp. 2004;26(1):74-9 (in Chinese).

Wang T. Deep Basin Gas in China. Beijing: Petroleum Industry Press; 2002 (in Chinese).

Wang WJ, Song N, Jiang NH, et al. The mixture laboratory experiment of immature oils and mature oils, making and using the mixture source theory plat and its application. Petrol Explor Devel. 1999;26(4):34-7 (in Chinese).

Wang XB, Tuo JC, Yan H, et al. The formation mechanism of deep oil and gas. The meeting abstract on Chinese sedimentology in 2001. Wuhan: China Univ Geosci; 2001. p. 163-4 (in Chinese).

Wang YM, Niu JY, Qiao HS, et al. An approach to the hydrocarbon resource potential of Bohai Bay Basin. Petrol Explor Dev. 2002;29(2):21-5 (in Chinese).

Wang YS, Pang XQ, Liu HM, et al. Low-potential reservoircontrolling characteristics and dynamics mechanism and its role in oil and gas exploration. J Earth Sci. 2013;38(1):165-72 (in Chinese)

Wang Y, Su J, Wang K, et al. Distribution and accumulation of global deep oil and gas. Nat Gas Geosci. 2012;23(3):526-34 (in Chinese).

Wang ZM, Wang QH, Wang Y. Poll formation condition and controlling factor for Hetian gas field in the Tarim Basin. Mar Oil Gas Geol. 2000;5(1):124-32 (in Chinese).

Waples DW. Time and temperature in petroleum formation: application and detachment free deformation. J Struct Geol. 1990;12(3):355-81.

Watkinson AJ, Ward EMG. Reactivation of pressure solution seams by a strike slip fault sequential, dilational jog formation and fluid flow. AAPG Bull. 2006;90(8):1187-200.

White IC. The geology of natural gas. Science. 1885;6(128):42-4.

Wilkinson M, Darby D, Haszeldine RS, et al. Secondary porosity generation during deep burial associated with overpressure leakoff: Fulmar Formation, United Kingdom Central Graben. AAPG Bull. 1997;81(5):803-13.

Williams LB, Hervig RL, Wieser ME, et al. The influence of organic matter on the boron isotope geochemistry of the gulf coast sedimentary basin, USA. Chem Geol. 2001;174:445-61.
Wood JR, Hewett TA. Reservoir diagenesis and convective fluid flow. AAPG Mem. 1984;37:99-110.

Wu FQ, Xian XF. Current state and countermeasure of deep reservoirs exploration. Sediment Geol Tethyan Geol. 2006;26(2):68-71 (in Chinese).

Wu YX, Wang PJ, Bian WH, et al. Reservoir properties of deep volcanic reservoirs in the Songliao Basin. Oil Gas Geol. 2012;33(4):236-47 (in Chinese).

Xiao ZH, Zhong NN, Huang ZL, et al. A study on hydrocarbon pooling conditions in tight sandstones through simulated experiments. Oil Gas Geol. 2008;29(6):721-5 (in Chinese).

Xie JL, Huang C, Wang XX. Distribution of proved reserves of carbonate oil and gas pools in China. Mar Orig Petrol Geol. 2009;14(2):24-30 (in Chinese).

Xie ZY, Jiang ZS, Zhang Y, et al. Novel method of whole rock thermal simulation and application to the evaluation of gas source rock. Acta Sedimentol Sin. 2002;20(3):510-4 (in Chinese).

Yang $\mathrm{XH}$, Ye JR, Sun YC, et al. Diagenesis evolution and preservation of porosity in the member2, Shahejie Formation, Qinan fault step zone. China Offshore Oil Gas (Geol). 1998;12(4):242-8 (in Chinese).

Ye JR, Wang LJ, Shao R. Fluid dynamic fields in hydrocarbon accumulation dynamics. Oil Gas Geol. 1999;20(2):86-9 (in Chinese).

Zappaterra E. Source-rock distribution model of the Periadriatic region. AAPG Bull. 1994;78(3):333-54.

Zhang DY. Fluid characteristics and reservoir forming condition in deep oil and gas reservoirs. Petrol Geol Recovery Effic. 2006;13(5):45-9 (in Chinese).

Zhang HF, Fang CL, Gao XZ, et al. Petroleum geology. Beijing: Petroleum Industry Press; 1999 (in Chinese).

Zhang WC, Li H, Li HJ, et al. Genesis and distribution of secondary porosity in the deep horizon of Gaoliu area, Nanpu Sag. Petrol Explor Dev. 2008;35(3):308-12 (in Chinese).

Zhang XD, Tan XC, Chen JS. Reservoir and controlling factors of the secondary member of the Jialing River Formation in the hit and the south transition strip of Sichuan. Nat Gas Geosci. 2005a;16(3):338-42 (in Chinese).

Zhang YW, Jin ZJ, Liu GC, et al. Study on the formation of unconformities and the amount of eroded sedimentation in Tarim Basin. Earth Sci Front. 2000;7(4):449-57 (in Chinese).

Zhang ZS, Wu BH. Research on volcanic reservoir and exploration technology home and abroad. Nat Gas Explor Dev. 1994;1:1-26 (in Chinese).

Zhang ZY, Shao LY, Zhang SH, et al. Distribution of mixed crude in western arc structural belt of Taibei Depression in TurpanHami Basin. Acta Petrol Sin. 2005b;26(2):15-20 (in Chinese).

Zhao MJ, Zeng Q, Zhang BM. The petroleum geological condition and prospecting orientation in Tarim Basin. Xinjiang Petrol Geol. 2001;22(2):93-6 (in Chinese).

Zhao WZ, Wang ZY, Zhang SC, et al. Successive generation of natural gas from organic materials and its significance in future exploration. Petrol Explor Devel. 2005;32(2):1-7 (in Chinese).

Zhao WZ, Zou CN, Gu ZD, et al. Preliminary discussion on accumulation mechanism of sand lens reservoirs. Petrol Explor Dev. 2007;34(3):273-83 (in Chinese).

Zhong DK, Zhu XM. Pore evolution and genesis of secondary pores in Paleogene clastic reservoirs in Dongying Sag. Oil Gas Geol. 2003;24(3):281-5 (in Chinese).

Zhong DK, Zhu XM, Wang HJ. Characteristics and formation mechanism analysis of deep buried sandstone reservoirs in China. Sci China. 2008;38(S1):11-8 (in Chinese).

Zhou J, Pang XQ. A method for calculation the quantity of hydrocarbon generation and expulsion. Petrol Explor Dev. 2002;29(1):24-7 (in Chinese). 
Zhou SX, Wang XB, Tuo JC, et al. Advances in geochemistry of deep hydrocarbon. Nat Gas Geosc. 1999;10(6):9-15 (in Chinese).

Zhu GY, Zhang SC. Hydrocarbon accumulation conditions and exploration potential of deep reservoirs in China. Acta Petrol Sin. 2009;30(6):793-802 (in Chinese).

Zhu GY, Zhang SC, Liang YB, et al. Dissolution and alteration of the deep carbonate reservoirs by TSR: an important type of deep- buried high-quality carbonate reservoirs in Sichuan Basin. Acta Petrol Sin. 2006;22(8):2182-94 (in Chinese).

Zhu ZQ, Zeng JH, Wang JJ. Microscopic experiment on oil flowing through porous media in low permeability sandstone. J Southwest Petrol Univ Sci Technol. 2010;32(1):16-20 (in Chinese).

Zou CN. Unconventional oil and gas geology. Beijing: Geological Publishing House; 2011. p. 50-2 (in Chinese). 